\title{
Evaluation of Passive Vents in New Construction Multifamily Buildings
}

Sean Maxwell, David Berger, and Marc Zuluaga

Consortium for Advanced Residential Buildings 


\section{NOTICE}

This report was prepared as an account of work sponsored by an agency of the United States government. Neither the United States government nor any agency thereof, nor any of their employees, subcontractors, or affiliated partners makes any warranty, express or implied, or assumes any legal liability or responsibility for the accuracy, completeness, or usefulness of any information, apparatus, product, or process disclosed, or represents that its use would not infringe privately owned rights. Reference herein to any specific commercial product, process, or service by trade name, trademark, manufacturer, or otherwise does not necessarily constitute or imply its endorsement, recommendation, or favoring by the United States government or any agency thereof. The views and opinions of authors expressed herein do not necessarily state or reflect those of the United States government or any agency thereof.

Available electronically at SciTech Connect http:/www.osti.gov/scitech

Available for a processing fee to U.S. Department of Energy

and its contractors, in paper, from:

U.S. Department of Energy

Office of Scientific and Technical Information

P.O. Box 62

Oak Ridge, TN 37831-0062

OSTI http://www.osti.gov

Phone: 865.576.8401

Fax: 865.576.5728

Email: reports@osti.gov

Available for sale to the public, in paper, from:

U.S. Department of Commerce

National Technical Information Service

5301 Shawnee Road

Alexandria, VA 22312

NTIS http://www.ntis.gov

Phone: 800.553 .6847 or 703.605 .6000

Fax: 703.605.6900

Email: orders@ntis.gov 


\title{
Evaluation of Passive Vents in New Construction Multifamily Buildings
}

Prepared for:

The National Renewable Energy Laboratory

On behalf of the U.S. Department of Energy's Building America Program

Office of Energy Efficiency and Renewable Energy

15013 Denver West Parkway

Golden, CO 80401

NREL Contract No. DE-AC36-08GO28308

\author{
Prepared by: \\ Sean Maxwell, David Berger, and Marc Zuluaga \\ Steven Winter Associates, Inc. \\ Consortium for Advanced Residential Buildings (CARB) \\ 61 Washington Street \\ Norwalk, CT 06854 \\ NREL Technical Monitor: Stacey Rothgeb \\ Prepared under Subcontract No. KNDJ-0-40342-05
}

February 2016 
The work presented in this report does not represent performance of any product relative to regulated minimum efficiency requirements.

The laboratory and/or field sites used for this work are not certified rating test facilities. The conditions and methods under which products were characterized for this work differ from standard rating conditions, as described.

Because the methods and conditions differ, the reported results are not comparable to rated product performance and should only be used to estimate performance under the measured conditions. 


\section{Contents}

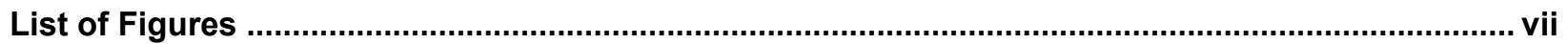

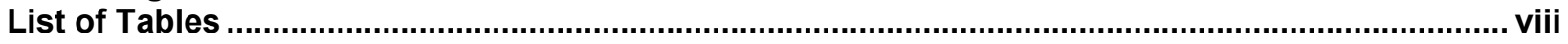

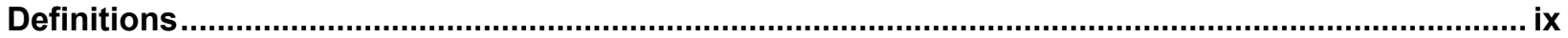

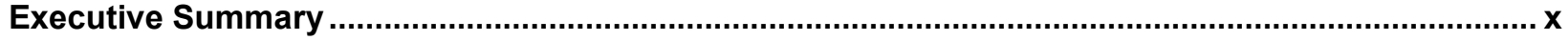

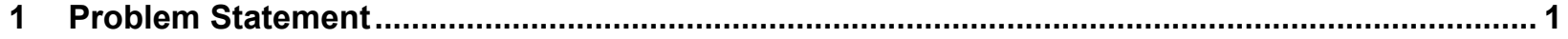

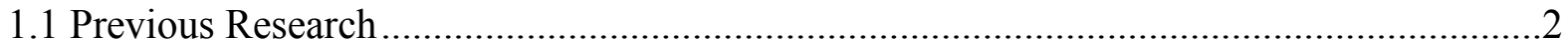

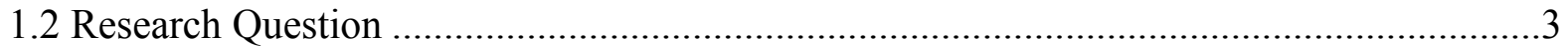

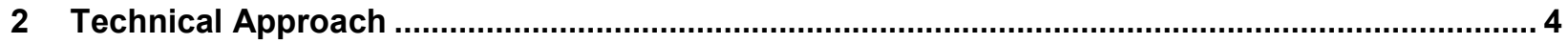

2.1 Outdoor Air through Passive Vents ......................................................................

2.2 Factors that Affect Ventilation System Performance and Choice of Measurements..........4

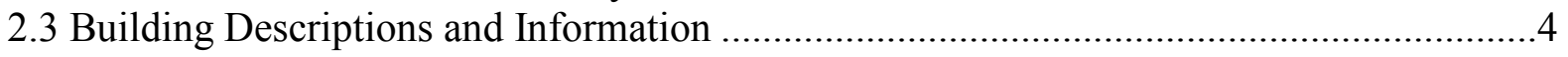

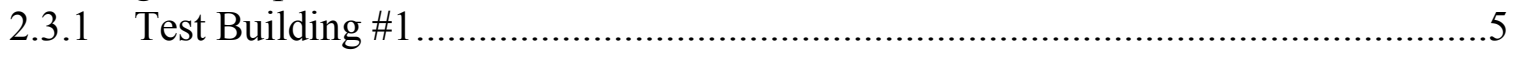

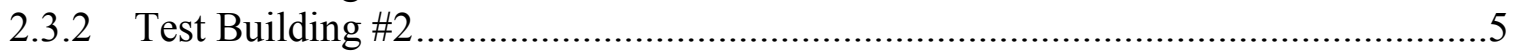

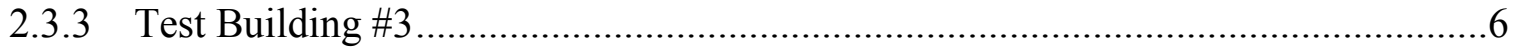

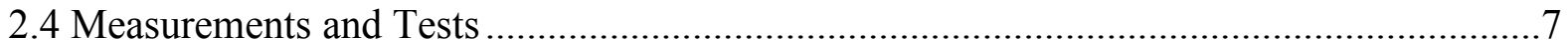

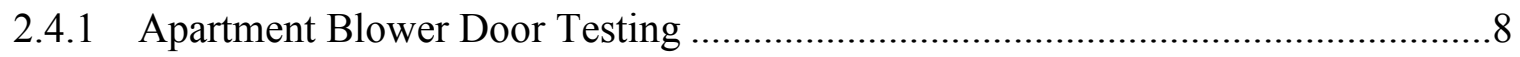

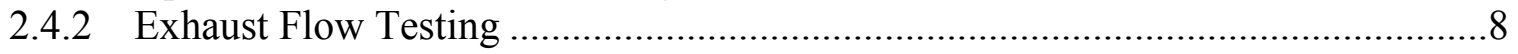

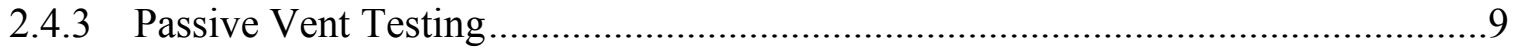

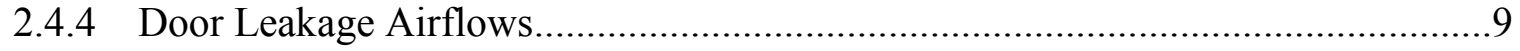

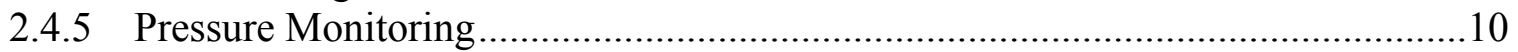

2.4.6 Exhaust Fan Power Consumption.................................................................. 11

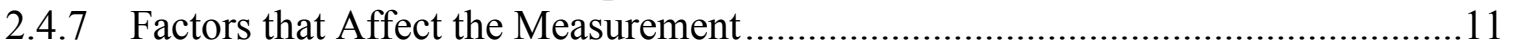

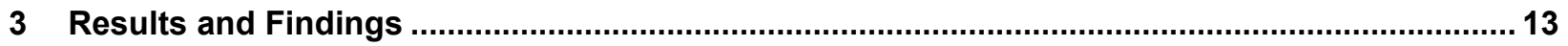

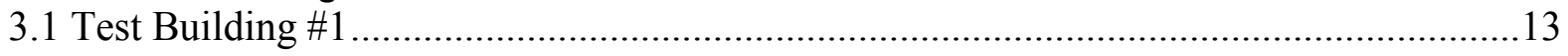

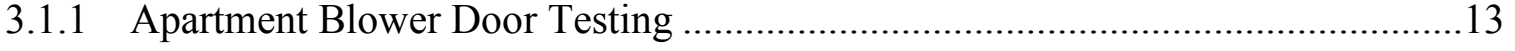

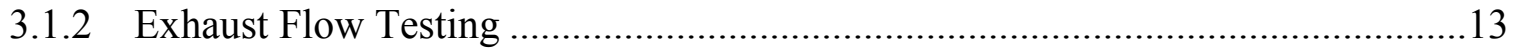

3.1.3 Passive Vent Testing ..................................................................................... 15

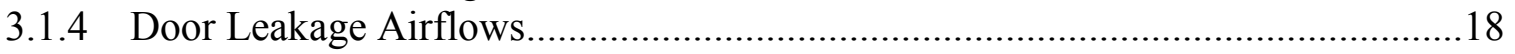

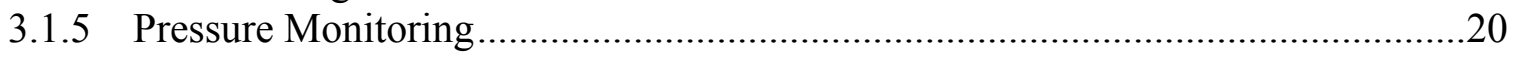

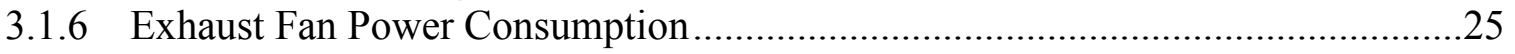

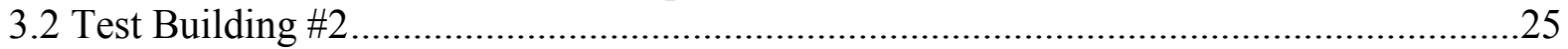

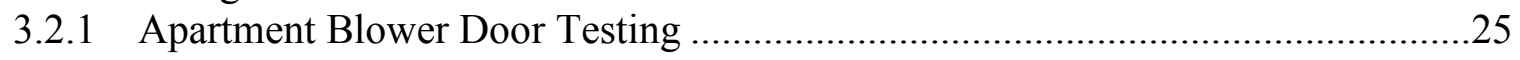

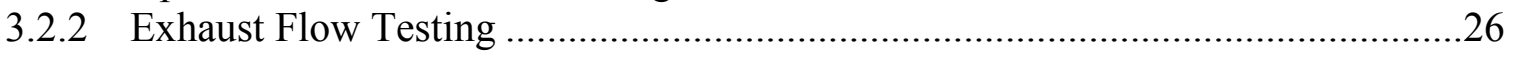

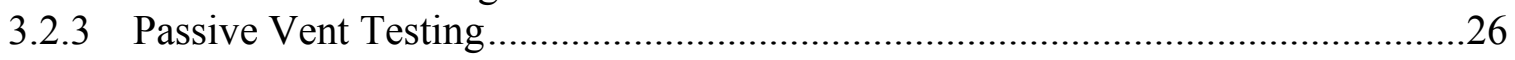

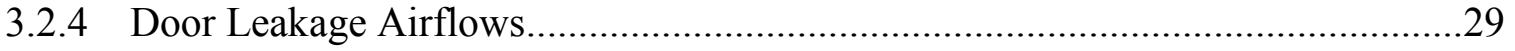

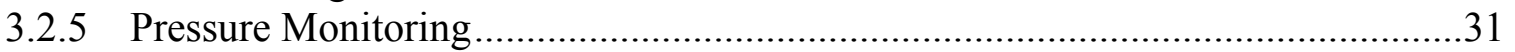

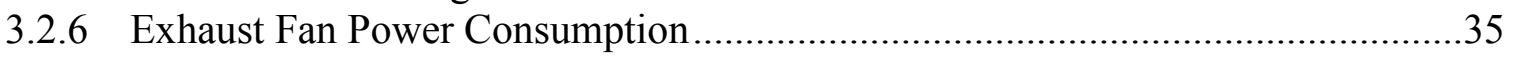

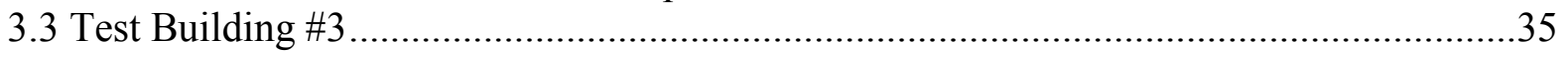

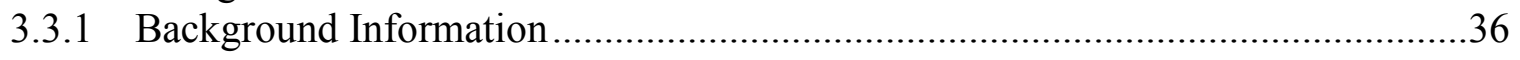

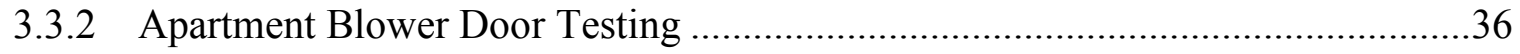

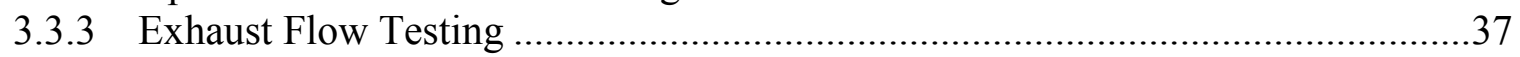

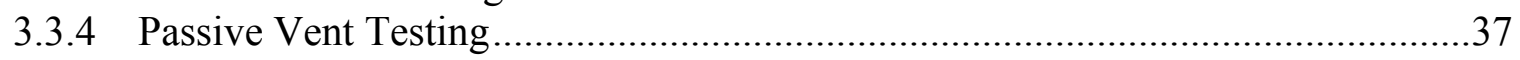

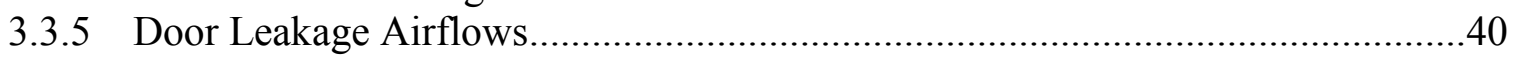

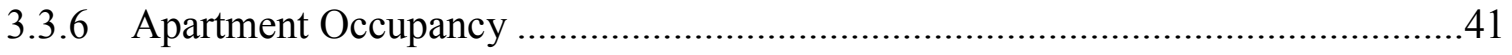

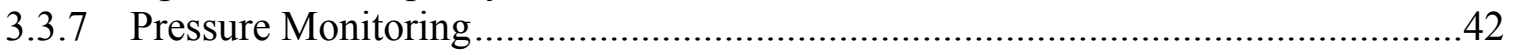

3.3.8 Exhaust Fan Power Consumption ................................................................ 47 
\begin{tabular}{l|l} 
u.s. DEPARTMENT OF & Energy Efficiency \& \\
ENERewable Energy
\end{tabular}

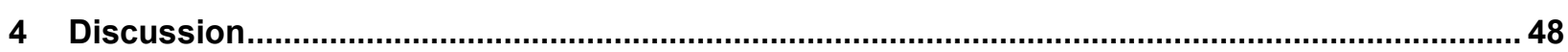

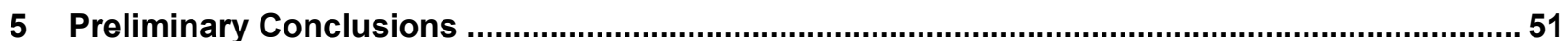

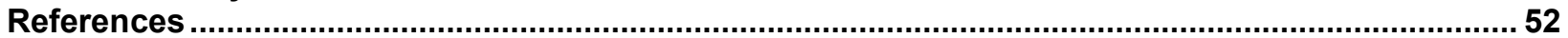




\section{List of Figures}

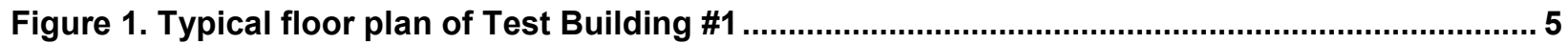

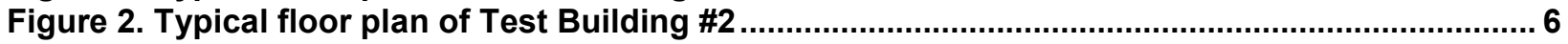

Figure 3. Typical floor plan of Test Building \#3 ......................................................................... 7

Figure 4. Powered flow hood. Image from The Energy Conservatory ............................................ 8

Figure 5. Setup for testing air leakage from a door frame ......................................................... 9

Figure 6. Typical pressure patterns in a multistory building in winter ........................................... 10

Figure 7. Placement of window data loggers for pressure measurement (shown without exterior

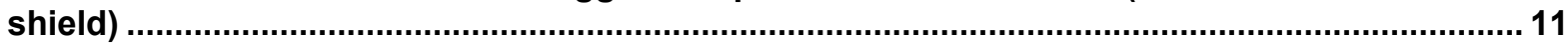

Figure 8. Placement of pressure transducer under corridor door ................................................ 11

Figure 9. Common trickle vent (left) and installation in a window frame (right) .............................15

Figure 10. Setup for testing airflow through trickle vents ......................................................... 16

Figure 11. Trickle vent flow at varying pressures ................................................................... 16

Figure 12. Cut for trickle vent in window frame (left), trickle vent removed; close-up of the opening

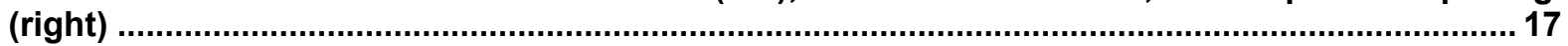

Figure 13. Setup for testing airflow through door gap with a plastic shroud and orifice plate........ 18

Figure 14. Pressure in several building spaces over time........................................................... 20

Figure 15. Pressure data monitored in building spaces over a 24-hour period .............................. 21

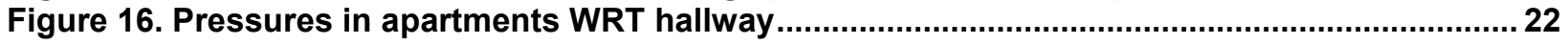

Figure 17. Pressures in Apartment 4K WRT hallway and outdoors ............................................... 23

Figure 18. Common airlet (left) and backside of Airlet with flaps (right) ..................................... 27

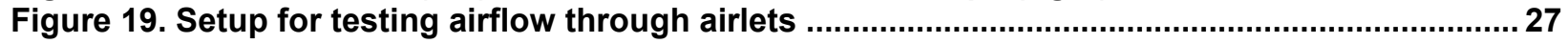

Figure 20. Airlet flow-apartment depressurized WRT outdoors ................................................. 28

Figure 21. Airlet flow_apartment pressurized WRT outdoors …............................................... 28

Figure 22. Door air leakage - apartment depressurized WRT corridor ............................................. 30

Figure 23. Door air leakage_apartment pressurized WRT corridor ................................................ 30

Figure 24. Pressure across airlets (apartment pressure WRT outside) over time ............................ 32

Figure 25. Pressure across door (apartment pressure WRT corridor) over time................................ 33

Figure 26. Airflow through airlet and door in Apartment 1A over time ............................................... 33

Figure 27. Airflow through airlet and door in Apartment 4G over time .......................................... 34

Figure 28. Typical trickle vent in open position (top) and with cover removed (bottom) ................. 38

Figure 29. Setup for testing airflow through trickle vents ............................................................ 38

Figure 30. Building \#3 trickle vent performance with trend lines added .......................................... 39

Figure 31. Holes cut in window frame for trickle vent.................................................................. 39

Figure 32. Setup for testing airflow around door with a blower door shroud and Duct Blaster fan 40

Figure 33. Building \#3 door air leakage ............................................................................................ 41

Figure 34. Contact closure data loggers to monitor window opening (left); door opening (right) ... 42

Figure 35. Arrangement of apartments under monitoring .............................................................. 42

Figure 36. Pressures in apartments WRT outside over 4 days .......................................................... 43

Figure 37. Pressures in apartments WRT outside over 24 hours ............................................... 44

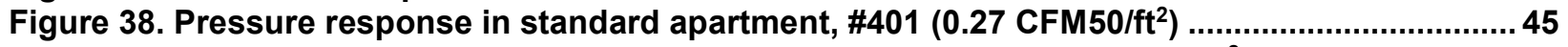

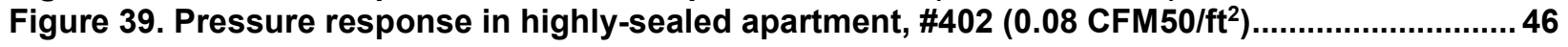

Unless otherwise noted, all figures were created by the CARB team. 


\section{List of Tables}

Table 1. Factors Affecting Ventilation Performance ................................................................... 4

Table 2. Measurements and Sampling Rates at Each Building Type ................................................. 8

Table 3. Building \#1 Apartment Airtightness Metrics .................................................................... 13

Table 4. Building \#1 Exhaust Flow Measurements.................................................................... 14

Table 5. Test Results Showing Calculated Leakage from a Plastic Shroud ...................................... 19

Table 6. Summary Flow Data from Apartment/Corridor Doors ..................................................... 22

Table 7. Summary Flow Data from Trickle Vents in Unoccupied Apartments.................................. 24

Table 8. Summary Maximum Flow Data from Trickle Vents in Occupied Apartments .......................24

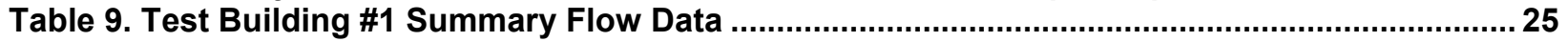

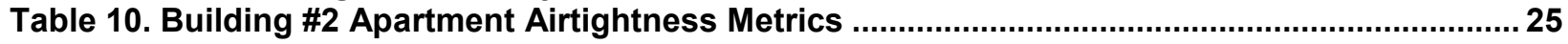

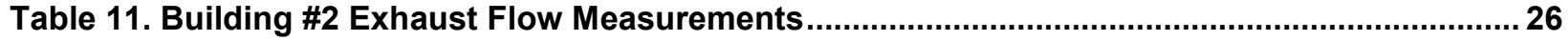

Table 12. Apartment Door Airflow Equation Coefficients and Exponents .......................................... 31

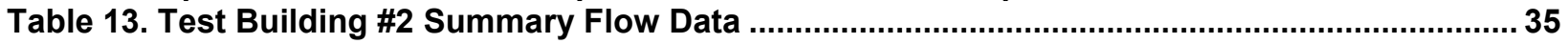

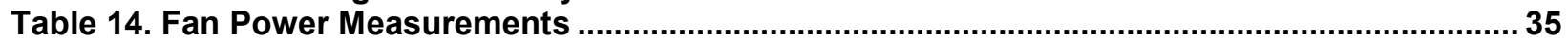

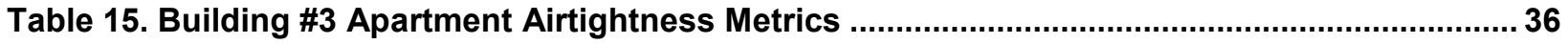

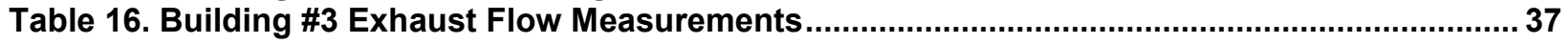

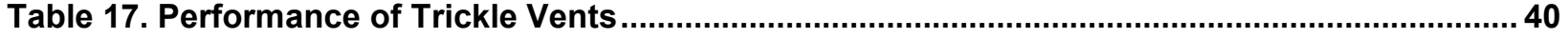

Table 18. Apartment Door Airflow Equation Coefficients and Exponents ...................................... 41

Table 19. Test Building \#3 Summary Flow Data .......................................................................... 47

Table 20. Comparison of Average Airtightness and Airflow in One-Bedroom Apartment Example 48

Unless otherwise noted, all tables were created by the CARB team. 


\section{Definitions}

BSC

CARB

CFM

CFM50

CFM $50 / \mathrm{ft}^{2}$

LEED

NYSERDA

$\mathrm{Pa}$

SWA

W

WRT
Building Science Corporation

Consortium for Advanced Residential Buildings

Cubic Feet per Minute

Cubic Feet per Minute Flow at a Test Pressure of 50 Pascals

CFM at a Test Pressure of 50 Pascals per Square Foot of Enclosure Area

Leadership in Energy \& Environmental Design

New York State Energy Research and Development Authority

Pascal

Steven Winter Associates

Watt

With Respect to 


\section{Executive Summary}

Exhaust ventilation and corresponding outdoor air strategies are being implemented in highperformance, new construction, multifamily buildings to meet program or code requirements for improved indoor air quality, but a lack of clear design guidance is resulting in poor performance of these systems despite the best intentions of the programs or standards. In 2014 the U.S. Department of Energy's Building America research team Consortium for Advanced Residential Buildings published a report titled Evaluation of Ventilation Strategies in New Construction Multifamily Buildings, which consistently demonstrated that commonly used outdoor air strategies are not performing as expected. This initial evaluation warranted additional research to develop the guidance the industry needs to make these ventilation systems perform at a high level. Descriptions of the four strategies evaluated in 2014 follow.

- The exhaust ventilation system that relied on outdoor air from a pressurized corridor was ruled out as a potential best practice because it conflicts with most fire codes.

- Ducting outdoor air directly to the apartments has the highest likelihood of success, but its first costs and operating costs are higher.

- Properly designed and executed outdoor air through space-conditioning systems has good performance potential.

- Passive systems are the least expensive option for providing outdoor air directly to apartments with respect to first costs and operating costs. However, little is known about how they perform under real-world conditions or how to implement them effectively. Based on the lack of data available on the performance of these low-cost systems and their frequent use in the high-performance building programs that require a provision for outdoor air, this research project sought to further evaluate the performance of passive vents.

This strategy uses engineered passive vents in the exterior envelope to provide ventilation air from the outside. Exhaust in apartments is provided by either central or in-unit fans that operate continuously. The negative pressure these fans create is meant to draw outdoor air into an apartment through the passive vents. The research focus for this system type is the functioning of passive vents under various pressure conditions. Because the passive vents are meant to operate in a general environment of negative apartment pressure, the research assessed whether these negative pressures prevail under a variety of environmental conditions.

The data from the evaluation of three test buildings show that the passive vents did not perform as expected. Although the operating pressures varied, at a pressure differential of $5 \mathrm{~Pa}$ the airflow through the vents was 3 CFM-9 CFM. Based on the type, quality, and number of vents installed, the average airflow through the passive vents was 6 CFM-20 CFM per apartment. Compared to the whole-house ventilation requirements from ASHRAE 62.2-2010, these airflows fall short of providing the 20 CFM-45 CFM that is typical of most apartments based on square footage and number of occupants. Airflow from the passive vents was $13 \%-36 \%$ of the exhaust ventilation rate. These are not always designed to provide balanced ventilation; however, compared to the exhaust rates, this strategy demonstrates that most of the makeup air comes from unintentional sources - from leaks in the exterior envelope, neighboring apartments, or the corridor. 
This is not to say that passive ventilation systems cannot operate as intended. Compared to mechanical outdoor air systems, they are simply more challenging to implement properly and effectively. Although this evaluation did not demonstrate that these systems performed as expected, it did identify the design criteria that affect performance.

Airtightness (specifically compartmentalization) is critical in creating an environment for passive vents to work properly. The apartments that were highly sealed had greater pressure differentials and more airflow from the passive vents. These apartments were also impacted less by conditions in adjacent units and other parts of the building. Other criteria are the size and number of passive vents, the exhaust fan airflow, the airtightness of the apartment entry door, and the quality of the passive vent and its installation. Because this low-cost outdoor air strategy continues to be allowed in high-performance building programs, design guidance is needed to help project teams implement them properly. Design guidance based on these criteria will be provided in a forthcoming passive vents measure guideline. 


\section{Problem Statement}

In multifamily buildings, particularly in the Northeast, exhaust ventilation strategies are typically used to meet the local exhaust and whole-house mechanical ventilation rates that are required by ASHRAE 62.2 (ASHRAE 2010a, 2010b). According to this standard, an exhaust system is "one or more fans that remove air from the building, causing outdoor air to enter by ventilation inlets or normal leakage paths through the building envelope." If a building owner is participating in a high-performance building program such as ENERGY STAR ${ }^{\circledR}$ Certified Homes, exhaust ventilation system flow rates must be verified in the field to demonstrate compliance with ASHRAE 62.2 ventilation rates. However, the source and quantity of makeup air are rarely addressed. Although ENERGY STAR Certified Homes, Version 3, Rev. 07, requires that "ventilation air comes directly from outdoors, not from adjacent dwelling units, garages, crawlspaces, or attics," dedicated outdoor air is not explicitly required, and the source and quantity are not verified (EPA 2010). The issue of where the ventilation air originates is gaining significance as airtightness standards for enclosures become increasingly stringent and the "normal leakage paths through the building envelope" disappear.

Some high-performance building programs, such as the U.S. Green Building Council's Leadership in Energy \& Environmental Design (LEED) for Homes and the New York State Energy Research and Development Authority's (NYSERDA's) Multifamily Performance Program, have recognized the importance of outdoor air despite a paucity of supporting data. These programs have already included additional prescriptive requirements for outdoor air strategies beyond ASHRAE 62.2 requirements, but they still have no commissioning requirements to verify that the outdoor air system actually works. For example, LEED for Homes Mid-Rise requires that "outdoor air must be provided to each unit directly from the outdoors" (LEED 2010). Although ASHRAE 62.2-2010, Section 6.1.1 accepts ventilation system design that "explicitly requires transfer air from corridors into units," LEED for Homes Mid-Rise explicitly prohibits "systems that rely on transfer air from pressurized hallways or corridors, adjacent dwelling units, attics, etc." Other programs, such as ENERGY STAR's Multifamily High Rise Program, are waiting for building research to inform their ventilation requirements.

As the industry waits for research results, exhaust ventilation approaches and any corresponding outdoor air strategies are being implemented in high-performance, new construction, multifamily buildings to meet program or code requirements. However, a lack of clear design guidance is resulting in poor implementation of these systems despite the best intentions of the programs or standards. Provisions for outdoor air, without depending on infiltration, come in many forms that range from fully ducted systems that deliver outdoor air directly to apartments, to designed holes in the envelope such as trickle vents, and to outdoor air dampers tied to the space-conditioning system. Pressurizing corridors by oversizing corridor space-conditioning systems to provide an indirect source of outdoor air to apartments is a controversial but common practice that has thus far led to high energy use with no data to justify the perceived indoor air quality benefit to the apartment.

In terms of first costs and operating costs, passive systems are one of the least expensive options for providing outdoor air directly to apartments; however, not enough is known about their effectiveness. Although these passive systems often qualify as meeting the dedicated outdoor air requirement for certain high-performance building programs, no testing procedures are in place 
to verify their performance. Design guidance is also not available to project teams for best implementing these passive systems. Product performance data from manufacturers are based on laboratory tests, and products are assumed to perform similarly in the field. Because all ventilation systems are designed to work within a specific operating environment, proper application involves matching expected performance to expected building pressures. Still, in the case of passive ventilation systems that are dependent on environmental conditions, the finished building will not necessarily demonstrate those conditions consistently. These systems need to be evaluated in the field to validate their performance. Based on the results of this evaluation, design guidance and test procedures can then be developed.

\subsection{Previous Research}

The U.S. Department of Energy's Building America research team Consortium for Advanced Residential Buildings (CARB) has been researching residential ventilation systems for more than a decade. In 2006, CARB tested and compared ventilation systems in high-performance singlefamily homes in South Chicago to evaluate performance and cost-effectiveness (Aldrich and Vijayakumar 2006). In 2008, Steven Winter Associates (SWA) evaluated the performance of self-balancing air dampers in central exhaust ventilation systems in multifamily homes. The importance of air sealing the exhaust duct work was evident, and methods including the Aeroseal technology were examined. This research was funded by the Partnership for Advancing Technology in Housing Program, and the report was published by the National Association of Home Builders Research Center. The work was frequently cited by Building Science Corporation (BSC) in its ventilation research study that was performed as part of an energy retrofit of an existing multifamily building in Philadelphia (Ueno et al. 2012).

In 2009, SWA, Camroden Associates (Terry Brennan), and the National Center for Healthy Homes developed two best practice guides (which are applicable to new construction and retrofits) for exhaust-only systems in multifamily buildings. These guidelines provide a blueprint for designing and implementing exhaust-only ventilation systems in multifamily buildings that meet ASHRAE 62.2 local exhaust and whole-house ventilation rate requirements (NCHH 2009a, 2009b).

In 2013, CARB again evaluated ventilation systems in single-family homes to determine performance and cost-effectiveness; however, this time the focus was on retrofitting existing homes (Aldrich and Arena 2013). Neither the BSC research nor these SWA/CARB research projects evaluated the source or quantity of the outdoor air.

The Canadian Mortgage and Housing Corporation has conducted considerable research on residential ventilation systems in mid-rise and high-rise multifamily buildings and has shown that ventilation systems can be affected by a complex interaction of factors. In one study, four alternative ventilation strategies were evaluated (CMHC 2003), including passive vents and three variations of heat recovery ventilation systems. The research revealed that passive vents are susceptible to wind and stack pressures and require that apartments be compartmentalized for proper function. Heat recovery ventilators performed well but were expensive and required greater maintenance.

BSC found that central ventilation systems in multifamily buildings often perform poorly overall. BSC recommends compartmentalizing apartments, sealing ductwork, and installing 
variable-speed, pressure-controlled fans with electronically commutated motors. The resulting system can improve performance and reduce heating energy and fan electric energy.

In 2010, SWA performed testing in a multifamily building that had taken the extra step to pair exhaust ventilation with appropriately sized trickle vents to provide a dedicated source of outdoor air. To support the development of the ENERGY STAR Multifamily High Rise program, the U.S. Environmental Protection Agency funded SWA to perform similar ventilation research in three additional mid-rise multifamily buildings. In 2013, CARB conducted an evaluation of four typical ventilation strategies in new construction, multifamily buildings, including passive vents (Maxwell et al. 2014). Based on the research in 2010 and 2013, a protocol for evaluating the performance of the compartmentalized apartment/unitized ventilation design was further refined and applied to the current research.

\subsection{Research Question}

This project focused on the following research question:

- Do passive vents perform reliably among multiple building installations as an outdoor air strategy? 


\section{Technical Approach}

\subsection{Outdoor Air through Passive Vents}

CARB evaluated the performance of a system that provides outdoor air to apartments through passive vents. This system uses engineered passive vents in the exterior envelope to provide ventilation air from the outside. Exhaust in apartments is provided by either central or in-unit fans that operate continuously. The negative pressure these fans create is meant to draw outdoor air into the apartment through the passive vents.

The research focus for this system type is the functioning of passive vents under various pressure conditions. Because the passive vents are meant to operate in a general environment of negative apartment pressure, the research assessed whether these negative pressures prevail under a variety of environmental conditions.

\subsection{Factors that Affect Ventilation System Performance and Choice of Measurements}

Many factors affect a ventilation system's ability to deliver outdoor air to apartments, including elements of the proposed building design, its as-built construction, and interactions with the occupants and the surrounding environment (Table 1).

Table 1. Factors Affecting Ventilation Performance

\begin{tabular}{|c|c|}
\hline \multirow{5}{*}{ Design Factors } & - Overall ventilation scheme \\
\hline & - Supply and exhaust design flow rates \\
\hline & - Choice of ventilation equipment \\
\hline & - Size and shape of building \\
\hline & - Choice of building materials and techniques \\
\hline \multirow{2}{*}{$\begin{array}{l}\text { Construction } \\
\text { Factors }\end{array}$} & - Quality of ventilation equipment and duct installation \\
\hline & $\begin{array}{l}\text { - Airtightness of the building's exterior envelope and interior } \\
\text { partitions }\end{array}$ \\
\hline \multirow{2}{*}{$\begin{array}{c}\text { Environmental } \\
\text { Factors }\end{array}$} & - Indoor and outdoor temperatures \\
\hline & - Wind pressures \\
\hline \multirow{3}{*}{ Human Factors } & - Operation of ventilation system's “modes" (high, low, etc.) \\
\hline & - Resident operation of windows and other air pathways \\
\hline & - Temperatures of building spaces \\
\hline
\end{tabular}

The tests described in Section 2.3 were chosen to evaluate construction and environmental factors in this study where possible. No attempt was made to quantify design factors, because they are too varied to consider in this study. The team did not adequately prepare for the influence of human factors, which led to difficulty in evaluating some of the other factors. Further studies should more fully anticipate this influence.

\subsection{Building Descriptions and Information}

Three test buildings were selected that implemented passive ventilation strategies to meet the requirements of a high-performance building program. Selection was based on construction schedules, high levels of air sealing, and owner enthusiasm for participating in this study. To facilitate initial testing in the apartments, CARB aimed to choose buildings that had just 
completed construction but were not yet fully occupied. The test buildings completed construction between late 2012 and mid-2014.

\subsubsection{Test Building \#1}

Test Building \#1 is located in the Bronx, New York and was part of the original evaluation of ventilation strategies CARB conducted in 2013. It is a five-story, T-shaped building with 13 apartments per floor. Each floor has a laundry room, refuse room, storage room, elevator bank, and two stairwells. Figure 1 shows a typical floor plan. Pressure monitoring was conducted in apartments $3 \mathrm{~F}, 4 \mathrm{~K}, 4 \mathrm{~L}, 4 \mathrm{M}, 5 \mathrm{~A}$, and $5 \mathrm{H}$, which are located on the third, fourth, and fifth floors.

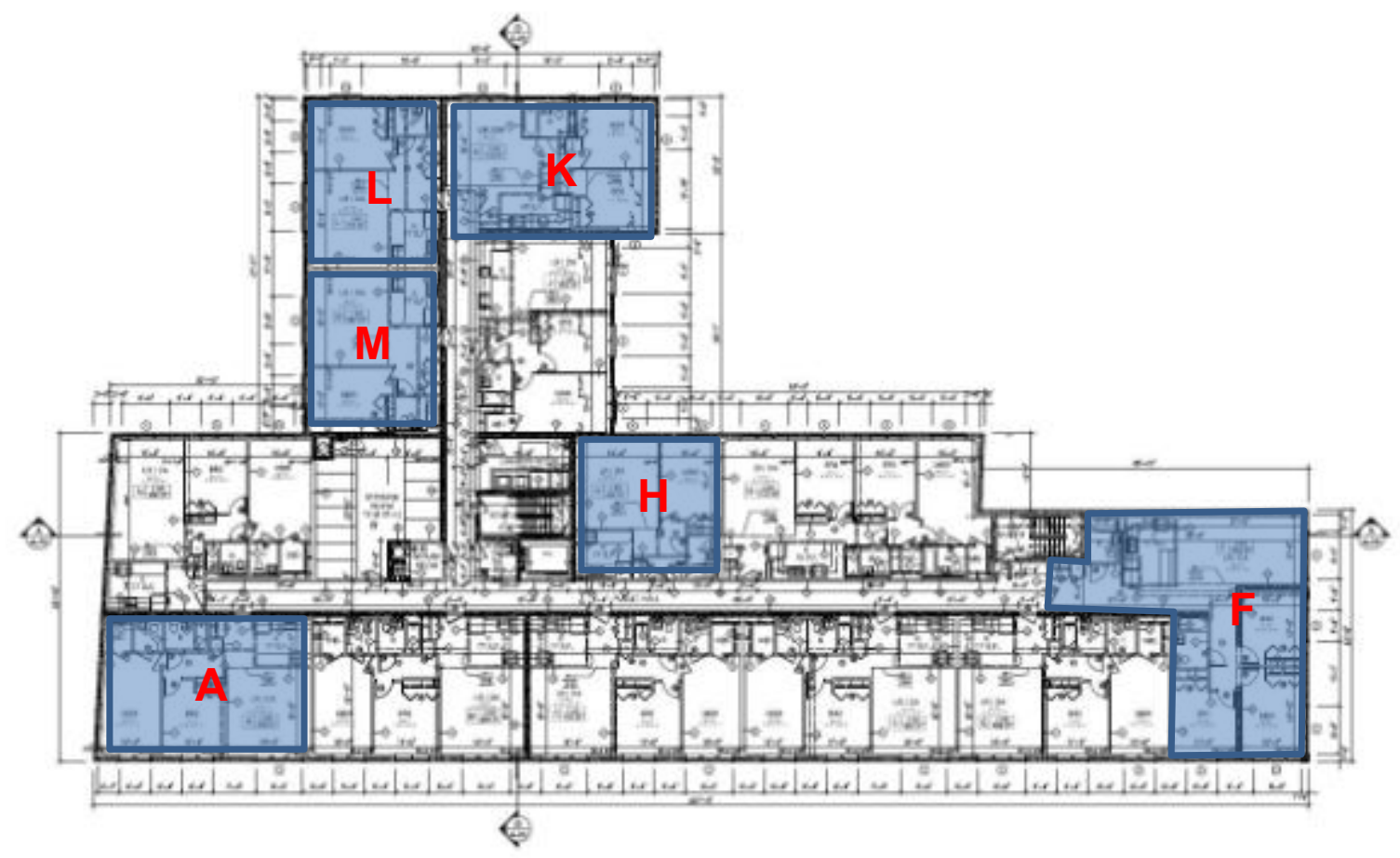

Figure 1. Typical floor plan of Test Building \#1

The building participated in LEED for Homes Certification and NYSERDA's Multifamily Performance Program during its construction, which required a provision for outdoor air and included testing of apartment airtightness and testing and balancing of heating, ventilating, and air-conditioning system flows. The apartments are heated by hydronic baseboard convectors. To meet the local exhaust and whole-house ventilation rates required by ASHRAE 62.2, the apartments are ventilated by continuously operating in-line fans that draw from kitchens and bathrooms. Outdoor air is intended to come from trickle vents that were installed in window frames. Each living room has one or two trickle vents; each bedroom has one. The method of sizing and selecting the trickle vents is unclear. All are the same make and model. The corridors are supplied with $275 \mathrm{CFM}$ per floor. This equates to a flow of $0.2 \mathrm{CFM} / \mathrm{ft}^{2}$ of corridor space or about 21 CFM per apartment. Results and findings are described in Section 3.1.

\subsubsection{Test Building \#2}

Test Building \#2 is located in Brooklyn, New York. It is a six-story, U-shaped affordable housing complex with 95 units. Each floor has a refuse room, elevator bank, and two stairwells. 
Figure 2 shows a typical floor plan. Pressure monitoring was conducted in apartments 1A, 2B, $3 \mathrm{~B}, 4 \mathrm{G}, 5 \mathrm{~B}$, and $6 \mathrm{~L}$, which are located on the respective floors.

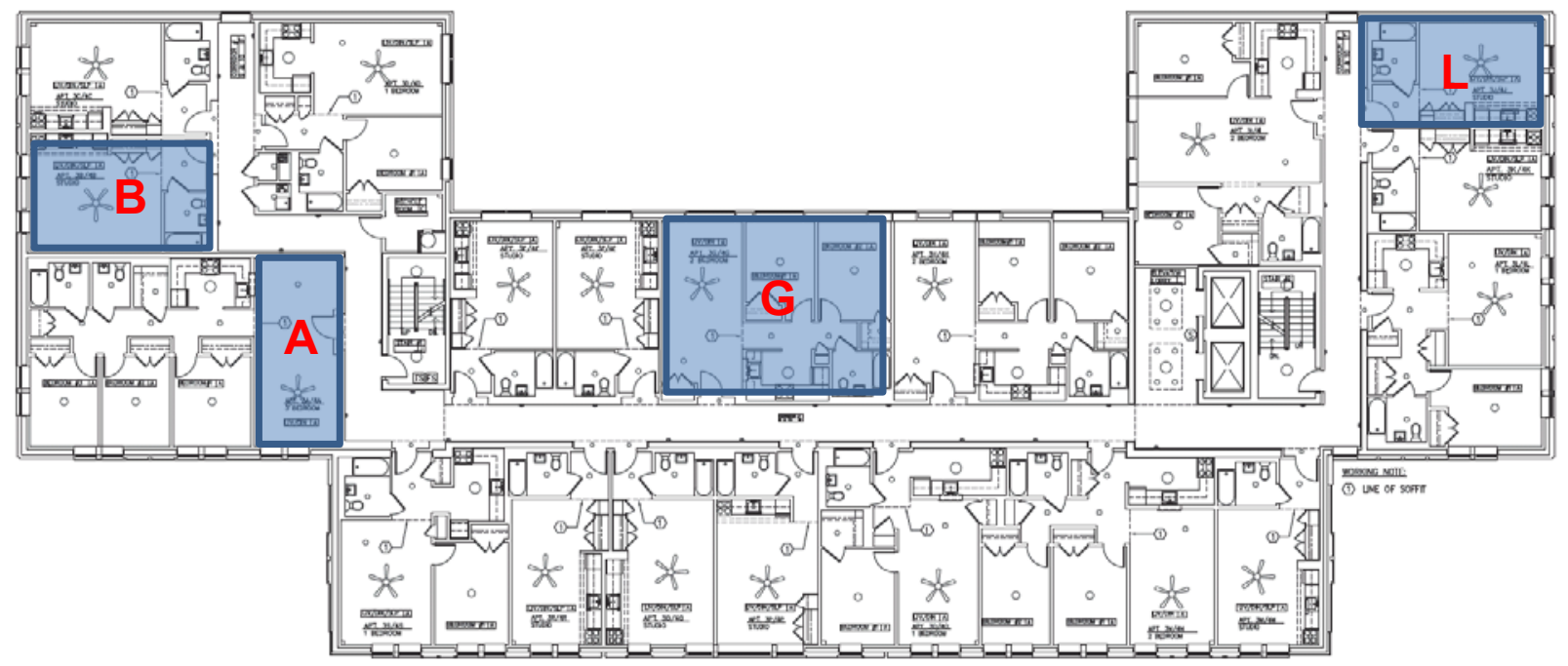

Figure 2. Typical floor plan of Test Building \#2

The building participated in LEED for Homes Certification and NYSERDA's Multifamily Performance Program during its construction. The apartments are heated by hydronic baseboard convectors. To meet the local exhaust and whole-house ventilation rates that are required by ASHRAE 62.2, the apartments are ventilated by continuously operating central exhaust fans that draw from kitchens and bathrooms. Outdoor air is intended to come from airlets installed in exterior walls. Each living room and each bedroom has one airlet. They are all the same size, make, and model. The corridors are supplied with 1,300 CFM per floor. This equates to a flow of $0.3 \mathrm{CFM} / \mathrm{ft}^{2}$ of corridor space or about $72 \mathrm{CFM}$ per apartment. Results and findings are described in Section 3.2.

\subsubsection{Test Building \#3}

Test Building \#3 is located in Brooklyn, New York. It is a nine-story, rectangular building with 54 apartments. It was built with insulated concrete forms, so the exterior walls are solid poured concrete. Each floor has a refuse room, elevator bank, and stairwell. Figure 3 shows a typical floor plan. Pressure monitoring was conducted in apartments 201, 202, 203, 301, 302, 303, 401, 402, and 403 on the second, third, and fourth floors. The monitoring was limited to these floors because the upper part of the building was still under construction. 


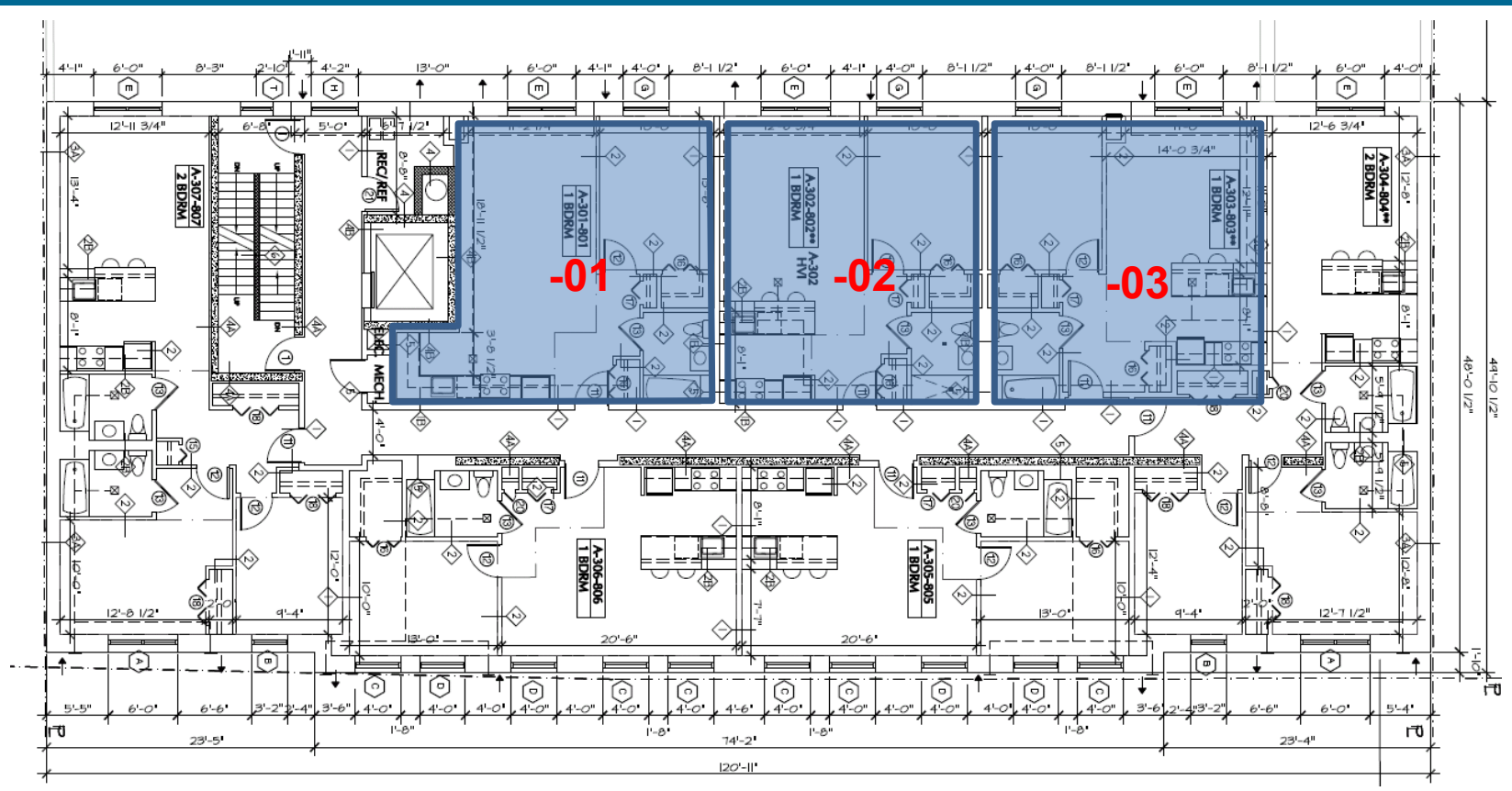

Figure 3. Typical floor plan of Test Building \#3

The building participated in NYSERDA's Multifamily Performance Program during its construction. The apartments are heated by fan coil units. To meet the local exhaust and wholehouse ventilation rates required by ASHRAE 62.2, the apartments are ventilated by continuously operating in-line fans that draw from kitchens and bathrooms. Outdoor air is intended to come from trickle vents that were installed in the window frames. Each living room and each bedroom has one trickle vent. All are the same size, make, and model. The corridors are supplied with 50 CFM per floor. This equates to a flow of $0.1 \mathrm{CFM} / \mathrm{ft}^{2}$ of corridor space or about $7 \mathrm{CFM}$ per apartment. Results and findings are described in Section 3.3.

\subsection{Measurements and Tests}

The tests listed in Table 2 were used to evaluate the passive vent strategy. For each building, the tests can be grouped into two main stages: detailed tests on building components and pressure monitoring. The table also shows minimum sampling rates for each test. These rates were determined based on the availability of previous test data and access to units for additional testing. Pressure monitoring was conducted for 2 weeks. The length of the sampling period was based on the availability of equipment, availability of occupied units, and need to collect data that were representative of the season. CARB aimed to make the sampling period as long as possible and still monitor all the buildings. Two figures are given for each test. The first represents the number of tests performed in each sample building. The second represents the number of tests as a percentage. In some cases an apartment has more than one item. For example, an apartment may have several passive vents. 
Table 2. Measurements and Sampling Rates at Each Building Type

\begin{tabular}{c|c|c|c|c|c|c}
\hline \multirow{2}{*}{ Test } & \multicolumn{5}{c}{$\begin{array}{c}\text { Number of Samples and Percentage } \\
\text { per Building }\end{array}$} \\
\cline { 2 - 8 } & \multicolumn{2}{|c|}{ Bldg \#1 } & \multicolumn{2}{|c|}{ Bldg \#2 } & \multicolumn{2}{|c}{ Bldg \#3 } \\
\hline Apartment Blower Door Testing & 9 & $14 \%$ & 21 & $22 \%$ & 19 & $35 \%$ \\
\hline Door Leakage Airflow & 5 & $8 \%$ & 6 & $6 \%$ & 9 & $17 \%$ \\
Passive Vent Testing & 5 & $3 \%$ & 5 & $3 \%$ & 6 & $6 \%$ \\
Apartment Exhaust Flows & 14 & $22 \%$ & 6 & $6 \%$ & 11 & $20 \%$ \\
\hline Pressure Monitoring & 5 & $8 \%$ & 6 & $6 \%$ & 9 & $17 \%$ \\
\hline
\end{tabular}

Section 2.4.1 through Section 2.4.3 include details about the tests that were designed to provide data on various aspects of building and ventilation performance. For improved context, Section 3 provides details about the tests that are specific to a particular building.

\subsubsection{Apartment Blower Door Testing}

Apartment airtightness (compartmentalization) is an important aspect of high-performance construction because it impacts the function of ventilation systems and other airflow patterns in an operating building. Evaluating apartment blower door $( \pm 1 \%$ of reading or $0.15 \mathrm{~Pa})$ data alongside ventilation performance measurements reveals correlations. Buildings selected for evaluation have recently participated in high-performance building programs in which singlepoint, single-unit unguarded depressurization tests were conducted at $50 \mathrm{~Pa}$ for more than $10 \%$ of the units to demonstrate air leakage that is lower than the threshold of $0.30 \mathrm{CFM} 50 / \mathrm{ft}^{2}$ of enclosure.

\subsubsection{Exhaust Flow Testing}

Exhaust flow testing involved using an orifice/pressure box (accuracy $\pm 10 \%$ ) or powered flow hood (accuracy $\pm 5 \%$ ) to measure airflow at apartment exhaust registers and comparing them to design values.

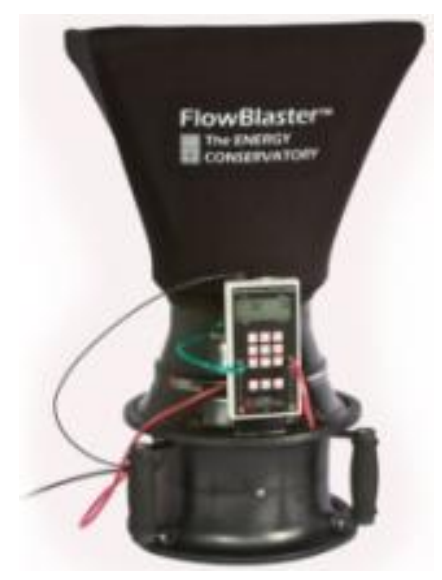

Figure 4. Powered flow hood. Image from The Energy Conservatory 


\subsubsection{Passive Vent Testing}

Passive vent testing involved inducing a pressure differential on either side of the vent and measuring the airflow. A capture box with a calibrated fan $( \pm 1 \%$ of reading or $0.15 \mathrm{~Pa})$ attached to it was sealed around each vent. The fan was used to create a pressure on one side. The pressures on the inside and outside aspects of each vent were measured with manometers, and the fan was used to measure the airflow.

\subsubsection{Door Leakage Airflows}

The testing apparatus for this experiment consists of a capture hood to encapsulate the door and capture airflow and a fan to impart a pressure on the hood and measure airflow. Readings were taken at different pressure drops across the door and the data analyzed to identify a basic curve for predicting airflow through a typical apartment door in the building. These data were then combined with pressure monitoring results to infer the direction and magnitude of airflow across the apartment doors throughout the building over time.

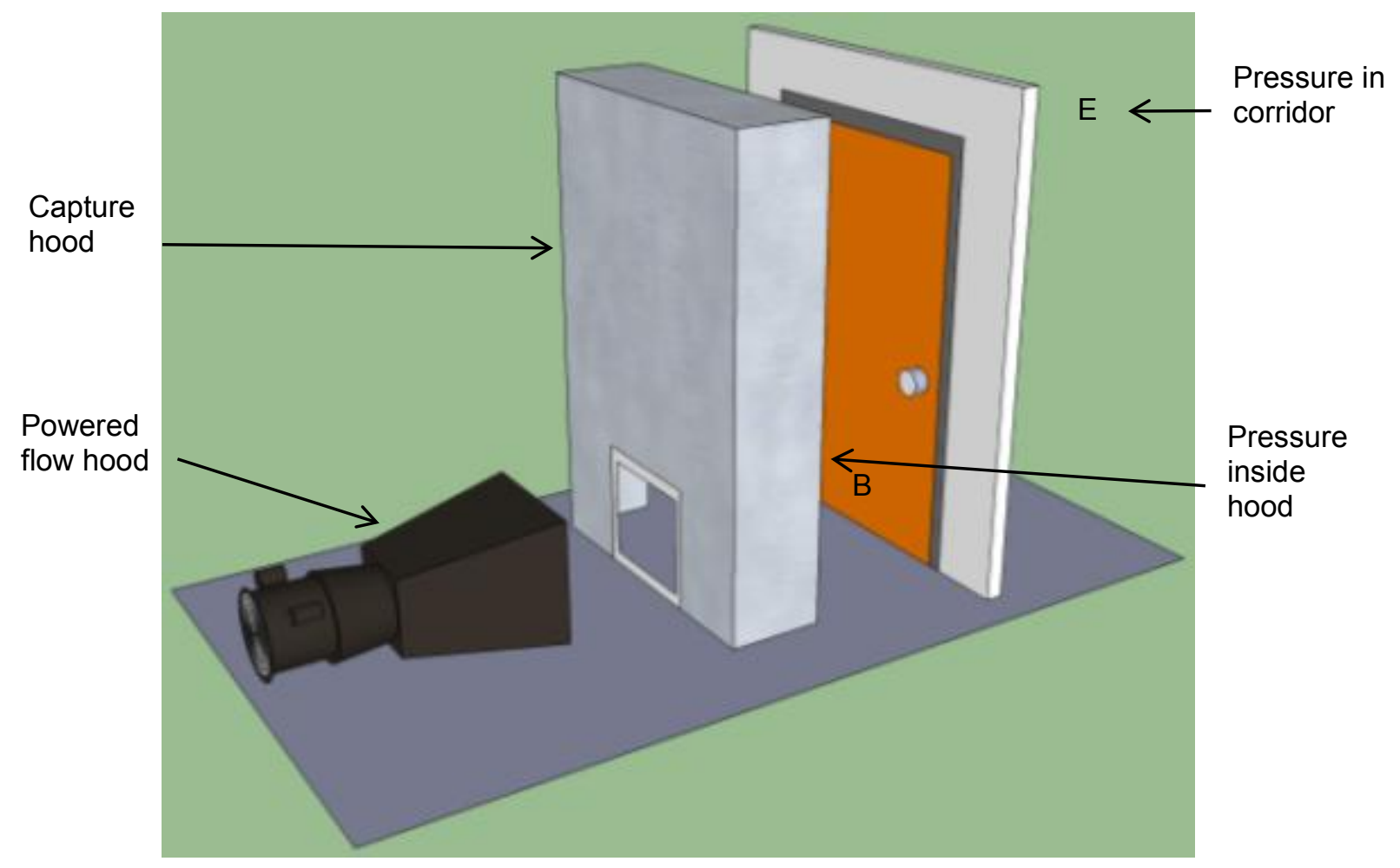

Figure 5. Setup for testing air leakage from a door frame

The testing apparatus is set up by constructing a capture hood from rigid polyisocyanurate foam board over the apartment entry door. This hood captured all airflow from the door frame and directed it to an opening where it was measured by a powered flow hood (accuracy $\pm 5 \%$ ). A pressure differential across the door (A to B) was developed at several levels. At each pressure differential, the powered flow hood measured the airflow. The powered flow hood can undergo pressurization and depressurization tests but must be configured separately for either mode.

Door leakage in Test Building \#1 was measured using an alternate orifice plate method, because the above method had not yet been developed. The orifice plate method is described in more 
detail in Section 3.1.4 for that building. Although the method was accurate, its setup was time consuming and cumbersome; thus, an easier, faster way to measure leakage is needed. The method described in this section is an improvement that was developed during the course of this study and was used in Building \#2 and Building \#3.

The two methods of measuring door leakage were not directly compared on the same building, but the orifice plate method was checked by comparing it to blower door results (Section 3.1.4).

\subsubsection{Pressure Monitoring}

Airflow patterns in buildings are dependent on pressure differentials. Understanding the major patterns of pressure fields is important to predicting the behavior of the airflow-related systems (mechanical, envelope, etc.) under various environmental and operational conditions. In typical buildings during the winter, as warm air rises, pressures that prevail on the exterior envelope are positive with respect to (WRT) the outside near the top of the building and negative at the bottom of the building. For a typical building, this results in airflow into the apartments on the lower floor and airflow out of the apartments on the upper floors (Figure 6). Because passive vents rely on airflow into the apartments to provide ventilation on all floors, buildings selected for the study were limited to high-performance buildings that required compartmentalization to minimize the impact of these seasonal pressure differentials.

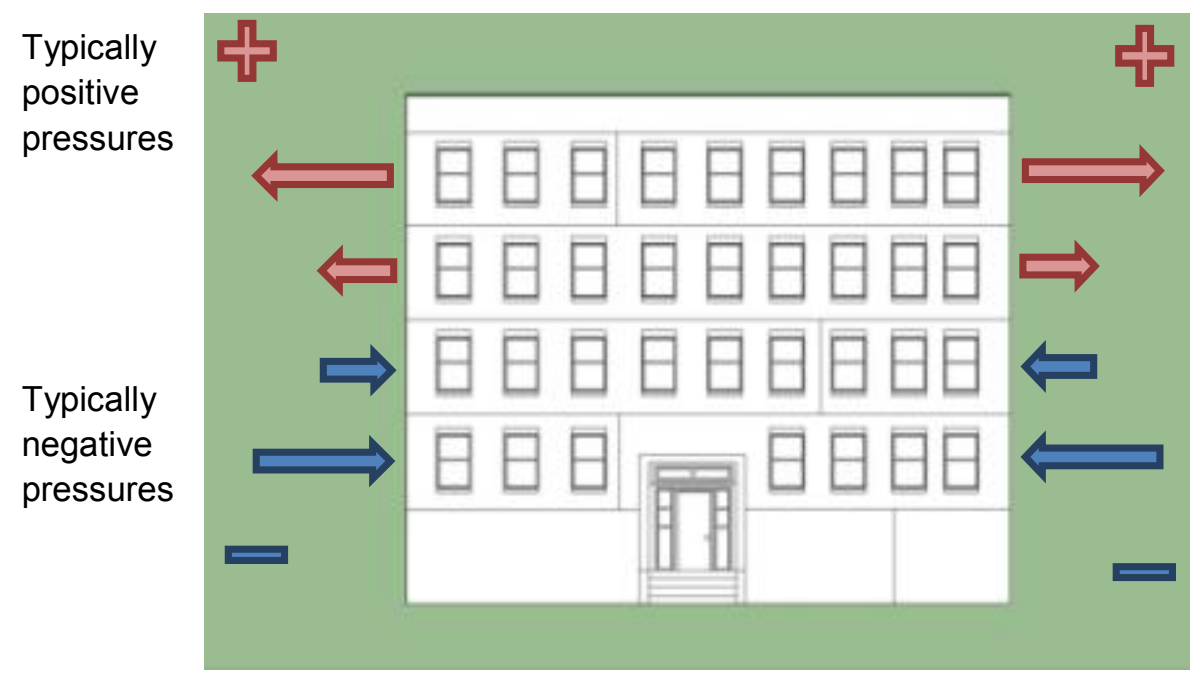

Figure 6. Typical pressure patterns in a multistory building in winter

By comparing the results of short-term airflow testing from the previous sections with a map of pressure differentials that were obtained through long-term pressure monitoring, the airflow through passive inlets and its variability can be predicted over time.

To create this map, an array of pressure sensors was used to monitor pressure differentials between key building areas. Five points were measured with digital gauges over a 1-2 week period. Pressure measurements with an accuracy of $\pm 3.5 \%$ between the apartment and the outside were collected at 1-minute intervals and then averaged over every hour to give a general picture of pressure in the spaces over time. Figure 7 shows the placement of window data loggers. 


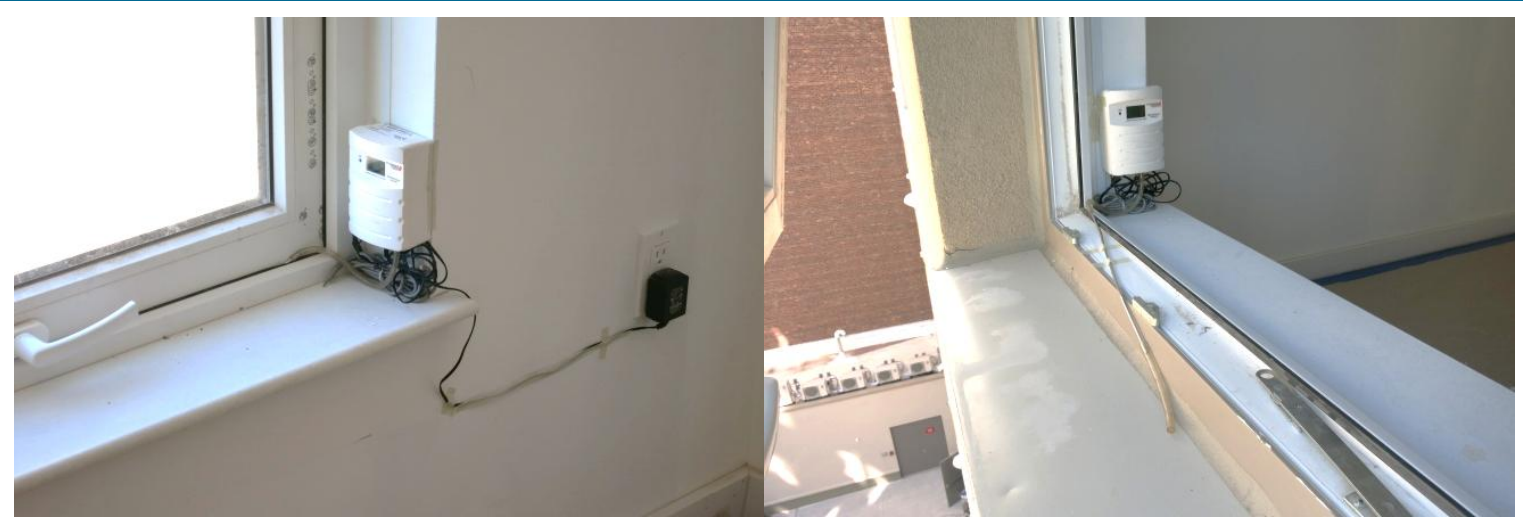

Figure 7. Placement of window data loggers for pressure measurement (shown without exterior shield)

Pressure measurements between the apartment and the corridor were also taken with data loggers at 1-minute intervals and averaged over every hour. Figure 8 shows the placement of a pressure transducer.

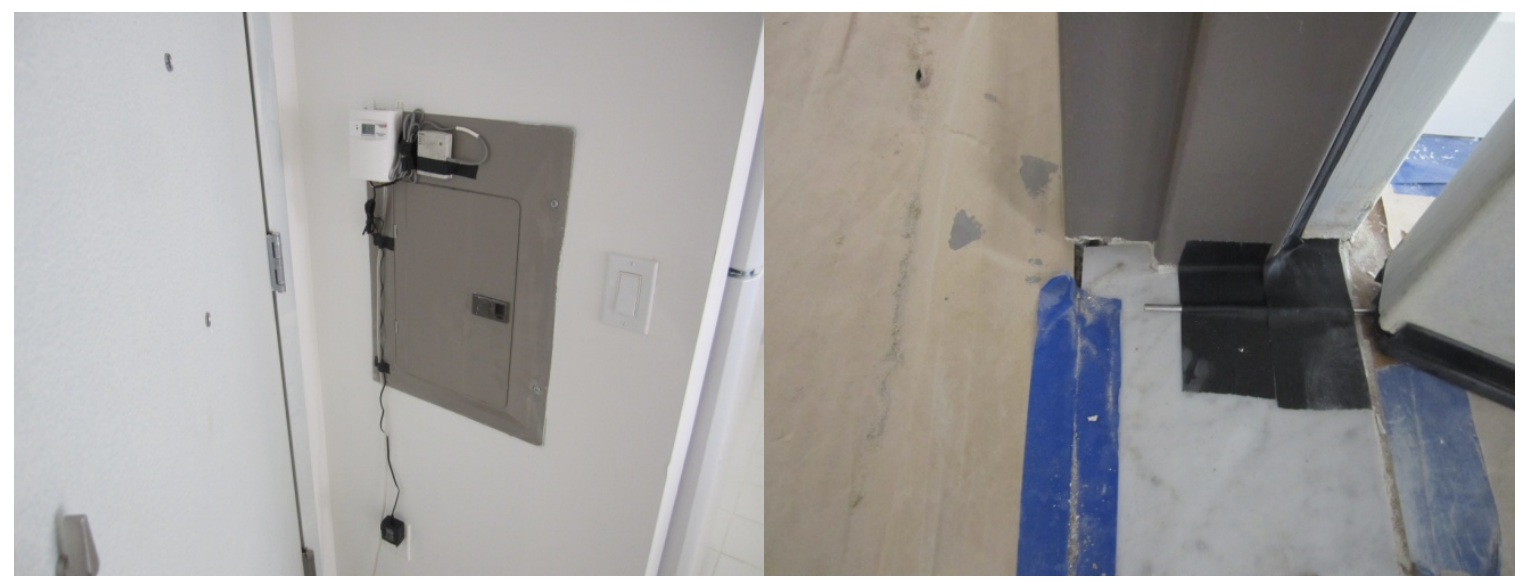

Figure 8. Placement of pressure transducer under corridor door

The goal of characterizing airflow at various pressures through passive vents and apartment entry doors is a predictable model of airflow patterns through these leakage points over time. Prevailing pressures monitored over time will indicate expected airflows.

\subsubsection{Exhaust Fan Power Consumption}

Fan electric power consumption was estimated from product literature at the flow rates measured. The electricity use combined with the flow rate was used to determine the relative fan efficiency in cubic feet per minute of air per watt (CFM/W).

\subsubsection{Factors that Affect the Measurement}

Environmental conditions play an important role in the operation of passive vents; the primary factors are wind and seasonal temperature variations (Section 2.4.5). Although all measurements show some uncertainty (due to equipment accuracy, environmental conditions, etc.), all data used for analysis purposes were direct measurements and were not calculated based on multiple measurement inputs, so the uncertainty from propagation of errors was minimized. Through rigorous testing, the researchers have good confidence in the passive vents' installed 
performance, because the measurements were repeatable when wind conditions were calm. For the short-term testing, the role of wind was clearly visible by the short-term fluctuation of the pressure monitoring results; however, the overall trends remained the same. Still, the specific effects of wind are difficult to quantify because of its intermittency and high variability. Local wind data were not collected as part of this study.

The location of an apartment within a building and fluctuations in flow through passive vents due to wind show no clear correlation. In general, apartments on higher floors experience greater pressure variation due to wind; however, the specific geometry and situation of the building on its site enhance or detract from the impact of wind speed and direction. Locations of trees, open spaces, setbacks, and other buildings all affect the local environment and can result in significant variations in building pressures for apartments on the same floor.

Occupant behavior is likely the largest influence on system behavior, but the effect is difficult to quantify or predict. Occupants may alter the operation of the ventilation system directly, for example by opening, closing, or blocking off vents or turning fans on or off. Occupants may affect vent airflow indirectly by opening windows or adding or removing seals such as weatherstripping.

Occupant interaction with the ventilation systems can pose a major challenge to measurement efforts, because either system alterations need to be recorded or the data need to be analyzed to understand the points at which occupant behavior is an influence. In this study, the CARB team attempted to educate residents on the aims of the study and the requirements for participation. For example, during the study residents were asked to operate only the windows that were equipped with open/closed data loggers. 


\section{Results and Findings}

The following subsections are organized by building.

\subsection{Test Building \#1}

The results from Test Building \#1 are from the previous evaluation of ventilation strategies (CARB 2014) but are provided here for context. Section 2.3.1provides descriptions of floor plans for this test building.

\subsubsection{Apartment Blower Door Testing}

Blower door testing was conducted in nine of the 65 apartments. The results show that apartments in this five-story building are generally well compartmentalized; the average total leakage rate is $0.11 \mathrm{CFM} 50 / \mathrm{ft}^{2}$ of apartment enclosure. For comparison, the leakage rate is also provided in terms of ACH50, which demonstrates that on average the apartments were able to meet the air leakage rates established in Section R402.4.1.2 of the 2012 International Energy Conservation Code ( 3 ACH50). Table 3 summarizes the test results.

Table 3. Building \#1 Apartment Airtightness Metrics

\begin{tabular}{|c|c|c|c|c|c|}
\hline Apartment & $\begin{array}{c}\# \\
\text { Beds }\end{array}$ & $\begin{array}{c}\text { Area } \\
\left(\mathbf{f t t}^{2}\right)\end{array}$ & $\begin{array}{c}\text { Flow } \\
\text { (CFM50) }\end{array}$ & ACH50 & CFM50/ft ${ }^{2}$ \\
\hline $2 B$ & 2 & 922 & 312 & 2.8 & 0.11 \\
\hline $2 \mathrm{~L}$ & 1 & 702 & 248 & 2.7 & 0.11 \\
\hline $3 C$ & 2 & 922 & 244 & 2.0 & 0.09 \\
\hline $3 G$ & 3 & 1,140 & 310 & 2.0 & 0.09 \\
\hline $4 \mathrm{~J}$ & 2 & 826 & 387 & 3.6 & 0.15 \\
\hline $4 M$ & 1 & 687 & 209 & 1.6 & 0.09 \\
\hline $5 B$ & 2 & 922 & 249 & 2.0 & 0.09 \\
\hline $5 F$ & 3 & 1,355 & 423 & 2.3 & 0.10 \\
\hline $5 K$ & 2 & 813 & 356 & 3.8 & 0.14 \\
\hline \multicolumn{4}{|c|}{ Average } & 2.5 & 0.11 \\
\hline
\end{tabular}

\subsubsection{Exhaust Flow Testing}

Each apartment in this building is equipped with a single in-line exhaust fan that serves multiple registers - one in each bathroom and kitchen. Each three-bedroom apartment and a few twobedroom apartments have two bathrooms. Each register is outfitted with an automatic balancing damper to limit the airflow from each register and balance airflow among them. Exhaust rates were measured from each register in 14 apartments. Table 4 summarizes the results. ASHRAE 62.2-2010 whole-house ventilation rates are provided for comparison.

To comply with ASHRAE 62.2-2010 continuous local exhaust rates, the design calls for 20 CFM from bathrooms and 85 CFM from kitchens for a total of 105 CFM-125 CFM per apartment, depending on the number of bathrooms. The average flow rate from a kitchen exhaust register was 35 CFM; from a bath exhaust register 23 CFM. Measured airflows in kitchens averaged 41\% of design; those from bathrooms averaged $115 \%$ of design. Difficulties specifying and 
constructing very small multibranch exhaust systems can account for much of this variation. In one-bathroom and two-bathroom units, the same exhaust fan (which was rated for $120 \mathrm{CFM}$ at 0.2 in. of water) was specified but at different static pressures.

Table 4. Building \#1 Exhaust Flow Measurements

\begin{tabular}{|c|c|c|c|c|c|c|c|}
\hline \multirow[b]{2}{*}{ Apartment } & \multirow{2}{*}{$\begin{array}{c}\# \text { of } \\
\text { Bedrooms }\end{array}$} & \multicolumn{3}{|c|}{ Exhaust Flow (CFM) } & \multirow{2}{*}{$\begin{array}{c}\text { Total } \\
\text { Flow } \\
\text { (CFM) }\end{array}$} & \multirow{2}{*}{$\begin{array}{c}\text { Design } \\
\text { CFM }\end{array}$} & \multirow{2}{*}{$\begin{array}{c}\text { ASHRAE } \\
\text { 62.2 Rate } \\
\text { (CFM) }\end{array}$} \\
\hline & & Kitchen & $\begin{array}{c}\text { Bath } \\
1\end{array}$ & $\begin{array}{c}\text { Bath } \\
2\end{array}$ & & & \\
\hline $1 \mathrm{~A}$ & 2 & 7 & 32 & - & 39 & 105 & 32 \\
\hline 1D & 3 & 21 & 40 & 21 & 82 & 125 & 42 \\
\hline $2 \mathrm{~A}$ & 2 & 33 & 23 & 22 & 78 & 125 & 32 \\
\hline $2 B$ & 2 & 34 & 19 & 37 & 90 & 125 & 32 \\
\hline 2D & 2 & 37 & 21 & 13 & 71 & 125 & 32 \\
\hline $2 F$ & 3 & 35 & 18 & 20 & 73 & 125 & 44 \\
\hline $2 \mathrm{~L}$ & 1 & 52 & 25 & - & 77 & 125 & 22 \\
\hline $3 \mathrm{C}$ & 2 & 40 & 24 & 25 & 89 & 125 & 32 \\
\hline $3 G$ & 3 & 25 & 24 & 19 & 68 & 125 & 41 \\
\hline 4J & 2 & 42 & 23 & - & 65 & 105 & 31 \\
\hline $4 \mathrm{M}$ & 1 & 41 & 23 & - & 64 & 105 & 22 \\
\hline $5 B$ & 2 & 37 & 15 & 16 & 68 & 125 & 32 \\
\hline $5 F$ & 3 & 35 & 20 & 9 & 64 & 125 & 44 \\
\hline $5 K$ & 2 & 54 & 30 & - & 84 & 105 & 31 \\
\hline \multicolumn{2}{|c|}{ Average } & 35 & \multicolumn{2}{|c|}{23} & & & \\
\hline
\end{tabular}

Automatic balancing dampers and newer fans that self-correct for installation variances may be able to help limit imbalances. In this building, automatic balancing dampers were used in kitchen and bathroom registers. In kitchens, maximum measured flows were still significantly lower than design, which indicates the dampers may have been incorrectly specified. However, because the design flow of $85 \mathrm{CFM}$ was higher than the $51 \mathrm{CFM}$ flow needed to meet the $5 \mathrm{ACH}$ requirement, some of the measured kitchen exhausts still complied with ASHRAE 62.2-2010. Measured flows in bathrooms were as high as $200 \%$ of design flow, which indicates those dampers were also incorrectly specified or simply unable to limit flows in bathrooms to design levels. In some kitchens and bathrooms measured values did not meet the minimum continuous local exhaust rates that are required by ASHRAE 62.2.

Even if exhaust flows were measured to show they met design, the makeup air needed to provide balanced ventilation was significantly greater than the supply of outdoor air needed to meet ASHRAE 62.2 whole-house rates, which are based on square footage and number of occupants (Table 4). In single-family homes, makeup air for exhaust fans presumably comes from the outdoors. In attached housing this is not necessarily true, so the makeup air is a mix of outdoor air and transfer air from other spaces. 


\subsubsection{Passive Vent Testing}

To evaluate whether the ASHRAE 62.2 whole-house rates are being satisfied by outdoor air, measurements of the amount of makeup air that enters an apartment from the outdoors through passive vents are needed. This test building uses trickle vents, a type of passive vent, to provide outdoor air to apartments. Figure 9 (left) shows a photo of one type of trickle vent; Figure 9 (right) shows another in a typical installation in a window frame. The window manufacturer typically installs the vents. An opening is created in the frame per the trickle vent manufacturer's specifications (typically 2 in.-4 in. ${ }^{2}$ ), and the vent is affixed to the window over the opening.
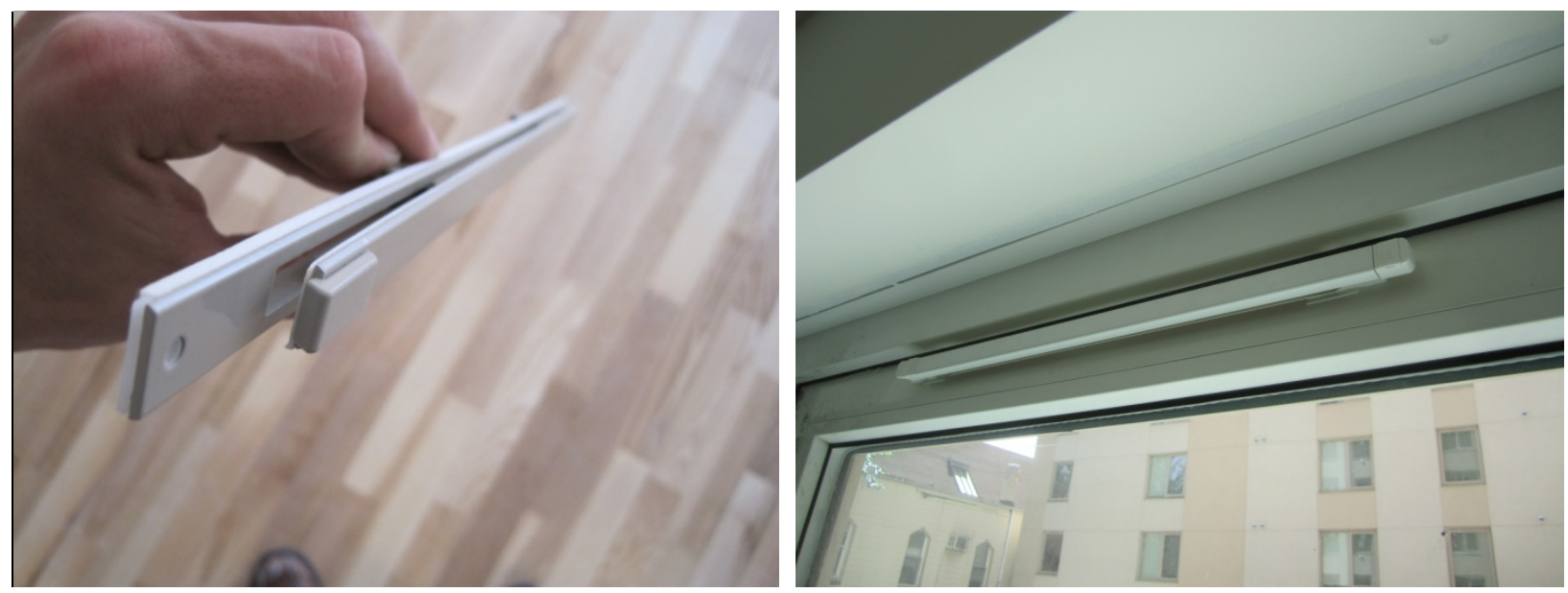

Figure 9. Common trickle vent (left) and installation in a window frame (right)

The manufacturers test the trickle vents to determine their performance at various pressures or wind speeds. This gives designers some information about how the devices might perform in their buildings. However, designers rarely know the typical pressures that will apply to a specific building, so this information is of limited value. In this building, each living room has one or two trickle vents and each bedroom has one.

The CARB team tested a sample of trickle vents to characterize their performance as installed. Five trickle vents were tested by inducing a pressure differential on either side and measuring the airflow. A capture box was sealed around each vent and a Duct Blaster fan from The Energy Conservatory was used to create a pressure on one side. The pressures on the inside and outside aspects of each vent were measured with manometers, and the calibrated fan was used to measure the airflow (accuracy $\pm 3 \%$ ). Figure 10 shows a photo of the testing apparatus. 


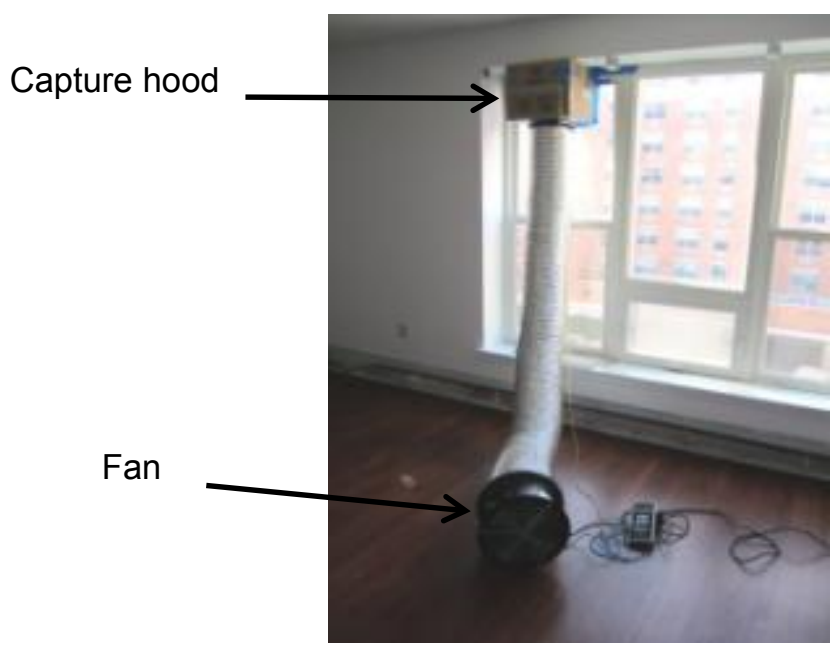

Figure 10. Setup for testing airflow through trickle vents

Figure 11 shows the test results for five separate vents. Airflow through the vents was measured at a variety of pressures. A clearly recognizable pattern emerges. The first trickle vent was tested under positive and negative pressures, and the results were almost identical. The remaining four vents were tested under negative pressure only. Figure 11 shows results from the negativepressure tests only.

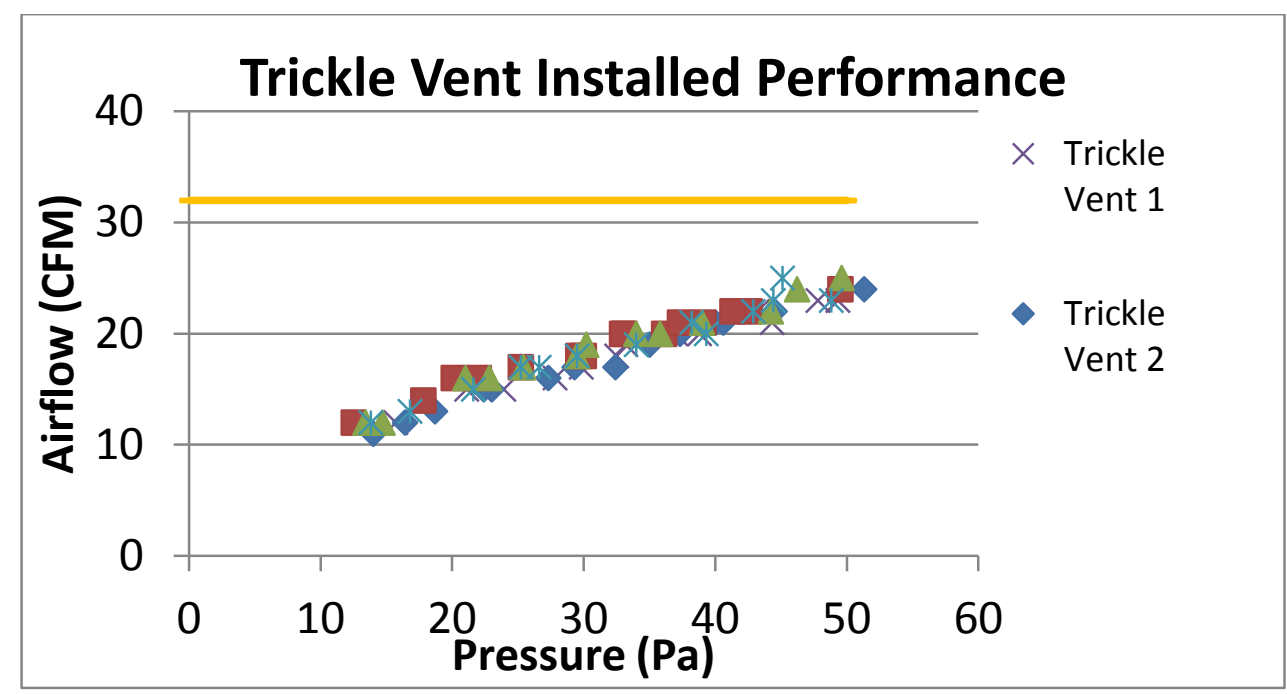

Figure 11. Trickle vent flow at varying pressures

The results show that trickle vents in this building are capable of airflow into an apartment but that a significant pressure differential across the vent is required. The orange horizontal line represents the ASHRAE 62.2 whole-house ventilation rate for a typical two-bedroom apartment. If this level of outdoor air (32 CFM) is desired, a pressure differential that exceeds $60 \mathrm{~Pa}$ across one vent is required. Alternatively, more trickle vents could be installed. For each to provide 10 CFM of air, a pressure of $10 \mathrm{~Pa}$ would be required. For reference, the typical pressure differential between apartment and the exterior is less than $5 \mathrm{~Pa}$. At $5 \mathrm{~Pa}$, each trickle vent would deliver only 6.7 CFM of outdoor air, which would require at least four or five vents to be installed in a two-bedroom apartment to meet the whole-house rate. 
In terms of providing "balanced" ventilation, the results show that trickle vents installed in typical buildings, as well as buildings with good levels of compartmentalization, are unlikely to achieve the pressure differentials needed to provide rates of makeup air anywhere equivalent to exhaust rates. The trickle vents are too small or too few, and the pressures commonly developed are much too weak to draw enough air from them. Because the ASHRAE 62.2 whole-house ventilation rates for apartments in multifamily buildings tend to be lower than the continuous local exhaust rates, these trickle vents could supply the recommended amount of outdoor air, even if do not provide fully balanced ventilation.

Trickle vents must be installed well to function as intended. In a building that CARB evaluated for other studies, the lack of measured performance from a trickle vent prompted an investigation of the installation. The vent cover was removed from the window frame and closely examined. The air pathway was significantly blocked through the layers of the window frame because the vent was poorly manufactured. The initial cut did not go through the depth of the frame, so secondary holes were drilled. The opening should be one continuous space that passes through the entire depth of the frame. Obviously, such defects negatively impact the function of the vents.
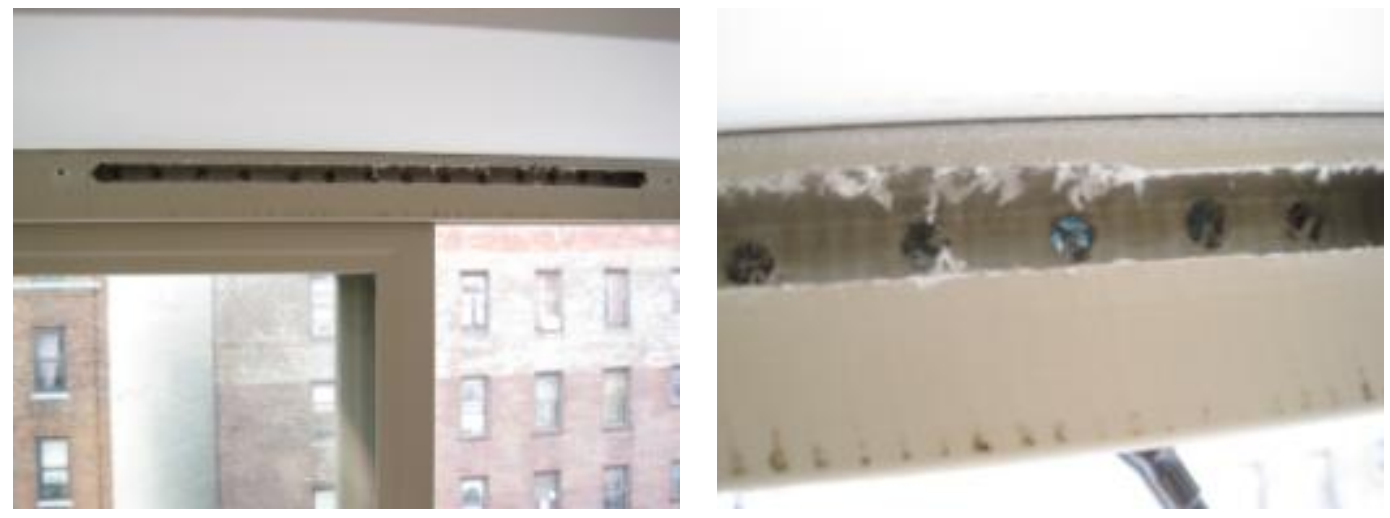

Figure 12. Cut for trickle vent in window frame (left), trickle vent removed; close-up of the opening (right)

The data gathered from testing airflow through the trickle vents in the test building were used to model how the vents function as a source of outdoor air over time. The relationship between pressure and airflow takes the general form:

Where:

$$
Q=C(\Delta P)^{n}
$$

Q represents flow

$\Delta \mathrm{P}$ is the pressure differential across the vent

$\mathrm{C}$ and $\mathrm{n}$ are empirically determined.

Using a linear regression on the logarithm of pressure and flow readings from all five vents of the same make and model, the pressure exponent $n$ and flow coefficient $C$ were derived. The equation used to calculate flow through these vents follows:

$$
Q=2.77 * \Delta P^{0.551}
$$




\subsubsection{Door Leakage Airflows}

In multifamily buildings, makeup air for exhaust fans is a mix of outdoor air and transfer air from other spaces. After the exhaust airflow and airflow into the apartments through trickle vents were measured, measurements of the makeup air from other leakage points such as the entry door were needed. In this test building, each door between apartments and corridors had a door sweep, but the sweep was not always tight to the door saddle. The door jambs and header also did not have weather-stripping. Thus, significant gaps allowed relatively easy passage of air between apartments and corridors. Simple measurements of the space around the door frames showed approximately 22 in. $^{2}$ of gap around them. For comparison, a typical two-bedroom apartment with three trickle vents has only 12 in. $^{2}$ of trickle vent opening. As mentioned in Section 2.4.4, equipment for testing the doors with a rigid capture hood the same way as Building \#2 and Building \#3 was not available, so doors were tested in two other ways to quantify the leakage area.

A blower door procedure to depressurize the apartment through a window; the apartment/corridor door gap was repeatedly taped and untaped to observe the difference in measured flow through the blower door. A difference of approximately 205 CFM50 was recorded in tests on two apartments, which is roughly equivalently to $20 \mathrm{in}^{2}$ of leakage.

Another approach used a sharp-edged orifice and pressure measurements to estimate door gap size and airflow under normal operating conditions in the apartment. A plastic shroud was taped over the door frame, and a plate with a sharp-edged orifice was fixed to the shroud. Figure 13 provides an illustration.

\section{Door "Shroud" Measurement Technique}

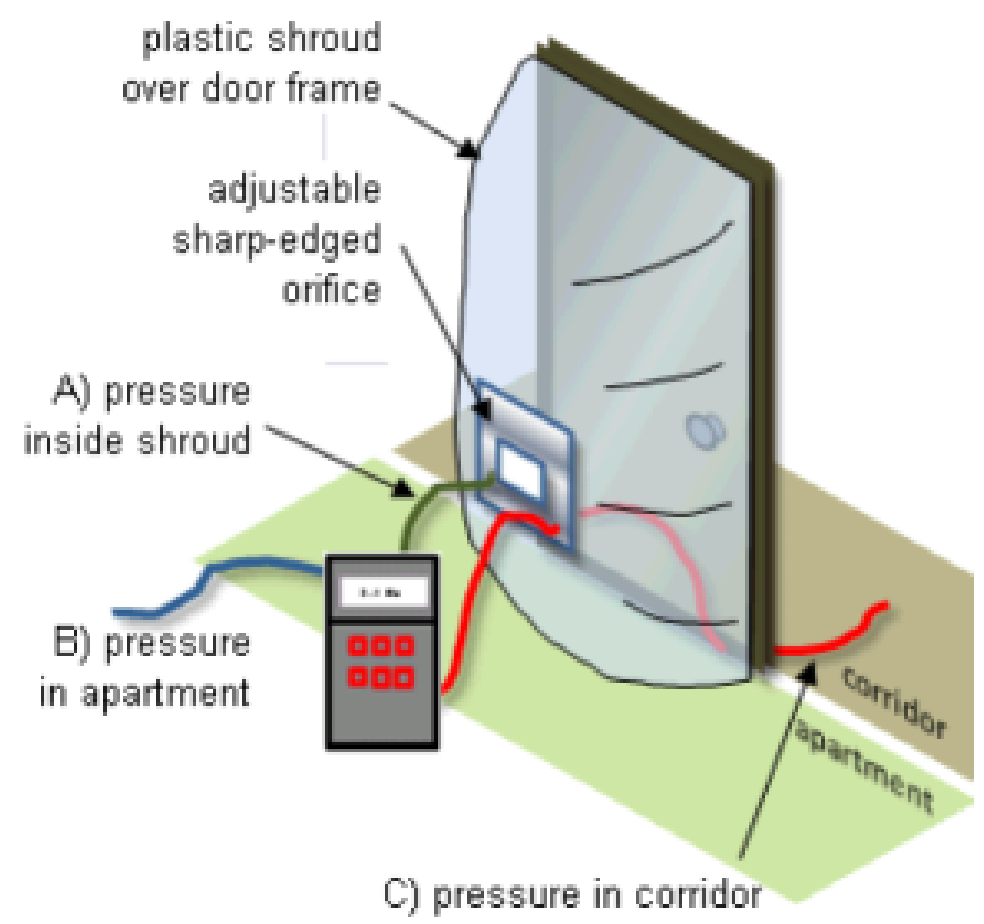

Figure 13. Setup for testing airflow through door gap with a plastic shroud and orifice plate 
The pressure differential between the inside of the apartment $(\mathrm{B})$ and in the corridor $(\mathrm{C})$ was kept at $1 \mathrm{~Pa}-2 \mathrm{~Pa}$ by adjusting the orifice size to reduce the restricting effect of the shroud on the door and keep airflow through it within a measurable range. The pressure differential across the plate was measured by subtracting the pressure inside the plastic shroud (A) from the pressure inside the apartment (B). Using a coefficient of discharge of 0.61 for the orifice plate, the flow at the measured pressure differential across the door yielded airflow estimates.

Measurements were taken in three apartments: two had their continuous exhaust fans running, and one had its exhaust fan disabled (Table 5). All three apartments were neighbors on the same floor.

Table 5. Test Results Showing Calculated Leakage from a Plastic Shroud

\begin{tabular}{c|c|c|c|c|c|c|c|c}
\hline Unit & $\begin{array}{c}\text { PD } \\
\text { Across } \\
\text { Orifice } \\
\text { (A-B) }\end{array}$ & $\begin{array}{c}\text { Corridor } \\
\text { Pressure } \\
\text { WRT } \\
\text { Apt } \\
\text { (C-B) }\end{array}$ & $\begin{array}{c}\text { Orifice } \\
\text { Size } \\
\left(\text { in. }{ }^{2}\right)\end{array}$ & $\begin{array}{c}\text { Calculated } \\
\text { Flow } \\
\text { Through } \\
\text { Door } \\
\text { (CFM) }\end{array}$ & $\begin{array}{c}\text { Inline } \\
\text { Exhaust } \\
\text { Fan } \\
\text { Operation }\end{array}$ & $\begin{array}{c}\text { Design } \\
\text { Exhaust } \\
\text { Fan Flow } \\
\text { (CFM) }\end{array}$ & $\begin{array}{c}\text { Measured } \\
\text { Exhaust } \\
\text { Fan Flow } \\
\text { (CFM) }\end{array}$ & $\begin{array}{c}\text { Calculated } \\
\text { Leakage } \\
\text { Area } \\
\left.\text { (in. }^{2}\right)\end{array}$ \\
\hline 3A & 4.0 & 1.2 & 27 & 60.0 & On & 125 & $\begin{array}{c}\text { Not } \\
\text { measured }\end{array}$ & 24.6 \\
\hline 3B & 1.3 & 1.7 & 2 & 2.5 & Off & N/A & N/A & N/A \\
\hline 3C & 3.1 & 1.2 & 27 & 52.8 & On & 125 & 89 & 26.3 \\
\hline
\end{tabular}

The airflow measurements indicate that operating the apartment exhaust fans has a significant effect on the amount of air being drawn from the corridor door in these apartments. In apartments $3 \mathrm{~A}$ and 3C, with the in-line fans exhausting about $90 \mathrm{CFM}, 60 \mathrm{CFM}$ and $53 \mathrm{CFM}$ were drawn through leakage around the door, respectively. In the apartment without the in-line exhaust fan operating, only 2.5 CFM was drawn through leakage around the door, which illustrates the difference the local exhaust makes in depressurizing the apartment. The low values precluded a calculation of the leakage area of this door.

The area of the gap around the door can be determined by using the measurements above. By subtracting the measured pressure drop across the apartment boundary $(\mathrm{C}-\mathrm{B})$ from the pressure drop across the shroud (A-B), the pressure drop across the door (A-C) can be determined. This pressure drop and the flow measured through the orifice can be used to find the area of the door gap. The average area of leakage around the doors calculated by this method is 25.5 in. $^{2}$, which shows good agreement with the other two measurement methods.

$$
A=Q / C_{d} *(2 \Delta P / \rho)^{11.5 *} 1.37(3)
$$

Where:

$A$ is the leakage area of the door

$Q$ is leakage through the door gaps (in CFM)

$C_{d}$ is the coefficient of discharge

$\Delta P$ is the pressure differential between inside and outside of the test system (in Pascals)

$\rho$ is the air density (in $\mathrm{kg} / \mathrm{m}^{3}$ ) 


\subsubsection{Pressure Monitoring}

With these short-term airflow measurements, pressure monitoring was then undertaken in several building spaces with the intent of understanding the airflow patterns over time between building spaces and between the building and the outside. Data were gathered at 1-second intervals and then averaged over every hour to give a general picture of pressure in the spaces over time. Data were collected during a shoulder season with a mix of warm and cool weather. Two of the apartments were unoccupied for at least 1 week; the rest were occupied. Definite patterns emerged when the occupied apartments were compared to the unoccupied apartments.

Figure 14 shows the pressure in several apartments throughout the building as well as the corridor, all WRT a single outdoor reference pressure. The figure shows unoccupied apartments were more negatively pressurized than occupied apartments. Apartment $4 \mathrm{~L}$ was unoccupied for the entire monitoring period; Apartment 4M was unoccupied until November 2, 2013, when a resident moved in and occupied the space, as demonstrated by the distinct change in pressure at that time.

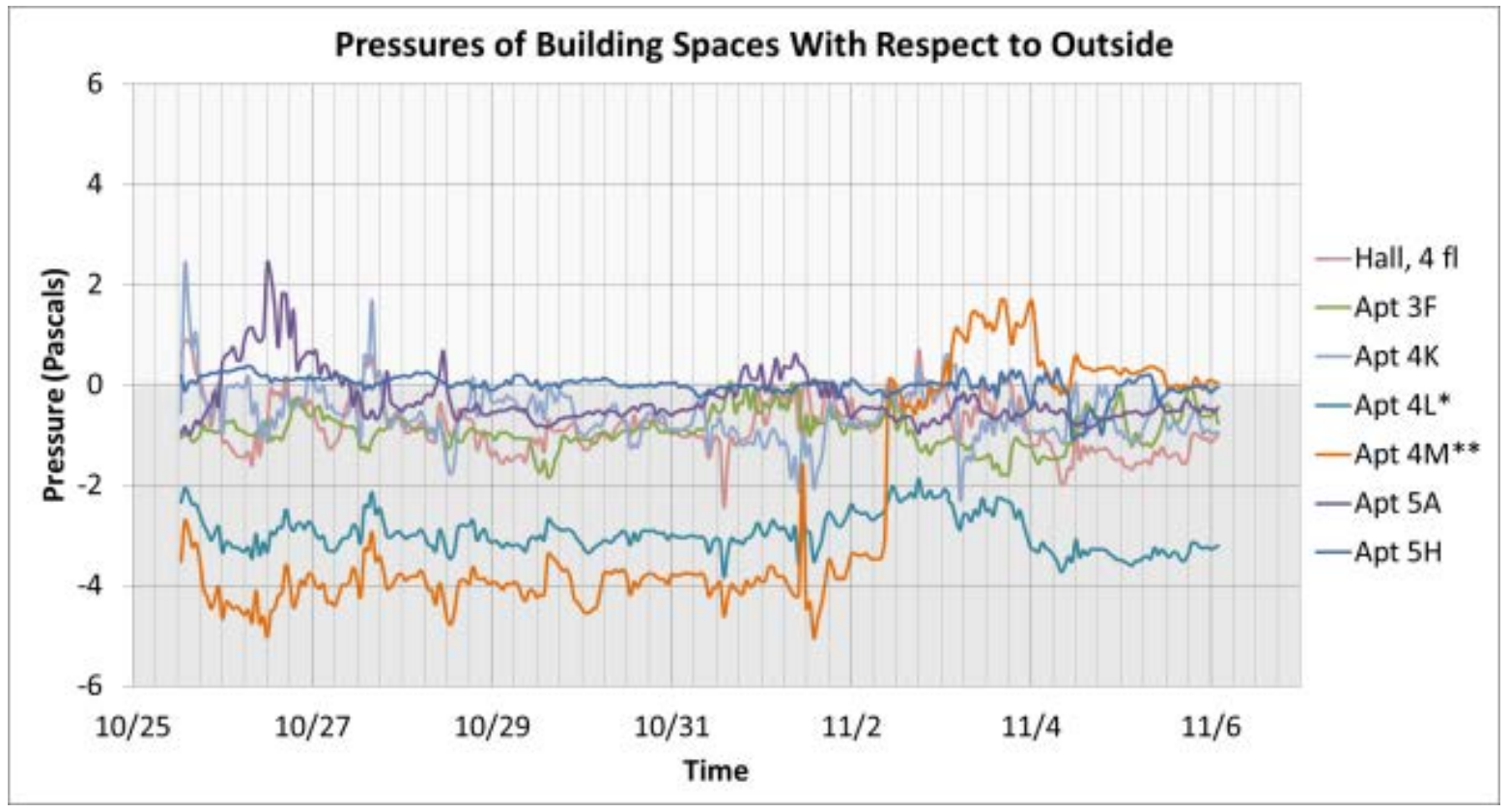

Notes:

Apartment 4L was unoccupied for the entire monitoring time. Apartment 4M was unoccupied until November 2, 2013.

\section{Figure 14. Pressure in several building spaces over time}

In this occupied building, the residents and the resident superintendent were unaware of the presence or function of the trickle vents installed in their windows. Several complained of a "stuffy" environment and preferred to open their windows to ventilate the apartments. Figure 15 shows the direct effect of an open window on the pressure in an apartment. Apartment $5 \mathrm{H}$ was observed with open windows at each visit, and the resident explained that he preferred more outdoor air than the trickle vent could provide. The pressure in this apartment was essentially neutral WRT the outside and showed free exchange of air with the outside. 


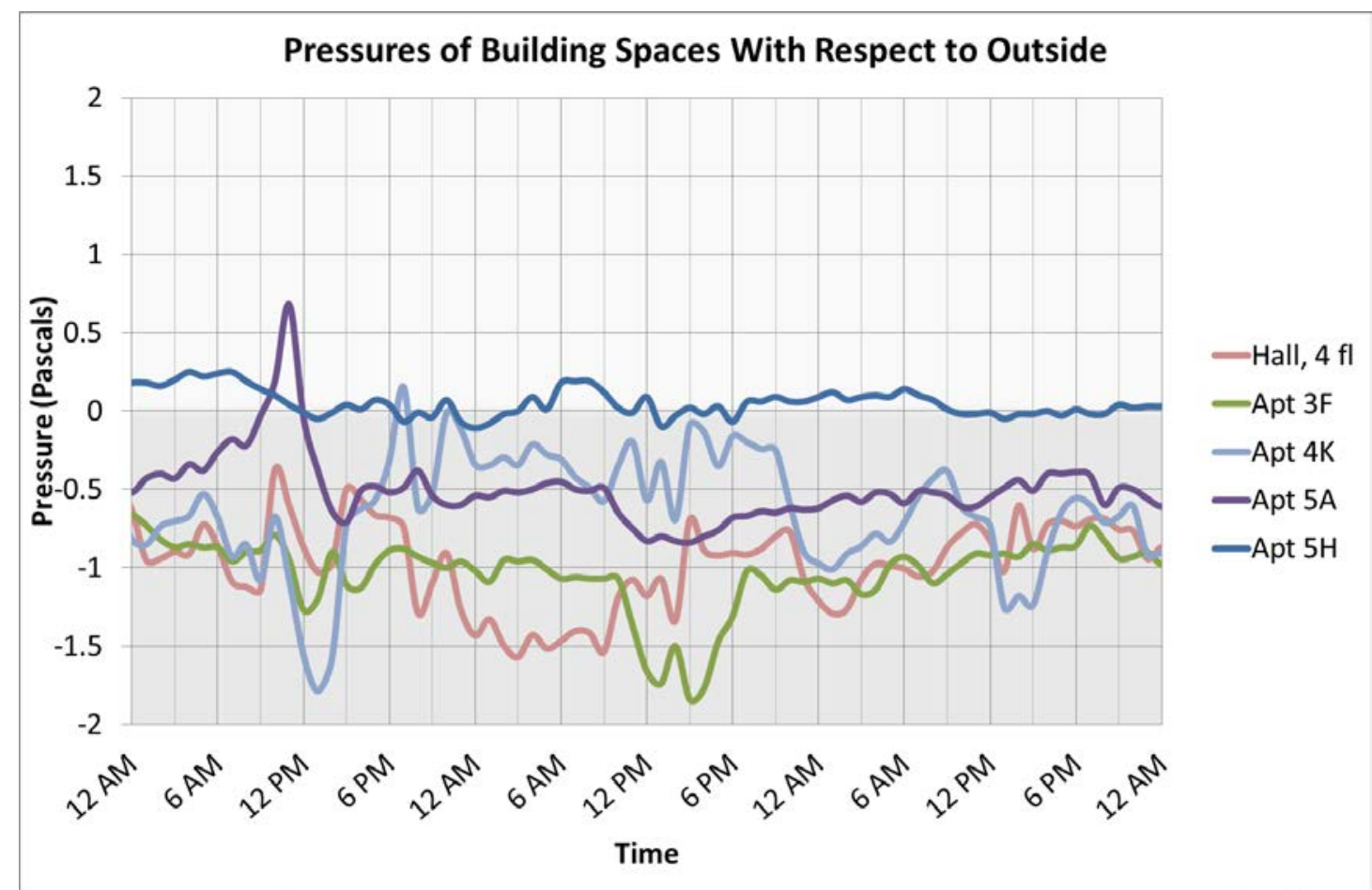

Figure 15. Pressure data monitored in building spaces over a 24-hour period

Other occupied apartments kept their windows closed more habitually according to interviews with residents. The third-floor apartment $(3 \mathrm{~F})$ shows a trend of generally lower pressure WRT outside; apartments on higher floors $(5 \mathrm{~A}, 5 \mathrm{H})$ have somewhat higher pressures. This concurs with a general pattern that is common to buildings in cooler weather, because stack effect increases the pressure on the upper floors and decreases it on the lower floors WRT the outside. The stack effect was somewhat less than typical because the building is well compartmentalized and the monitoring was conducted during mild weather.

Pressures between apartments and their neighboring hallways were also recorded (Figure 16). Unoccupied apartments appear to be significantly more depressurized relative to the hallway than occupied apartments. This indicates that air predominantly flows into unoccupied apartments from the corridors and concurs with earlier testing that measured the airflow through the corridor door into an unoccupied apartment at 53 CFM-60 CFM. In occupied apartments, open windows obviously dominate the airflow dynamics. In this test building, as well as many others, residents open windows during mild weather. 


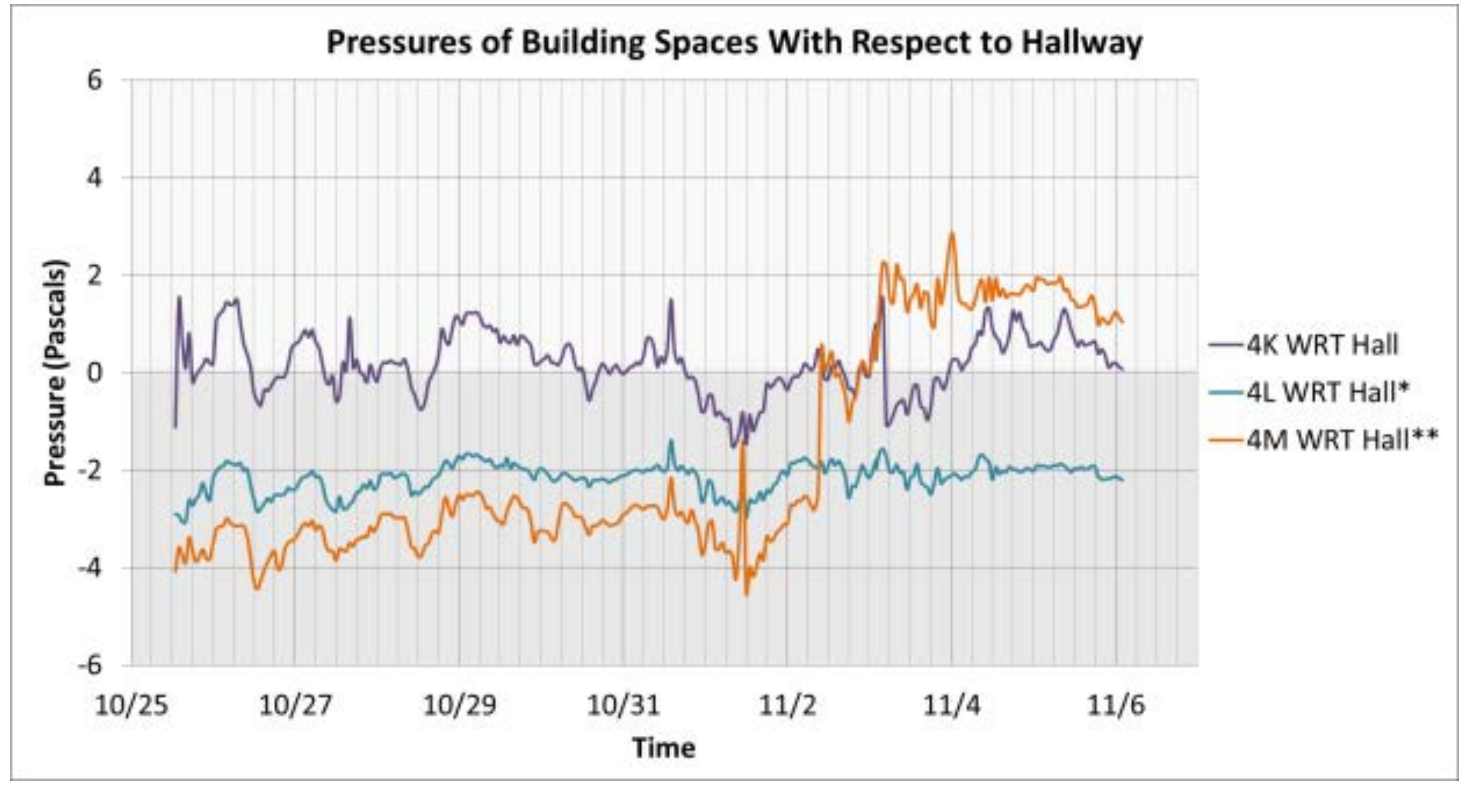

Notes: Apartment $4 \mathrm{~L}$ was unoccupied for the entire monitoring time. Apartment 4M was unoccupied until November 2, 2013.

Figure 16. Pressures in apartments WRT hallway

The equation for an orifice opening can be used by applying the pressures measured through monitoring to the area of the door leakage measured in previous tests

$$
Q=A * C_{d} *(2 \Delta P / \rho)^{0.5 *} 1.37
$$

Where:

$Q$ is leakage through the door gaps (in CFM)

$A$ is the leakage area of the door

$C_{d}$ is the coefficient of discharge

$\triangle P$ is the pressure differential between inside and outside of the

test system (in Pascals)

$\rho$ is the air density (in $\mathrm{kg} / \mathrm{m}^{3}$ )

This equation was used to calculate the airflow through the door at any given time if the pressure is known. Applying this to the pressure monitoring data, the bulk flow of air into or out of an apartment can be determined. Table 6 shows these calculated values for three apartments. Values from apartment $4 \mathrm{~K}$, in which windows were opened occasionally, contrast with the values from apartments $4 \mathrm{~L}$ and $4 \mathrm{M}$, which were unoccupied with their windows closed.

Table 6. Summary Flow Data from Apartment/Corridor Doors

Negative numbers indicate flow from apartment into corridor.

\begin{tabular}{c|c|c|c}
\hline & Apt 4L & Apt 4M & Apt 4K \\
\hline Average (CFM) & 55 & 66 & -13 \\
Maximum (CFM) & 65 & 78 & 39 \\
Minimum (CFM) & 44 & 55 & -45 \\
Tested Condition & Unoccupied & Unoccupied & Occupied \\
\hline
\end{tabular}


The calculated airflows show that the two unoccupied apartments drew significant air from the corridors and the occupied Apartment $4 \mathrm{~K}$ sometimes delivered air into the corridor. The pressure in this apartment fluctuated wildly, and flows are significant in either direction, possibly because the windows were opened. The apartment sometimes drew a significant amount of air from the corridor (up to 39 CFM); at other times it sent air in the other direction (up to 45 CFM into the corridor). Because neighboring apartments on the same floor were consistently negatively pressurized with their windows closed, the cause of the wild swings of pressure and airflow in the other direction are assumed to be caused by windows opening and closing.

The monitored pressure data from Apartment $4 \mathrm{~K}$ are quite variable and illustrate the impact of opening windows on the pressure dynamics of the building. Figure 17 shows an observed correlation between the pressure in the apartment WRT the outside and WRT the corridor. When a window is opened in the apartment, pressure WRT the outside approaches zero, and the pressure WRT the hallway increases to positive territory. This change in pressure results in air flowing from the apartment into the corridor for a time, as indicated by the directional arrows. In this building, apartments with their windows open may vent air into the corridor; apartments with their windows closed draw air from the corridor.

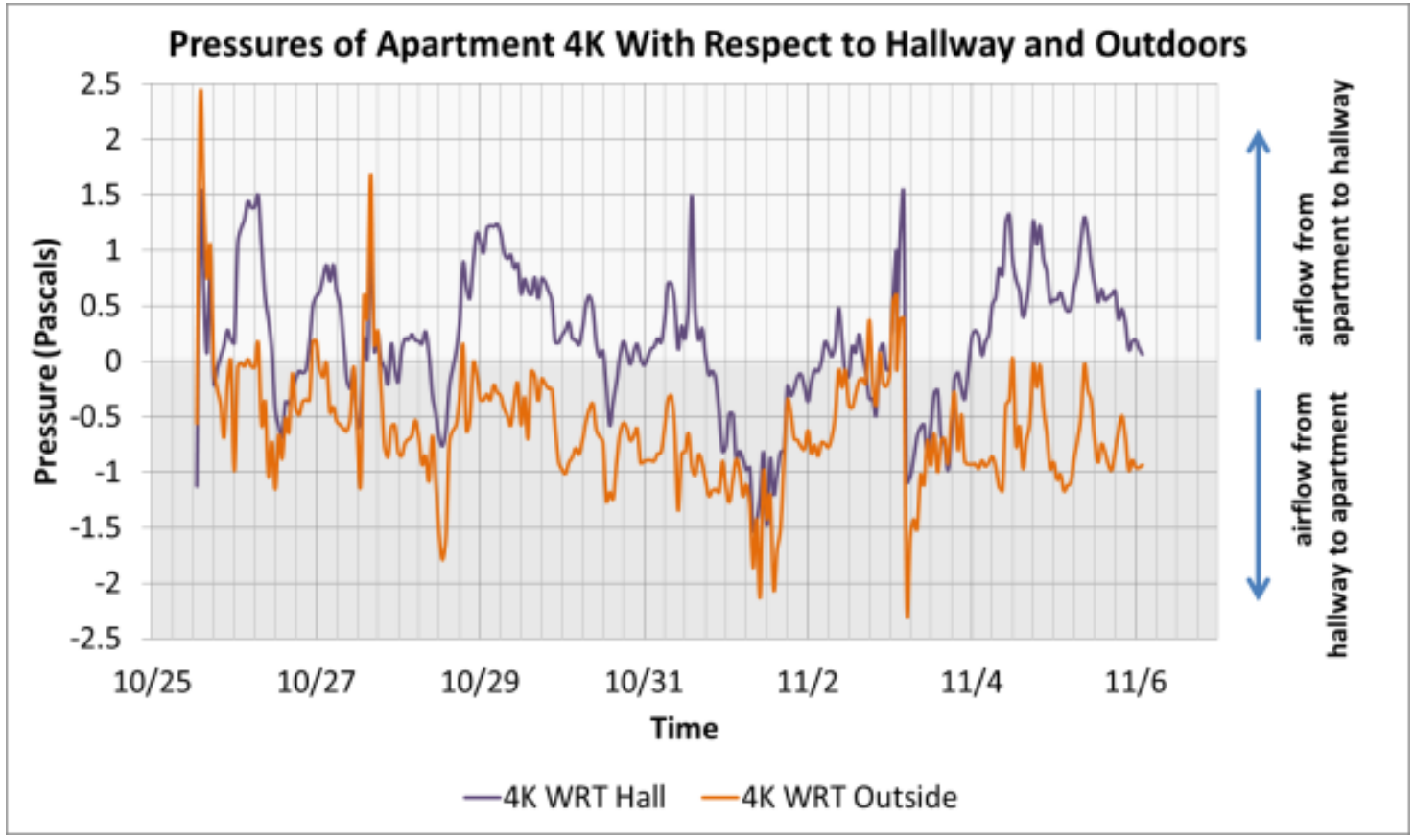

Figure 17. Pressures in Apartment 4K WRT hallway and outdoors

Applying Eq. 2 to the pressure monitoring data, the bulk flow of air into or out of an apartment through the trickle vents can also be determined. In Apartment 4L, an unoccupied apartment, the three trickle vents are calculated to deliver on average 5 CFM each, at $-3 \mathrm{~Pa}$ WRT the outside, which was the average pressure in this apartment. Apartment $4 \mathrm{M}$ was unoccupied for the beginning two-thirds of the monitoring period. During this time, the average flow was calculated at almost 6 CFM per trickle vent and the average pressure was $-4 \mathrm{~Pa}$ WRT the outside (Table 7). 
Table 7. Summary Flow Data from Trickle Vents in Unoccupied Apartments

\begin{tabular}{c|c|c}
\hline Apartment & Apt 4L & Apt 4M \\
\hline Floor & 4 & 4 \\
\hline Average Pressure WRT Outside (Pa) & -3 & -4 \\
ASHRAE 62.2 Flow (CFM) & 22 & 22 \\
\hline Flow from Single Trickle Vent \\
\hline Average & 5.0 & 5.9 \\
Minimum & 3.9 & 4.8 \\
Maximum & 5.8 & 6.7 \\
\hline Flow from All Trickle Vents in Apartment \\
\hline \# Beds & 1 & 1 \\
\hline \# Trickle Vents & 3 & 2 \\
Total Flow & 15.1 & 11.9 \\
Tested Condition & Unoccupied & Unoccupied \\
\hline
\end{tabular}

${ }^{a}$ Data from Apartment 4M were taken from the unoccupied period only.

The other three apartments were occupied during the monitoring period. CARB requested that residents keep their windows closed; however, the data suggest that windows were opened during the monitoring period, because the pressure WRT outdoors ranged from $-4.3 \mathrm{~Pa}$ to $4.5 \mathrm{~Pa}$. The state of the window at each point throughout the monitoring period could not be determined; therefore, only the maximum pressure WRT the outside was used. When the pressure differential between the apartment and the outside was greatest, the windows were assumed to be closed. This is useful in framing the range of pressures that can expected in this test building. An open window on the leeward side of the building could also produce negative pressure in the apartments (Table 8).

Table 8. Summary Maximum Flow Data from Trickle Vents in Occupied Apartments

\begin{tabular}{c|c|c|c|c}
\hline Apartment & Apt 3F & Apt 4K & Apt 5A & Apt 5H \\
\hline Floor & $3 \mathrm{rd}$ & 4 th & 5 th & 5 th \\
Maximum Pressure WRT Outside $\mathbf{( P a )}$ & -1.8 & -2.2 & -1.0 & -1.1 \\
\hline Maximum Flow From Single Trickle Vent & 3.9 & 4.3 & 2.8 & 2.9 \\
\hline Maximum Flow from All Trickle Vents in Apartment \\
\hline \# Beds & 3 & 2 & 2 & 1 \\
\hline \# Trickle Vents & 5 & 4 & 3 & 2 \\
\hline Total Flow & 19.5 & 17.2 & 8.4 & 5.8 \\
Tested Condition & Occupied & Occupied & Occupied & Occupied \\
\hline
\end{tabular}

Table 9 compares the calculated airflows from door leakage in Table 6 to calculated airflows from trickle vents for two apartments (4L and $4 \mathrm{M}$ ) in which no windows were opened during the monitoring period. Airflow from the corridor into these two apartments dominates the makeup air pattern. These flows were unintentional, but they are several times higher than those from the trickle vents. 
Table 9. Test Building \#1 Summary Flow Data

\begin{tabular}{c|c|c}
\hline & Apt 4L & Apt 4M \\
\hline Air from Corridor Door & 54.8 & 66.1 \\
\hline Air from Trickle Vents & 15.1 & 11.9 \\
Measured Apartment Exhaust & $71^{\mathrm{a}}$ & 64 \\
\hline Tested Condition & Unoccupied & Unoccupied \\
\hline
\end{tabular}

${ }^{\text {a }}$ Exhaust was not measured in Apartment 4L. The average from similar apartments was used.

\subsubsection{Exhaust Fan Power Consumption}

The in-line exhaust fans used in this building are Panasonic WhisperLine FV-10NLF1, nominally rated for $120 \mathrm{CFM}$. Product literature lists fan efficiency at no less than $3.3 \mathrm{CFM} / \mathrm{W}$.

\subsection{Test Building \#2}

Results from Test Building \#2 are provided in Section 3.2.1 through Section 3.2.6. Floor plans and building description for this test building are provided in Section 2.3.2.

\subsubsection{Apartment Blower Door Testing}

Blower door testing was conducted in 21 of the 95 apartments in this six-story building (Table 10). The average total leakage rate is $0.24 \mathrm{CFM} 50 / \mathrm{ft}^{2}$ of apartment enclosure, which is higher than Building \#1 and 2012 International Energy Conservation Code requirements (3 ACH50 in climate zone 3). However, it is still lower than the threshold of $0.30 \mathrm{CFM} 50 / \mathrm{ft}^{2}$.

Table 10. Building \#2 Apartment Airtightness Metrics

\begin{tabular}{|c|c|c|c|c|c|}
\hline Apartment & \# Beds & Area $\left(\mathrm{ft}^{2}\right)$ & $\begin{array}{c}\text { Flow } \\
\text { (CFM50) }\end{array}$ & ACH50 & CFM50/ft ${ }^{2}$ \\
\hline $1 E$ & Studio & 300 & 414 & 7.5 & 0.28 \\
\hline $1 G$ & 2 & 745 & 721 & 5.3 & 0.26 \\
\hline $2 F$ & Studio & 303 & 378 & 7.8 & 0.28 \\
\hline $2 G$ & 1 & 546 & 587 & 6.7 & 0.28 \\
\hline $2 I$ & 2 & 806 & 661 & 5.5 & 0.24 \\
\hline $2 R$ & Studio & 315 & 440 & 8.7 & 0.30 \\
\hline $3 C$ & Studio & 325 & 378 & 7.0 & 0.26 \\
\hline $3 H$ & 2 & 689 & 687 & 6.0 & 0.27 \\
\hline $3 P$ & Studio & 326 & 439 & 8.1 & 0.11 \\
\hline $3 S$ & 1 & 522 & 565 & 6.5 & 0.09 \\
\hline 4J & Studio & 293 & 362 & 7.4 & 0.26 \\
\hline $4 M$ & Studio & 318 & 364 & 6.9 & 0.25 \\
\hline $4 N$ & 2 & 713 & 723 & 6.1 & 0.27 \\
\hline $4 Q$ & Studio & 336 & 423 & 7.5 & 0.10 \\
\hline 5I & 2 & 750 & 695 & 5.7 & 0.25 \\
\hline $5 K$ & Studio & 299 & 346 & 7.2 & 0.25 \\
\hline $5 \mathrm{~L}$ & 1 & 628 & 568 & 5.6 & 0.24 \\
\hline $6 A$ & 3 & 974 & 740 & 4.6 & 0.22 \\
\hline $6 B$ & Studio & 347 & 375 & 6.5 & 0.25 \\
\hline 6D & 1 & 518 & 577 & 6.7 & 0.28 \\
\hline $6 G$ & Studio & 334 & 408 & 7.3 & 0.28 \\
\hline \multicolumn{4}{|c|}{ Average } & 6.7 & 0.24 \\
\hline
\end{tabular}




\subsubsection{Exhaust Flow Testing}

Test Building \#2 has a central ventilation system. Rooftop fans serve each kitchen and bathroom exhaust riser. Each register is outfitted with an automatic balancing damper to limit the airflow from the register and balance airflow among them. Exhaust rates were measured from the registers in 15 apartments (Table 11). ASHRAE 62.2-2010 whole-house ventilation rates are again provided for comparison.

Table 11. Building \#2 Exhaust Flow Measurements

\begin{tabular}{|c|c|c|c|c|c|c|}
\hline \multirow{2}{*}{ Apartment } & \multirow{2}{*}{$\begin{array}{l}\# \text { of } \\
\text { Beds }\end{array}$} & \multicolumn{2}{|c|}{ Exhaust Flow (CFM) } & \multirow{2}{*}{$\begin{array}{c}\text { Total } \\
\text { Flow } \\
\text { (CFM) }\end{array}$} & \multirow{2}{*}{$\begin{array}{c}\text { Design } \\
\text { CFM }\end{array}$} & \multirow{2}{*}{$\begin{array}{c}\text { ASHRAE } \\
\text { 62.2 Rate } \\
\text { (CFM) }\end{array}$} \\
\hline & & Kitchen & Bath & & & \\
\hline $1 \mathrm{E}$ & Studio & 25 & 25 & 50 & 55 & 18 \\
\hline $1 G$ & 2 & 28 & 22 & 50 & 55 & 30 \\
\hline $2 F$ & Studio & 31 & 21 & 52 & 55 & 18 \\
\hline $2 G$ & 1 & 25 & 19 & 44 & 75 & 20 \\
\hline $2 \mathbf{R}$ & Studio & 26 & 25 & 51 & 55 & 18 \\
\hline $3 \mathrm{C}$ & Studio & 27 & 23 & 50 & 55 & 18 \\
\hline $3 \mathbf{H}$ & 2 & 28 & 21 & 49 & 75 & 29 \\
\hline $3 \mathbf{P}$ & Studio & 9 & 27 & 36 & 55 & 18 \\
\hline $3 S$ & 1 & 24 & 17 & 41 & 75 & 20 \\
\hline $5 \mathbf{I}$ & 2 & 29 & 28 & 57 & 55 & 30 \\
\hline $5 K$ & Studio & 29 & 24 & 53 & 55 & 18 \\
\hline 6A & 3 & 30 & $26 \& 27$ & 83 & 100 & 40 \\
\hline $6 B$ & Studio & 26 & 29 & 55 & 55 & 18 \\
\hline 6D & 1 & 30 & 26 & 56 & 75 & 20 \\
\hline $6 \mathrm{G}$ & Studio & 32 & 23 & 55 & 55 & 18 \\
\hline \multicolumn{2}{|c|}{ Average } & 27 & 24 & & & \\
\hline
\end{tabular}

To comply with ASHRAE 62.2-2010 continuous local exhaust rates, the continuous exhaust design calls for 25 CFM from bathrooms and 30 CFM-50 CFM from kitchens for a total of 55 CFM-100 CFM per apartment. The average flow rates from the kitchen and bath exhaust registers were 27 and 24 CFM, respectively. The combined measured airflows ranged from $65 \%$ of design to $104 \%$. The design and measured CFM were closer to the rates required by ASHRAE 62.2 for local exhaust; exhaust fell short in a few instances. Similar to Test Building \#1, wholehouse ventilation rates were still significantly lower than the makeup air needed to provide balanced ventilation.

\subsubsection{Passive Vent Testing}

To evaluate whether the ASHRAE 62.2 whole-house rates are being satisfied by outdoor air, the makeup air that enters an apartment from the outdoors through passive vents needs to be measured. Test Building \#2 uses airlets, a type of passive vent. Airlets are similar to trickle vents in that they provide outdoor air to apartments based on the pressure differential between the inside and the outside. Each apartment has one airlet in the living room and one in each 
bedroom. Each consists of a 4-in. diameter cylindrical opening that connects the inside of the apartment to the exterior. The cylinder has a filter. The grille that fits over the cylinder has plastic flaps on the back side that are designed to limit the airflow as the pressure increases, similar to a constant air regulator damper. Figure 18 shows an airlet installed and removed.
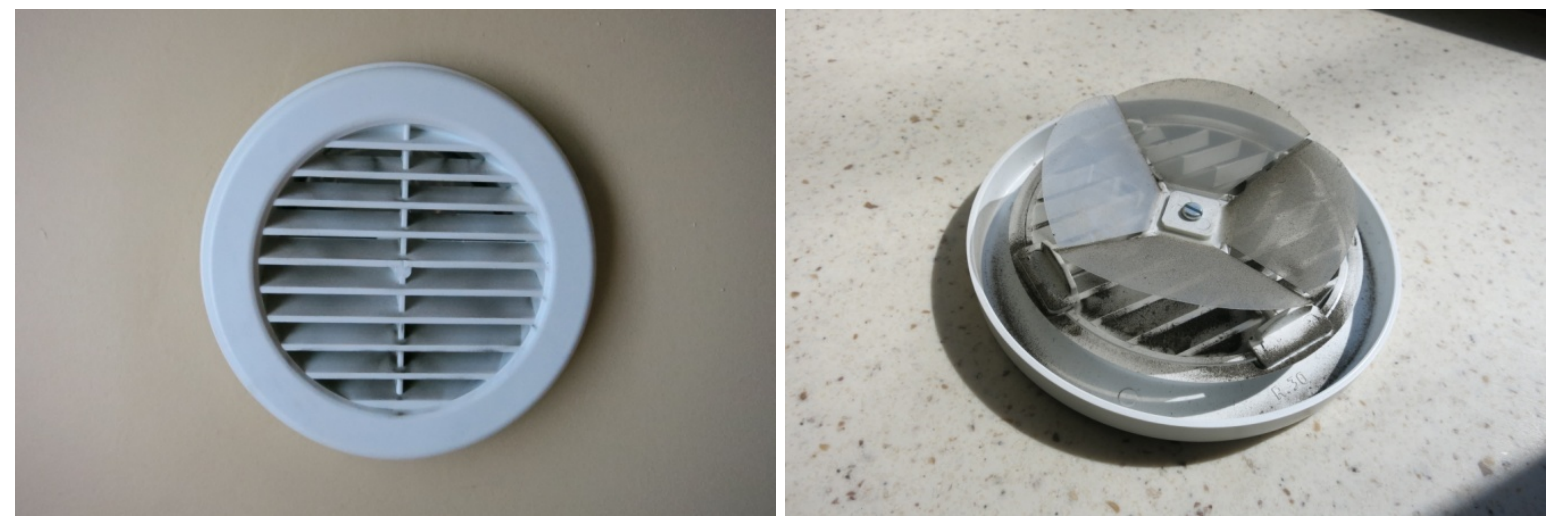

Figure 18. Common airlet (left) and backside of Airlet with flaps (right)

In Test Building \#2, airlets were tested to characterize their performance as installed. Five airlets were tested by inducing a pressure differential on either side and measuring the airflow. A capture box with a mounted calibrated fan was sealed around each vent. The fan was used to create a pressure on one side. The pressures on the inside and outside aspects of each vent were measured with manometers, and the fan was used to measure the airflow (Figure 19).
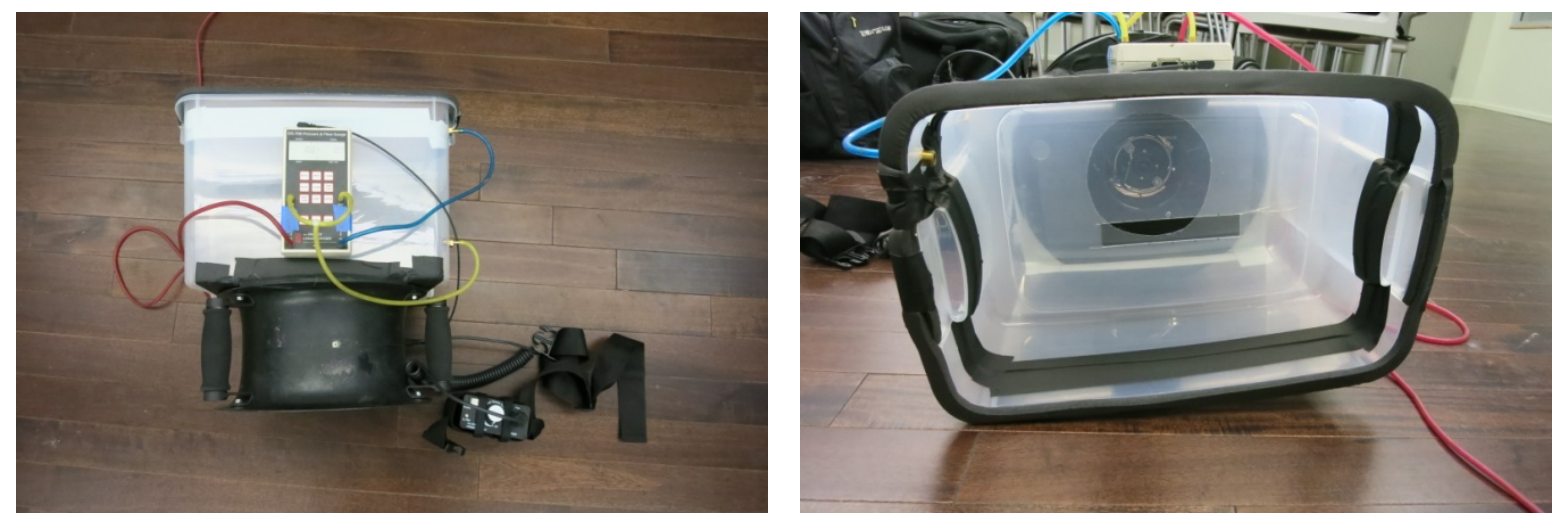

Figure 19. Setup for testing airflow through airlets

Five airlets were tested by using this procedure under positive and negative pressures. Because the airlet is a passive device, it provides outdoor air only when the apartment is depressurized WRT the outside. When it is positively pressurized, air flows from the apartment to the outside environment, which is not the intended design operation. Under this condition, the plastic flaps are forced open and may begin to flutter under higher pressures. As a result, the performance is variable under positive pressure. Figure 20 and Figure 21 show the results of the depressurized and pressurized tests, respectively. The orange horizontal line in Figure 20 represents the ASHRAE whole-house ventilation rate for a typical one-bedroom apartment in this test building. 


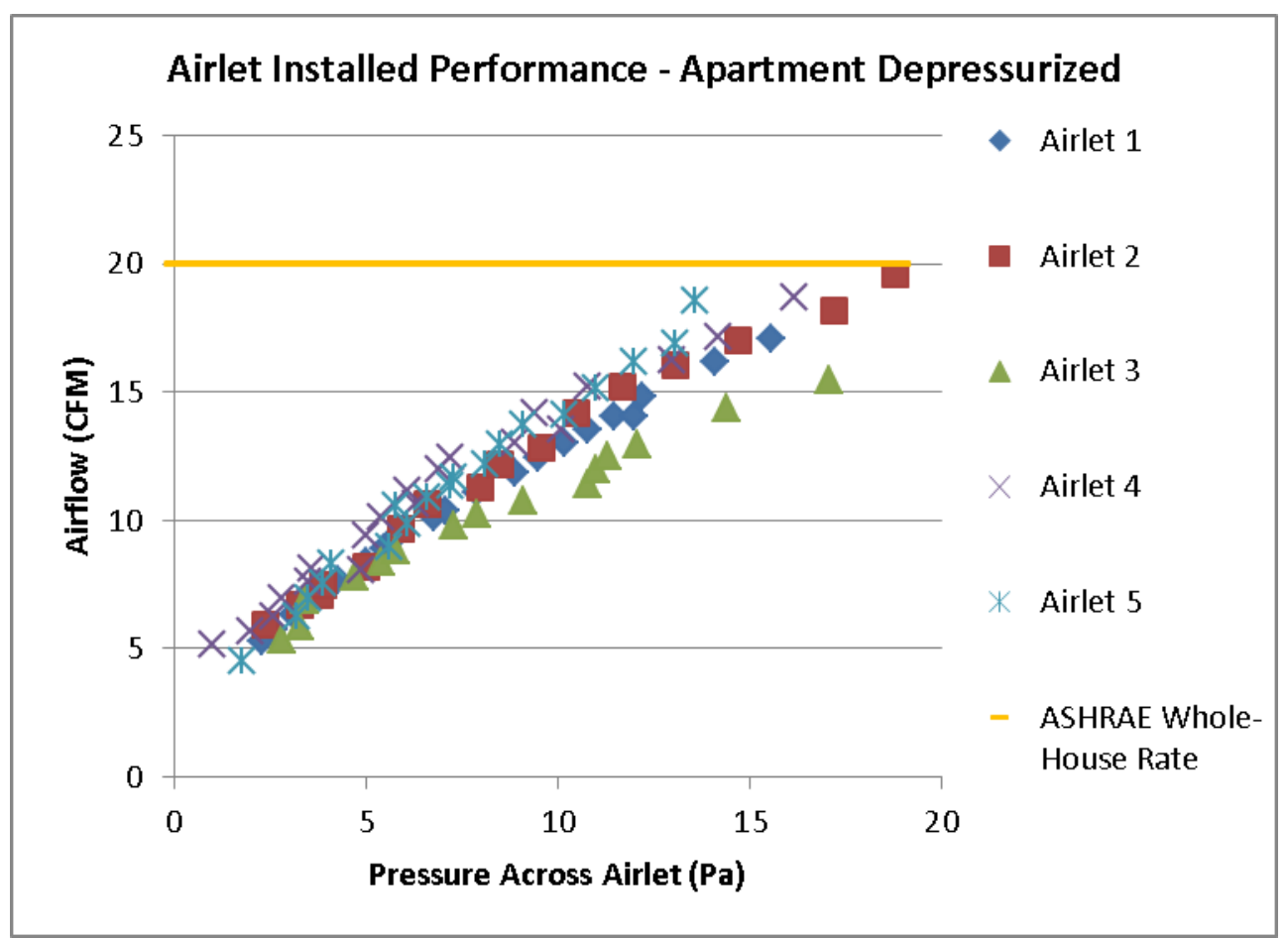

Figure 20. Airlet flow-apartment depressurized WRT outdoors

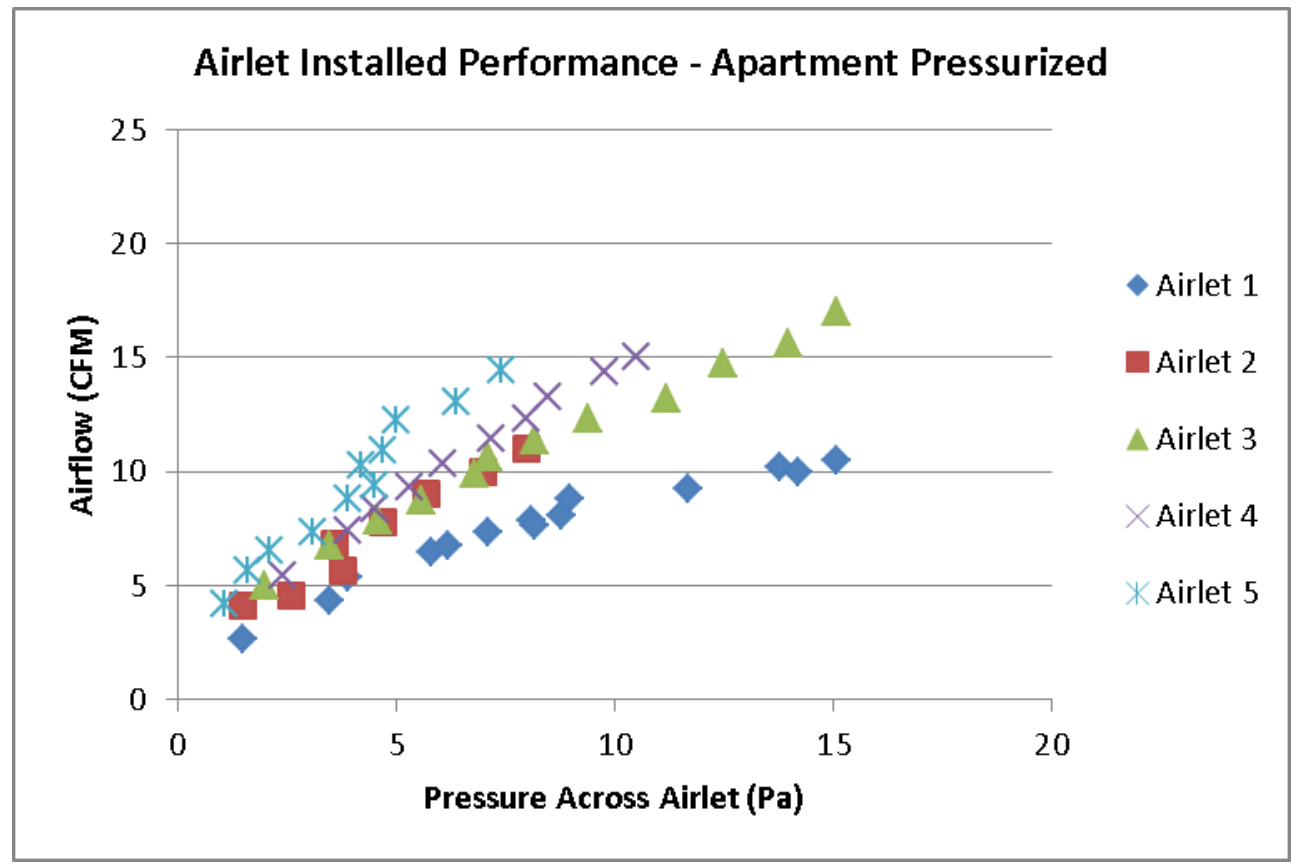

Figure 21. Airlet flow-apartment pressurized WRT outdoors

The results for the pressurization tests shown in Figure 21 are provided to show the variability in flow under these conditions. The amount of air leaving the apartment through the airlets was not a focus of this research, so a flow equation for this condition was not developed. The data collected from the depressurization tests were used to derive an equation for airflow as a function of pressure differential when the apartment is depressurized WRT the outside and is given as: 


$$
Q=3.36^{*} \Delta P^{0.597}(5)
$$

The results show that the airlets tested can provide airflow in an apartment when it is depressurized WRT the outside. Under normal building operating conditions in this test building, the apartments typically experienced a depressurization of 2-10 Pa. This equates to a flow of 5 CFM-13 CFM across one airlet. Given these typical flows, two to four airlets would be required in a typical one-bedroom apartment to meet the ASHRAE whole-house ventilation rate. For comparison to Test Building \#1, at $5 \mathrm{~Pa}$, each airlet would provide $8.7 \mathrm{CFM}$ of outdoor air, slightly greatly than the 6.7 CFM from one trickle vent.

Similar to the trickle vents, airlets must be installed according to the manufacturer's specifications to function as intended. The manufacturer states that best results will be achieved in units with tight air-vapor retarders and continuous exhaust from bathrooms, kitchen, and laundry. The manufacturer also recommends locating the airlet within $12 \mathrm{in}$. of the ceiling. In several buildings CARB evaluated, including Test Building \#2, continuous exhaust and good airtightness were achieved. However, the airlets were not installed near the ceiling but were instead located approximately 18 in. above the floor. The location of the airlet does not significantly affect the pressure differential or airflow; however, it does have an impact on occupant comfort. Locating the airlet near the ceiling allows the cool outdoor air that is drawn in during the heating season to mix with the warmer room air. When the airlet is located near the floor, less mixing occurs. This can prompt complaints about cold air, which are unfortunately often resolved by closing the airlet and eliminating the intended source of outdoor air.

\subsubsection{Door Leakage Airflows}

Similar to Test Building \#1, having measured the exhaust airflow and airflow into the apartments through the airlets, measurements of the unintended makeup air from around the apartment entry door were needed. The flow around the apartment door was tested and measured in five apartments. The apartment doors had weather-stripping around the sides and top and a door sweep at the bottom, except apartment 1A, which lacked a sweep.

The doors were tested for pressurization and depressurization (Figure 22 and Figure 23). As expected, even at low pressures, door leakage in Apartment 1A was significantly higher due to the missing door sweep. The leakage area for each door was calculated from the data collected. The door leakage area for apartment 1A was $20 \mathrm{in.}^{2}$, because it lacked a sweep. The values for the other four doors were significantly lower, with an average leakage area of $2.5 \mathrm{in.}^{2}$. Except for 1A, these doors had about 90\% lower leakage area than Test Building $\# 1$. 


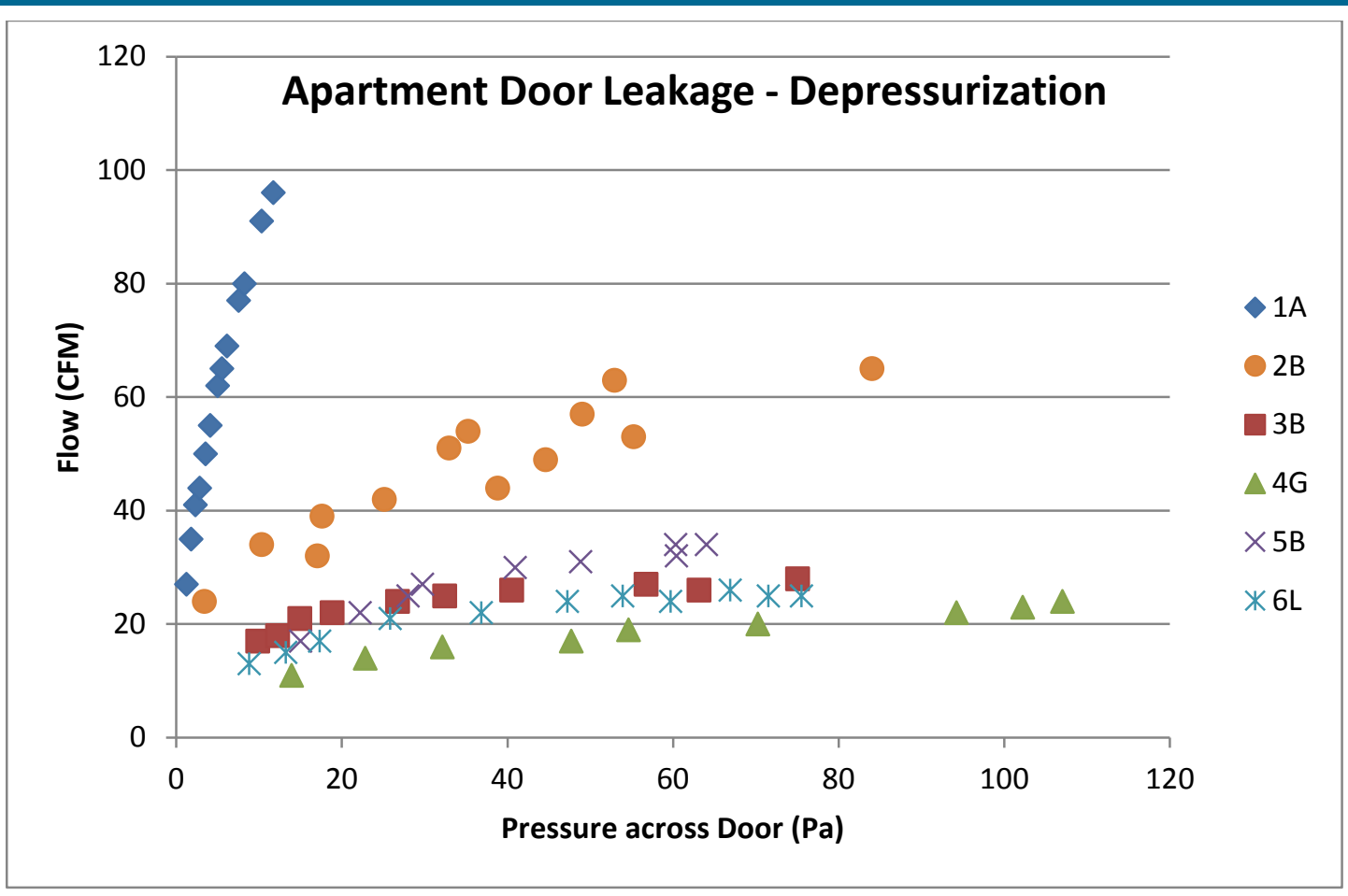

Figure 22. Door air leakage-apartment depressurized WRT corridor

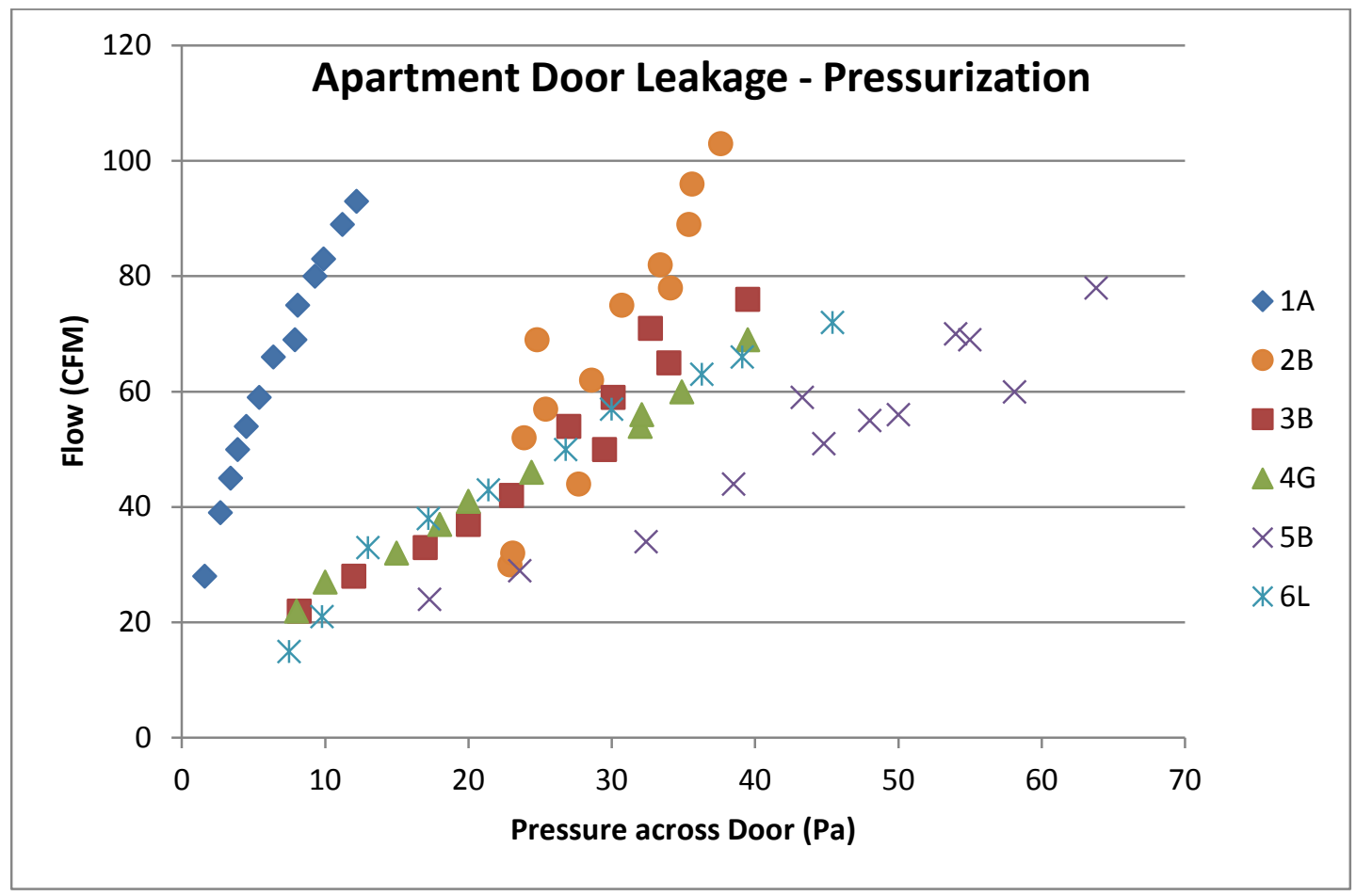

Figure 23. Door air leakage—apartment pressurized WRT corridor

The doors with sweeps still exhibited a variety of leakage curves, which can likely be attributed to physical variations between the sweep and the door installation. As a result, the equation for the airflow through each door was determined. These six equations will be applied to the 
pressure monitoring data to determine the airflow over time for the respective apartment. The equation again takes the general form:

$$
Q=C(\Delta P)^{n}
$$

Where:

Q represents flow

$\Delta \mathrm{P}$ is the pressure differential across the door

$\mathrm{C}$ and $\mathrm{n}$ are empirically determined.

Table 12 summarizes these values.

Table 12. Apartment Door Airflow Equation Coefficients and Exponents

\begin{tabular}{c|c|c|c|c}
\hline \multirow{2}{*}{ Apartment } & \multicolumn{2}{|c|}{ Depressurization } & \multicolumn{2}{c}{ Pressurization } \\
& $\mathbf{C}$ & $\mathbf{n}$ & $\mathbf{C}$ & $\mathbf{n}$ \\
\hline 1A & 25.12 & 0.553 & 22.01 & 0.580 \\
2B & 15.41 & 0.322 & 0.10 & 1.925 \\
3B & 10.79 & 0.228 & 3.63 & 0.811 \\
4G & 4.48 & 0.355 & 5.36 & 0.677 \\
5B & 5.55 & 0.442 & 1.60 & 0.921 \\
\hline 6L & 6.93 & 0.312 & 3.30 & 0.828 \\
\hline
\end{tabular}

\subsubsection{Pressure Monitoring}

With these airflow equations developed for the airlet and door, pressure monitoring was then undertaken in several building spaces with the intent of understanding the airflow patterns over time between building spaces and between the building and the outside. Pressure monitoring was conducted in five apartments for a 2 -week period during the spring of 2014. Pressure measurements between the apartment and the outside and between the apartment and the corridor were collected at 1-second intervals and then averaged over every hour to give a general picture of pressure in the spaces over time. All the apartments were occupied during the monitoring period.

As learned in Test Building \#1 from the previous evaluation (Maxwell et al. 2014), the operation of windows has a significant impact on the measurements. As a result, a data logger was installed on the main window in each apartment. The logger recorded when the window was opened and closed. The remaining windows in the apartment were closed and locked at the beginning of the monitoring period. A note was placed on them that instructed residents to use only the windows that were equipped with the data loggers. This information was also conveyed directly to the residents at the time of setup. Residents were promised a small financial compensation for adhering to the requests for the study period.

Figure 24 shows the pressure across the airlets in the test apartments. The measurements were taken WRT the outside. A negative pressure indicated the apartments were depressurized WRT the outdoors and therefore air would flow into the apartments. As previously mentioned, the 
operation of windows impacted the measurements; therefore, only the data about closed windows are plotted. The pressure data logger in apartment $6 \mathrm{~L}$ malfunctioned; therefore, no data for that apartment were recorded.

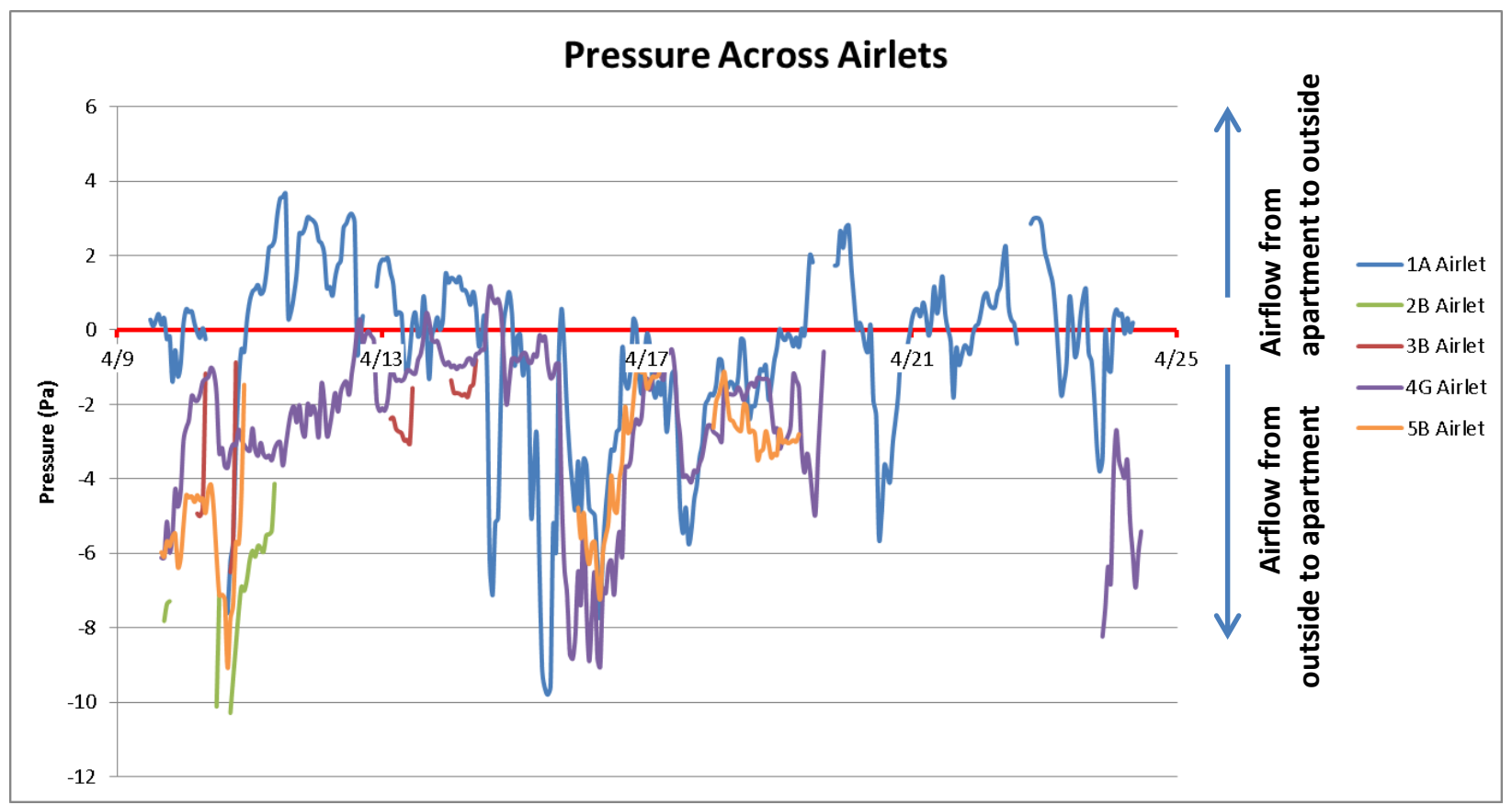

Figure 24. Pressure across airlets (apartment pressure WRT outside) over time

The windows-closed data collected from each apartment showed considerable variation. Apartments $1 \mathrm{~A}$ and $4 \mathrm{G}$ generated substantial data over 13 days and 10.5 days, respectively. Apartment 5B yielded almost 5 days, and both 2B and 3B yielded less than 1 day. This may be due to the mild weather conditions during which the monitoring was conducted and the residents' preference for using the windows for outdoor air.

For the windows-closed periods, all five apartments typically experienced negative pressure across the airlet $(-2 \mathrm{~Pa}$ to as high as $-10 \mathrm{~Pa})$. This indicates air typically flowed into the apartments as designed. Only Apartment 1A experienced significant periods of positive pressure, possibly because its entrance door lacked a sweep. The monitoring period was during mild spring weather, so stack effect was minimized.

The pressure across each apartment door was also monitored and was taken by measuring the pressure of the apartment WRT the corridor. Again, a negative pressure indicated flow into the apartment (Figure 25). In all five samples, the average pressure over the windows-closed periods was positive and resulted in flow from apartments into the corridor. This was contrary to expectations and to CARB's measurements in other buildings. Investigation revealed that the rooftop unit that supplied the corridors with 1,300 CFM per floor was not operating and was likely also not operating during the monitoring period. The slight negative pressure in the corridors could possibly be attributed to the elevators, refuse room exhaust, or open windows in that space, which were not monitored. 


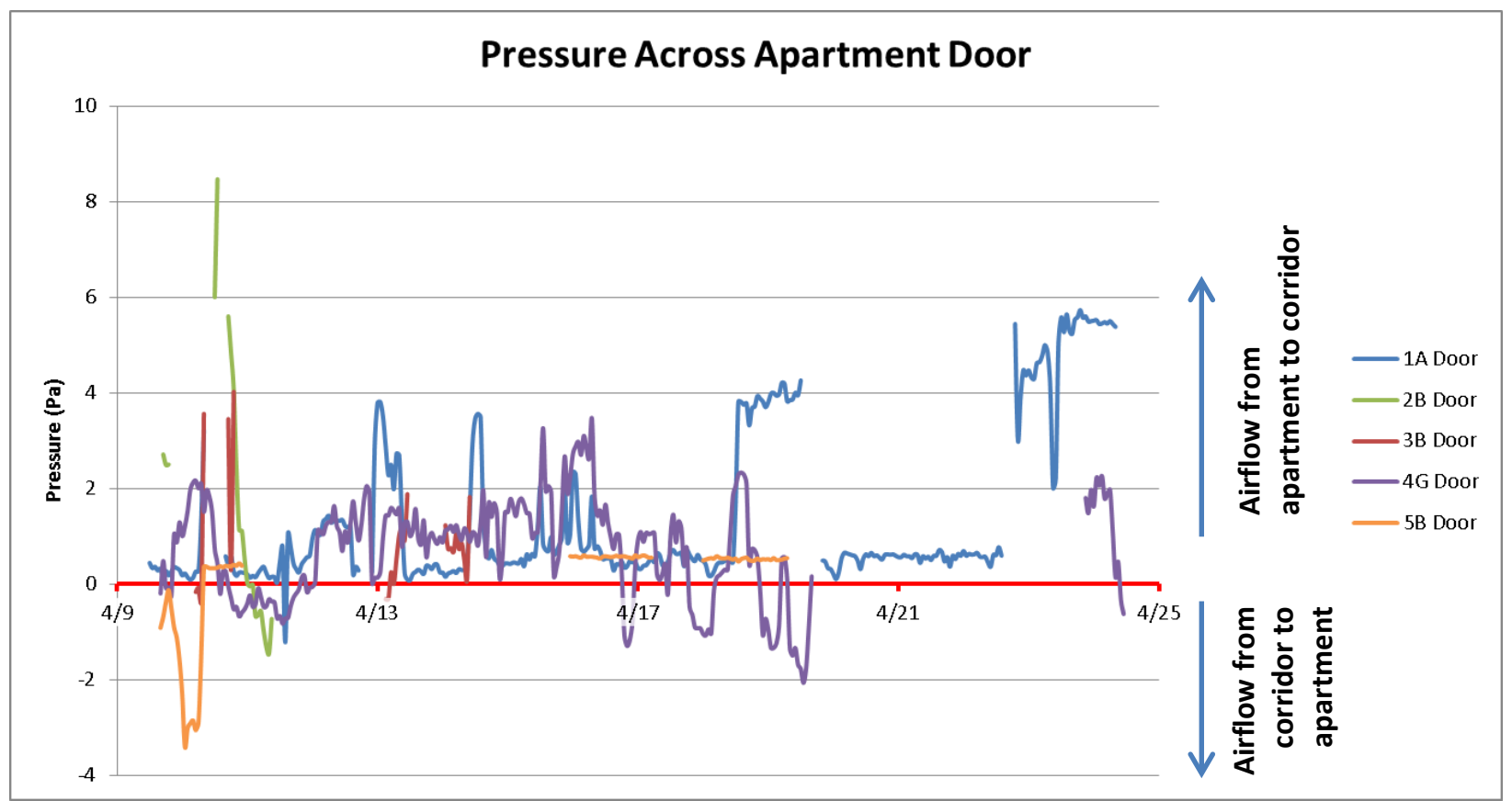

Figure 25. Pressure across door (apartment pressure WRT corridor) over time

The equations developed in Sections 3.2.3 and 3.2.4 were applied to the monitored pressure data to calculate airflow through airlets and doors. The results for Apartments $1 \mathrm{~A}$ and $4 \mathrm{G}$ are plotted in Figure 26 and Figure 27. The remaining three apartments are not shown because they generated few window-closed data.

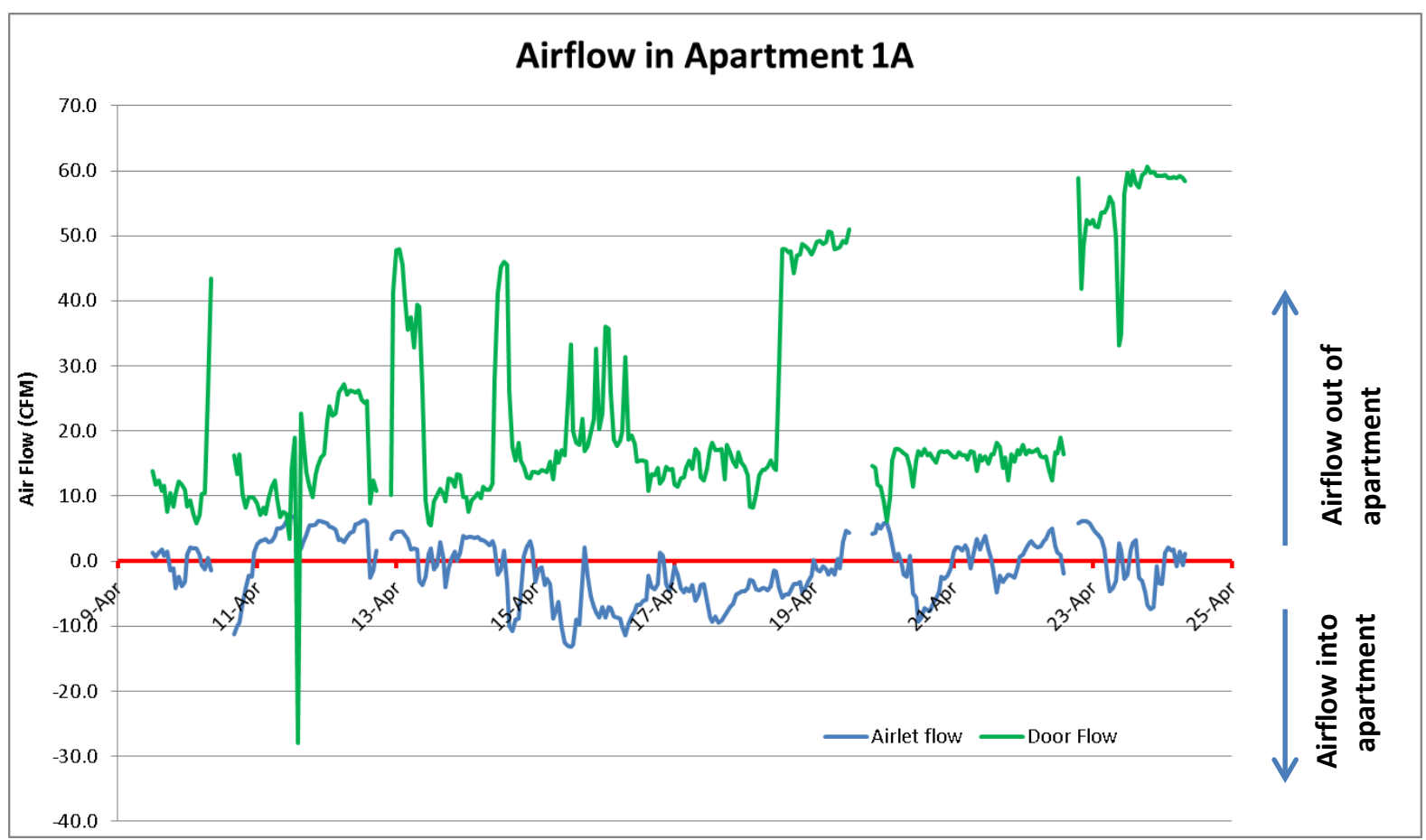

Figure 26. Airflow through airlet and door in Apartment 1A over time 


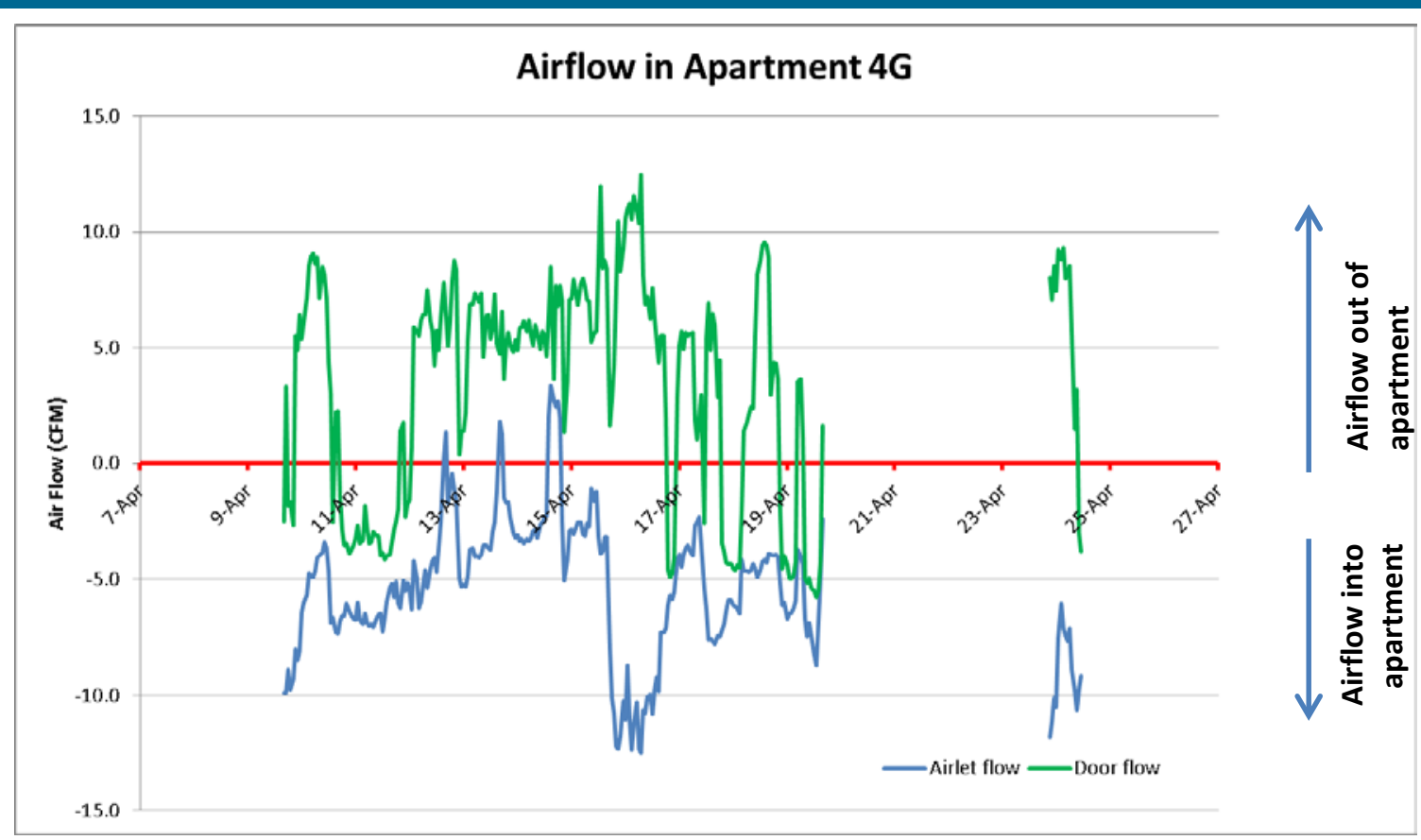

Figure 27. Airflow through airlet and door in Apartment 4G over time

The net airflow around the door of each apartment is from the apartment to the corridor, as demonstrated by the positive airflow values in the figures. Although the pressures across the doors in Apartments 4G and 1A were similar for most of the time (Figure 25), in Apartment 1A the calculated airflow was considerably higher, at times exceeding 50 CFM. As identified earlier, this was primarily due to the lack of a door sweep.

Both apartments also experienced a net movement of air from the outside into the apartment through the airlets, as demonstrated by the negative airflow values in the figures. The average calculated airflows through the airlets for $1 \mathrm{~A}$ and $4 \mathrm{G}$ were 1.1 CFM and 5.4 CFM, respectively. Again, the discrepancy was likely due to the lack of door sweep. The missing sweep essentially decreased the airtightness of Apartment 1A and prevented it from maintaining the depressurization needed to induce greater airflow through the airlet.

Table 13 summarizes the averaged airflow for each apartment. The values for airflow were determined using only data from the monitoring period in which the windows were closed for each apartment. For Apartments 2B and 3B, this represents less than 1 full day of data for each apartment. Apartment 5B has approximately 3.5 days of windows-closed data; $1 \mathrm{~A}$ and $4 \mathrm{G}$ have 14 and 11 days, respectively.

Comparing these data to Test Building \#1 reveals significantly less leakage from around the doors, but air often flowed out of the apartments into the corridor (positive values). The weatherstripping on the doors in Test Building \#2 decreased the leakage into the apartment but did not effectively prevent flow out of the apartment. That phenomenon was likely a combination of factors, including the lack of supply to the corridor and the stack effect that resulted in airflow from the corridors to the elevator and stairwell shafts. Although the exhaust rates were lower in Test Building \#2, many apartments can maintain a stronger negative pressure than those in Test Building \#1. As a result, airflow was slightly greater through the airlets than through the trickle 
vents. This is counterintuitive, because Test Building \#2 had seemingly lower levels of airtightness than Test Building \#1 according to the compartmentalization test results; however, the leaky doors in Building \#1 are not reflected in that test.

Table 13. Test Building \#2 Summary Flow Data

\begin{tabular}{c|c|c|c|c|c}
\hline & Apt 1A & Apt 2B & Apt 3B & Apt 4G & Apt 5B \\
\hline Floor & 1 & 2 & 3 & 4 & 5 \\
\# of Bedrooms & Studio & Studio & Studio & 2 & Studio \\
\# of Airlets & 1 & 1 & 1 & 3 & 1 \\
\hline Average Pressure WRT Outside (Pa) & -0.6 & -6.9 & -2.6 & -2.6 & -3.9 \\
Air from Corridor Door & 23.2 & -4.3 & 1.8 & 3.5 & -0.4 \\
\hline Air from All Airlets & -1.1 & -10.6 & -5.7 & -16.2 & -7.4 \\
Measured Apartment Exhaust & 51 & 50 & 50 & 48 & 60 \\
\hline
\end{tabular}

Negative values indicate flow into the apartment

\subsubsection{Exhaust Fan Power Consumption}

As described in Section 3.2.2, exhaust ventilation in the bathrooms and kitchens of each apartment is provided by a central system. Air is exhausted from each riser by rooftop fans. Thirty-six fans exhaust air from the apartments. Several models of Greenheck Vari-Green fans were used. All the fans are variable speed, direct drive with $1 / 4$-hp motors. The power of 13 fans was measured in the field. Table 14 summarizes the rated power, design airflows, and measured power. The average rated power consumption was $2.33 \mathrm{CFM} / \mathrm{W}$.

Table 14. Fan Power Measurements

\begin{tabular}{c|c|c|c|c|c}
\hline Fan \# & Model \# & $\begin{array}{c}\text { Measured } \\
\text { Power (W) }\end{array}$ & $\begin{array}{c}\text { Rated } \\
\text { Power (W) }\end{array}$ & $\begin{array}{c}\text { Design Flow } \\
\text { (CFM) }\end{array}$ & CFM/W \\
\hline K-4 & G-097-VG & 170 & 112 & 180 & 1.61 \\
\hline K-6 & G-085-VG & 130 & 84 & 310 & 3.70 \\
K-8 & G-085-VG & 130 & 84 & 300 & 3.58 \\
\hline K-9 & G-098-VG & 210 & 149 & 360 & 2.41 \\
K-10 & G-085-VG & 140 & 84 & 310 & 3.70 \\
\hline T-6 & G-097-VG & 160 & 84 & 150 & 1.79 \\
T-7 & G-097-VG & 170 & 112 & 175 & 1.56 \\
\hline T-8 & G-097-VG & 150 & 75 & 125 & 1.68 \\
T-10 & G-097-VG & 170 & 84 & 150 & 1.79 \\
\hline T-11 & G-080-VG & 140 & 75 & 250 & 3.35 \\
T-12 & G-097-VG & 170 & 84 & 150 & 1.79 \\
\hline T-13 & G-097-VG & 170 & 112 & 175 & 1.56 \\
T-14 & G-097-VG & 160 & 84 & 150 & 1.79 \\
\hline \multicolumn{5}{|c}{ Average } \\
\hline
\end{tabular}

\subsection{Test Building \#3}

Section 3.3.1 through Section 3.3.8 provide results from Test Building \#3. Section 2.3.3 provides floor plans and building description for this test building. 


\subsubsection{Background Information}

This test building also participated in a separate CARB research project that evaluated the use of aerosolized sealants for automated sealing of building enclosures. The process was developed by The Western Cooling Efficiency Center at University of California Davis and uses pressurized air to atomize and aerosolize sealant particles. A blower door is used to pressurize an apartment, then the sealant is carried by air currents to leaks, where the particles stick to the edges of leaks and seal them. The sealant accumulates until leaks are virtually sealed.

As part of that study, four apartments $(202,303,402$, and 403) were sealed using this process. These apartments achieved very tight compartmentalization of less than 0.10 CFM $50 / \mathrm{ft}^{2}$ of enclosure area. These and five other apartments were sealed by conventional means and were the subjects of detailed testing and monitoring for this study. The goal was to understand the impact of enhanced compartmentalization on the effectiveness of passive vents as a ventilation strategy.

\subsubsection{Apartment Blower Door Testing}

Blower door testing was conducted in 19 of 54 apartments in this nine-story building. Four of the apartments had been sealed with aerosol and the other 15 had conventional air sealing. The average total leakage rate was $0.08 \mathrm{CFM} 50 / \mathrm{ft}^{2}$ of apartment enclosure for the aerosol-sealed apartments and $0.25 \mathrm{CFM} 50 / \mathrm{ft}^{2}$ for the standard sealed apartments. Although both approaches resulted in airtightness lower than the required threshold of $0.30 \mathrm{CFM} 50 / \mathrm{ft}^{2}$, only the apartments sealed with aerosol were lower than the 3 ACH50 required by 2012 International Energy Conservation Code. Table 15 summarizes the results of the tests.

Table 15. Building \#3 Apartment Airtightness Metrics

\begin{tabular}{|c|c|c|c|c|c|}
\hline Apartment & \# Beds & Area $\left(\mathbf{f t}^{2}\right)$ & Flow (CFM50) & ACH50 & CFM50/ $\mathbf{f t}^{2}$ \\
\hline $202^{a}$ & 1 & 610 & 180 & 2.1 & 0.09 \\
\hline $\mathbf{3 0 3}^{\mathrm{a}}$ & 1 & 612 & 167 & 2.0 & 0.08 \\
\hline $402^{\mathrm{a}}$ & 1 & 610 & 158 & 1.9 & 0.08 \\
\hline $403^{\mathrm{a}}$ & 1 & 612 & 127 & 1.5 & 0.06 \\
\hline \multicolumn{4}{|c|}{ Average of Aerosol -Sealed Apartments } & 1.9 & 0.08 \\
\hline 201 & 1 & 586 & 585 & 7.2 & 0.28 \\
\hline 203 & 1 & 612 & 375 & 4.4 & 0.26 \\
\hline 205 & 1 & 549 & 523 & 6.9 & 0.26 \\
\hline 301 & 1 & 586 & 579 & 7.1 & 0.28 \\
\hline 302 & 1 & 610 & 356 & 4.2 & 0.26 \\
\hline 305 & 1 & 549 & 548 & 7.2 & 0.27 \\
\hline 401 & 1 & 586 & 564 & 7.0 & 0.27 \\
\hline 505 & 1 & 549 & 505 & 6.7 & 0.25 \\
\hline 605 & 1 & 549 & 569 & 7.5 & 0.28 \\
\hline 607 & 2 & 800 & 415 & 3.7 & 0.14 \\
\hline 704 & 2 & 826 & 653 & 5.7 & 0.21 \\
\hline 705 & 1 & 549 & 465 & 6.1 & 0.23 \\
\hline 805 & 1 & 549 & 590 & 7.8 & 0.29 \\
\hline 902 & 1 & 576 & 578 & 7.3 & 0.29 \\
\hline 907 & 1 & 610 & 475 & 5.6 & 0.20 \\
\hline \multicolumn{4}{|c|}{ Average of Standard Sealed Apartments } & 6.3 & 0.25 \\
\hline
\end{tabular}

${ }^{a}$ Apartments sealed with aerosol 


\subsubsection{Exhaust Flow Testing}

Similar to Test Building \#1, all kitchens and bathrooms in Test Building \#3 were ventilated by individual in-line exhaust fans. Each exhaust register was outfitted with an automatic balancing damper to limit the airflow from - and balance airflow among - the registers. Exhaust rates were measured from the registers in ten apartments.

Table 16 summarizes the results. ASHRAE 62.2-2010 whole-house ventilation rates are provided for comparison.

Table 16. Building \#3 Exhaust Flow Measurements

\begin{tabular}{c|c|c|c|c|c}
\hline \multirow{2}{*}{ Apartment } & \multirow{2}{*}{$\begin{array}{c}\text { \# of } \\
\text { Beds }\end{array}$} & \multicolumn{2}{|c|}{ Exhaust Flow (CFM) } & Total & ASHRAE \\
\cline { 3 - 4 } Flow & Kitchen & Bath & 62.2 Rate \\
(CFM) & (CFM) \\
\hline $\mathbf{2 0 1}$ & 1 & 45 & 50 & 95 & 21 \\
$\mathbf{2 0 2}$ & 1 & 52 & 35 & 87 & 21 \\
$\mathbf{2 0 3}$ & 1 & 46 & 48 & 94 & 21 \\
$\mathbf{3 0 1}$ & 1 & 52 & 51 & 103 & 21 \\
$\mathbf{3 0 2}$ & 1 & 39 & 59 & 98 & 21 \\
$\mathbf{4 0 1}$ & 1 & 52 & 48 & 100 & 21 \\
$\mathbf{4 0 2}$ & 1 & 48 & 55 & 103 & 21 \\
\hline $\mathbf{4 0 3}$ & 1 & 52 & 55 & 107 & 21 \\
$\mathbf{6 0 5}$ & 1 & 51 & 44 & 95 & 20 \\
\hline $\mathbf{9 0 2}$ & 1 & 48 & 41 & 89 & 21 \\
\hline \multicolumn{2}{l|}{ Average } & $\mathbf{4 8 . 5}$ & $\mathbf{4 8 . 6}$ & $\mathbf{9 7 . 1}$ & $\mathbf{2 1}$ \\
\hline
\end{tabular}

To comply with ASHRAE 62.2-2010 continuous local exhaust rates, the continuous exhaust needs at least $20 \mathrm{CFM}$ from bathrooms and $5 \mathrm{ACH}$ in kitchens, which results in 40-50 CFM per kitchen in this test building. The average measured flow rates from the kitchen and bath exhaust registers were 48.5 and 48.6 CFM, respectively.

In this building, the average measured flow $(97 \mathrm{CFM})$ was higher than minimum rates required by ASHRAE 62.2 for local exhaust ( 65 CFM), which resulted in rates that were significantly higher than required by ASHRAE 62.2 for whole-house ventilation (21 CFM). If those two rates were more similar, the outdoor air for whole-house ventilation could also provide the makeup air for the exhaust system rather than using transfer air. The result would be balanced ventilation that minimally meets the requirements for good indoor air quality, but not so overventilated to incur an energy penalty. The question remains whether this can be achieved in practice using passive vents rather than typical balanced mechanical ventilation systems.

\subsubsection{Passive Vent Testing}

To evaluate whether the ASHRAE 62.2 whole-house rates were satisfied by outdoor air, measurements of makeup air that enters an apartment from the outdoors through passive vents are needed. Like Test Building \#1, this building uses trickle vents that were installed in window 
frames to provide outdoor air. Each apartment has one trickle vent in the living room and one in each bedroom. Figure 26 shows one such vent in the open position.
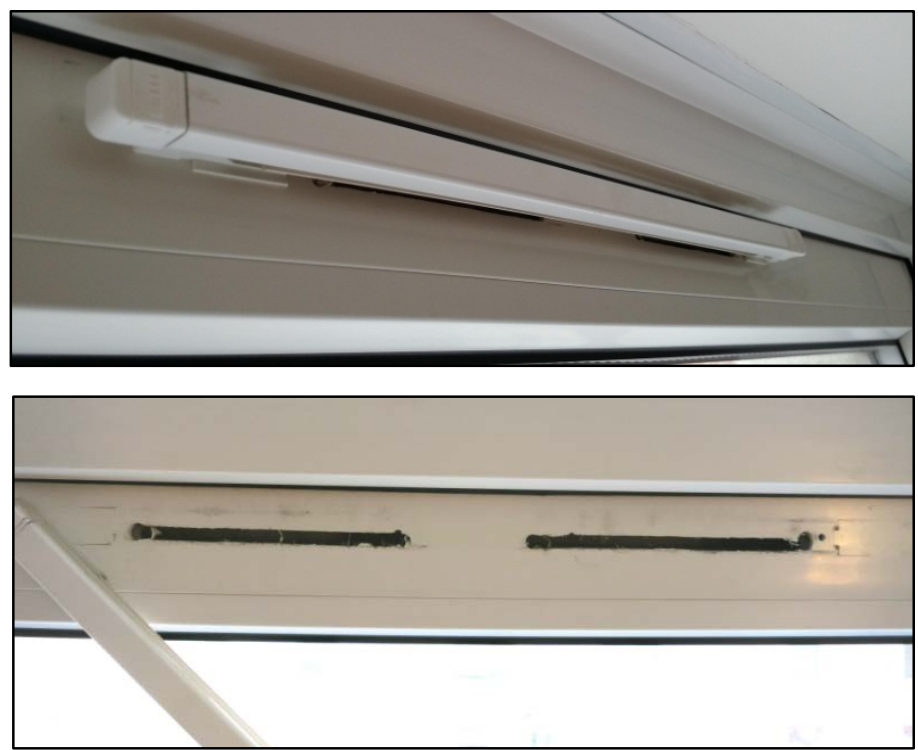

Figure 28. Typical trickle vent in open position (top) and with cover removed (bottom)

Five trickle vents were tested to characterize their installed performance. The procedure from Test Building \#1 was modified to facilitate the testing process. A Duct Blaster fan from The Energy Conservatory was attached to a capture hood to create a test chamber that puts the trickle vent under negative pressure. An orifice plate accessory from The Energy Conservatory was used to measure flows from 2.4 CFM and higher. Induced pressures during the testing ranged from about $10 \mathrm{~Pa}$ to almost $60 \mathrm{~Pa}$.
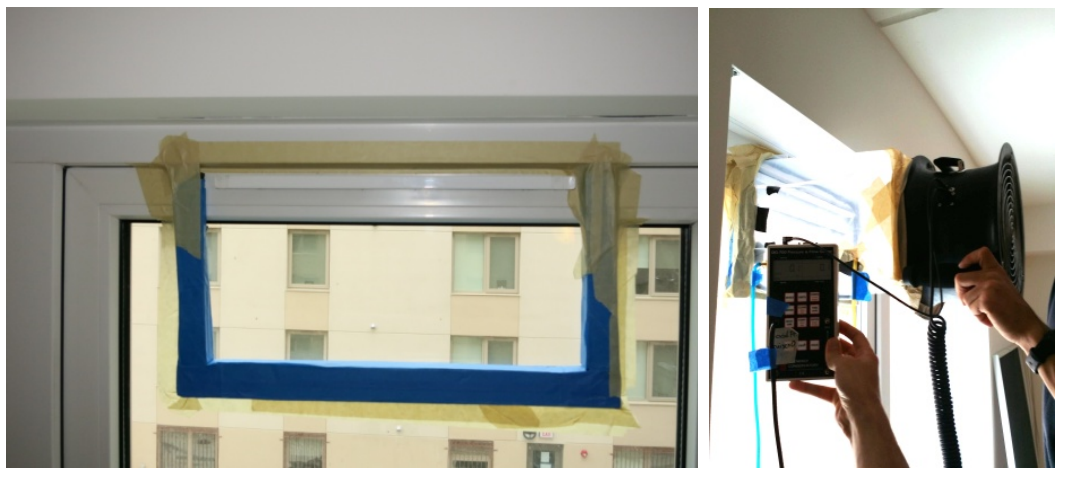

Figure 29. Setup for testing airflow through trickle vents

The data show that the trickle vents deliver 3-5 CFM at $5 \mathrm{~Pa}$. This is slightly lower than the vent performance in the other test buildings at the same pressure. Figure 28 shows the results from the tests of the five trickle vents. The orange horizontal line represents the ASHRAE whole-house ventilation rate for a typical one-bedroom apartment in this test building. 


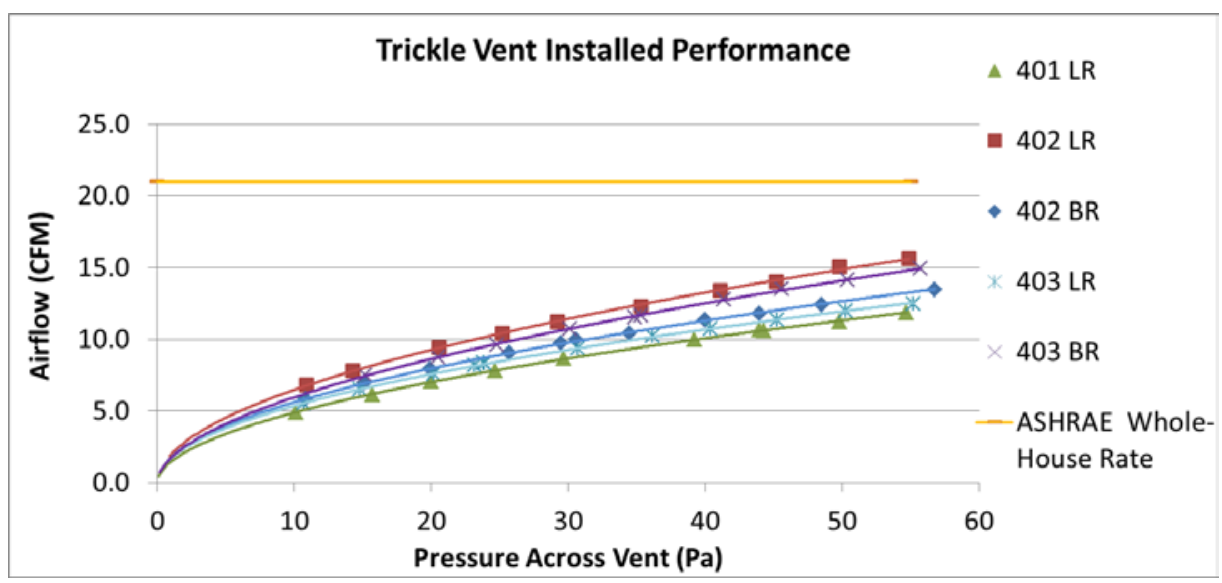

Figure 30. Building \#3 trickle vent performance with trend lines added

The data collected were used to derive an approximate equation for airflow as a function for pressure differential and is given as:

$$
Q=1.72 * \Delta P^{0.516}(7)
$$

As described in Test Building \#1, trickle vents were installed in windows by cutting holes through layers of the window frames. Figure 29 shows two such holes cut on the interior surface of a frame. Another set of holes is cut on the exterior side. The trickle vent assembly, which consists of an interior operable vent and an exterior hood and insect screen, were attached to the frame over these holes. The holes were presumably cut with a router or other rotary tool. See irregular edges, trimmings, and starter holes in Figure 31.

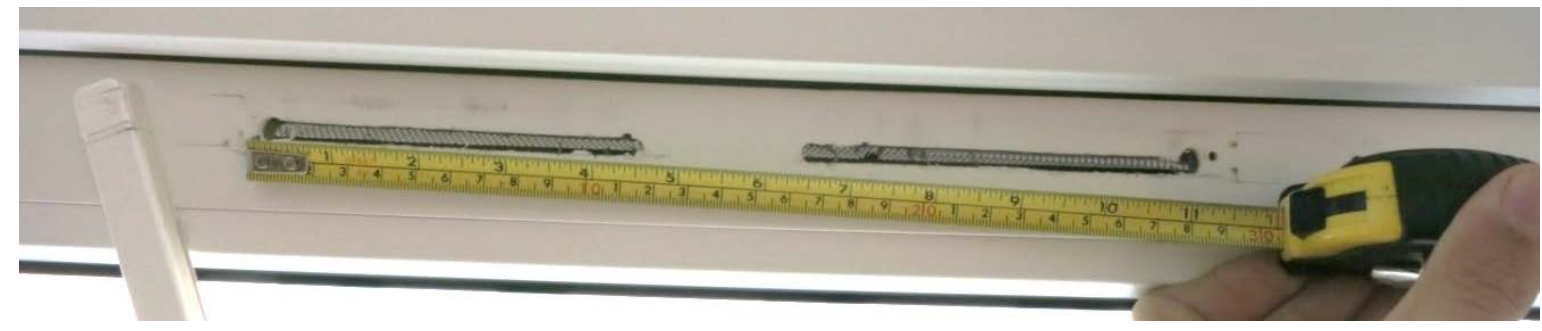

Figure 31. Holes cut in window frame for trickle vent

Specifications for this model of trickle vent call for a slot 3/8 in. wide and approximately $10 \mathrm{in}$. long, with a total free area of $4 \mathrm{in.}^{2}$. The holes in these windows are only $7 / 32 \mathrm{in}$. wide and various lengths; free area ranges from 1.6 to 2 in. $^{2}$, less than half of the specification. The result is lower airflow than specification.

Estimating the reduced airflow based on a simple measurement of actual free area still yielded higher airflows than those measured through testing (Table 17). This is not unexpected, because the vent is not a simple orifice; several layers of resistance between the inside and the outside affect flow. Combined with free area that is smaller than the specification, measured airflow is considerably lower than intended. Average airflow at $5 \mathrm{~Pa}$ is 4 CFM from each trickle vent. Had the trickle vents been installed with 4 in. ${ }^{2}$ of opening as specified, the flow would be approximately $8 \mathrm{CFM}$ at $5 \mathrm{~Pa}$, which is closer to the airflows observed in the other two test 
buildings. Because each one-bedroom apartment in this building has two trickle vents, this amounts to $8 \mathrm{CFM}$, which is considerably lower than the outdoor air needed to meet ASHRAE 62.2 whole-house ventilation or the makeup air for the local exhaust systems.

Table 17. Performance of Trickle Vents

\begin{tabular}{|c|c|c|c|c|}
\hline \multirow[b]{2}{*}{ Vent } & \multirow{2}{*}{$\begin{array}{c}\text { Free Area } \\
\quad\left(\text { in. }{ }^{2}\right)\end{array}$} & \multicolumn{2}{|c|}{ Airflow (CFM) at $5 \mathrm{~Pa}$} & \multirow{2}{*}{$\begin{array}{c}\% \\
\text { Difference }\end{array}$} \\
\hline & & Test Data & $\begin{array}{c}\text { Estimated Based } \\
\text { on Free Area }\end{array}$ & \\
\hline TV1 & 2.0 & 4.5 & 4.7 & $4 \%$ \\
\hline TV2 & 1.9 & 3.9 & 4.4 & $11 \%$ \\
\hline TV3 & 2.0 & 3.8 & 4.7 & $24 \%$ \\
\hline TV4 & 1.9 & 4.1 & 4.5 & $10 \%$ \\
\hline TV5 & 1.6 & 3.4 & 3.7 & $8 \%$ \\
\hline Average & 1.9 & 4.0 & 4.4 & $12 \%$ \\
\hline
\end{tabular}

\subsubsection{Door Leakage Airflows}

As with the other test buildings, the exhaust airflow and airflow into the apartments were measured through the passive vents, measurements of the unintended makeup air from around the apartment entry door were needed. The flow around the apartment door was tested and measured in nine apartments. The test setup was different from Building \#1 and Building \#2, because a faster setup was sought. A blower door frame was set up just outside the closed apartment door on the other side of the threshold. The setup pressurized the space between the blower door shroud and the apartment door. The pressure across the door was measured, along with the airflow through The Energy Conservatory Duct Blaster (Figure 32), which was used as a pressurization fan. The Energy Conservatory TECLOG software recorded pressures and airflows from the fan.

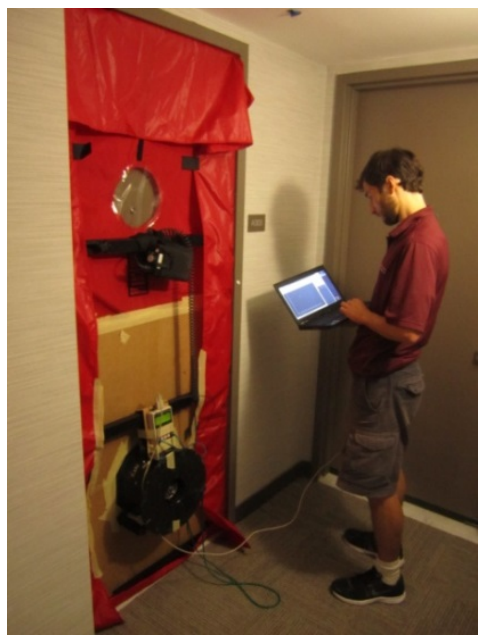

Figure 32. Setup for testing airflow around door with a blower door shroud and Duct Blaster fan

The apartment doors have weather-stripping around the sides and top and most had door sweeps at the bottom, but the doors varied significantly in tightness and fit. This led to variation in the leakage performance of the doors (Figure 33). The leakage area for each door was calculated from the data collected. The door leakage area ranged from 2.2 to $7.2 \mathrm{in}^{2}$; the average leakage 
area was $4.8 \mathrm{in.}^{2}$. This is much smaller than the door leakage areas from Test Building \#1, but almost double the average door leakage area as Test Building \#2.

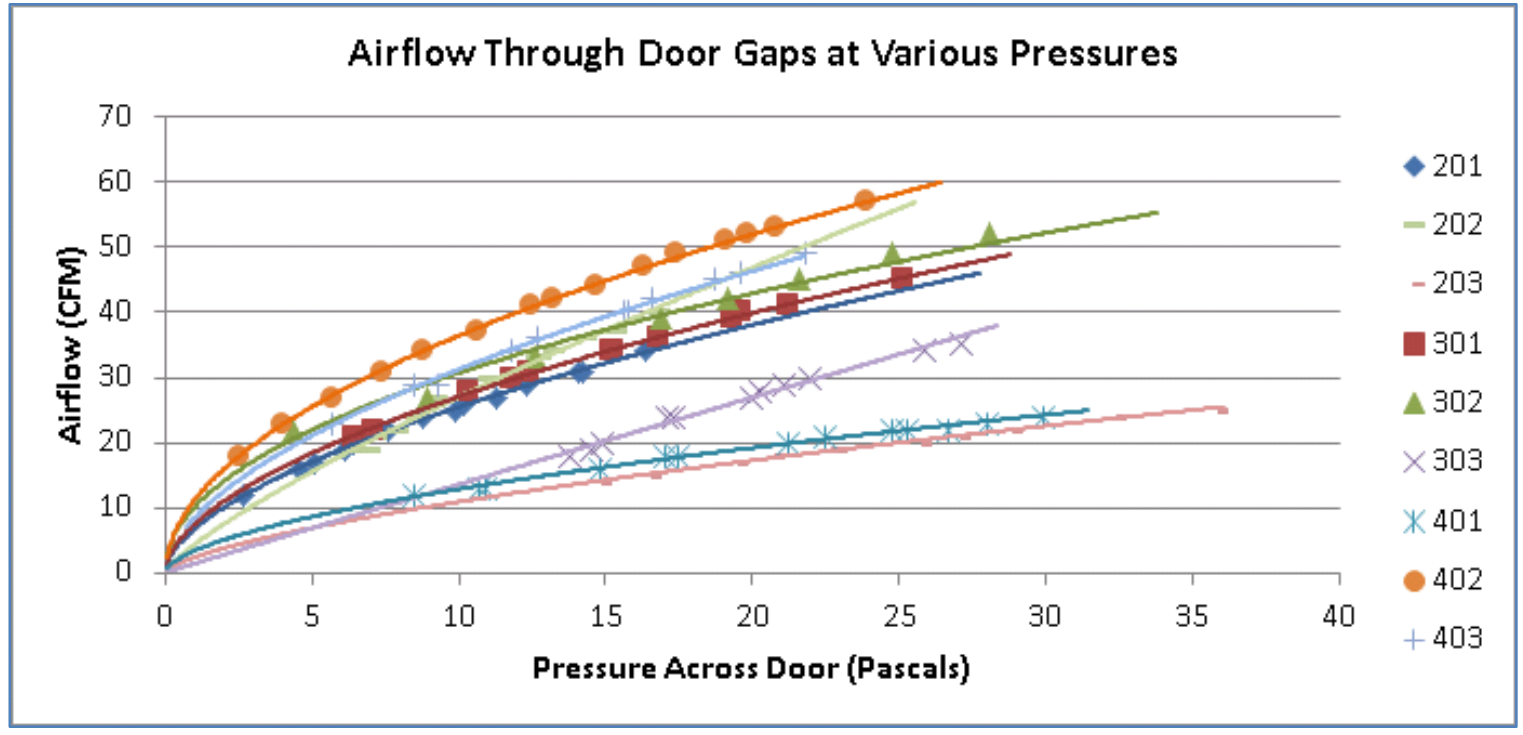

Figure 33. Building \#3 door air leakage

The doors exhibited a range of leakage curves, which can be attributed to physical variations between the doors. As a result, the equation for the airflow around each door was determined. The equation again takes the general form as Eq. 1 where $\mathrm{Q}$ represents flow, $\Delta \mathrm{P}$ is the pressure differential across the door, and $\mathrm{C}$ and $\mathrm{n}$ are empirically determined. Table 18 summarizes these values.

Table 18. Apartment Door Airflow Equation Coefficients and Exponents

\begin{tabular}{c|c|c}
\hline Apartment & $\mathbf{C}$ & $\mathbf{n}$ \\
\hline $\mathbf{2 0 1}$ & 6.6 & 0.58 \\
$\mathbf{2 0 2}$ & 3.8 & 0.80 \\
$\mathbf{2 0 3}$ & 2.3 & 0.66 \\
$\mathbf{3 0 1}$ & 7.4 & 0.56 \\
$\mathbf{3 0 2}$ & 10.1 & 0.48 \\
$\mathbf{3 0 3}$ & 1.2 & 0.99 \\
$\mathbf{4 0 1}$ & 3.2 & 0.58 \\
$\mathbf{4 0 2}$ & 11.3 & 0.51 \\
$\mathbf{4 0 3}$ & 8.5 & 0.57 \\
\hline Average & 6.0 & 0.64 \\
\hline
\end{tabular}

Because the equation differs substantially for each door, in contrast to Building \#2, average values for these coefficients were determined so the pressure monitoring data from a given apartment could be used to determine the airflow around an "average" door.

\subsubsection{Apartment Occupancy}

No apartments were occupied during the monitoring period, but workers periodically entered the units because the building was still under construction. Data loggers that showed door openings 
and closings and window operation were placed to confirm that apartments were operating under the intended conditions.

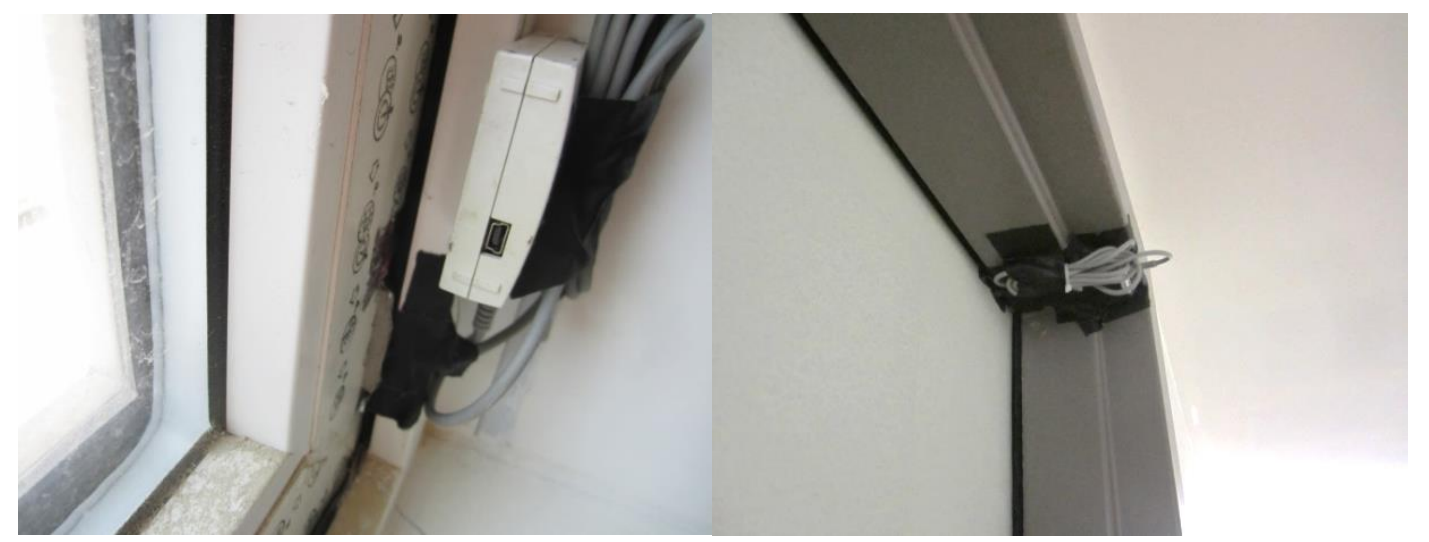

Figure 34. Contact closure data loggers to monitor window opening (left); door opening (right)

\subsubsection{Pressure Monitoring}

Pressure monitoring was conducted in nine apartments over several weeks in the fall of 2014. After the initial monitoring period, ongoing construction, particularly workers opening and closing doors and windows in the building, interfered with measurements. Given the uncertainty of the operating conditions in apartments during the logging period, short-term pressure monitoring was performed on two apartments. Additional long-term monitoring was then conducted with supplementary sensors and loggers.

Pressures in nine apartments were monitored overall in a grid pattern on the same side of the building. Each apartment had a similar size and layout; all one-bedroom apartments had one bathroom; each had ventilation in the kitchen and bathroom. The cross-section of the apartments, from the perspective of the corridor, is shown in Figure 35. As mentioned in Section 3.3.1, Apartments 202, 303, 402, and 403 had received enhanced air sealing with aerosol sealant, which resulted in compartmentalization lower than $0.10 \mathrm{CFM} 50 / \mathrm{ft}^{2}$. The relative airtightness of the apartments that had received the enhanced sealing is shown in the graphic on the right side of Figure 35. Pressure monitoring showed significantly different behavior between the aerosol airsealed and conventionally air-sealed apartments.

\begin{tabular}{|c|c|c|}
\hline \multicolumn{3}{|c|}{ Apartments } \\
\hline 401 & $402^{*}$ & $403^{*}$ \\
\hline 301 & 302 & $303^{*}$ \\
\hline 201 & $202^{*}$ & 203 \\
\hline
\end{tabular}

\begin{tabular}{|c|c|c|}
\hline \multicolumn{3}{|c|}{$\begin{array}{c}\text { Airtightness } \\
\text { (CFM50/ft2) }\end{array}$} \\
\hline 0.27 & $0.08^{*}$ & $0.06^{*}$ \\
\hline 0.28 & 0.17 & $0.08^{*}$ \\
\hline 0.28 & $0.09^{*}$ & 0.18 \\
\hline
\end{tabular}

* Indicates the apartment had enhanced air sealing with aerosol.

Figure 35. Arrangement of apartments under monitoring

Monitoring pressures in all nine apartments over time was more challenging than anticipated. Factors that affected the measurements included operation of doors and windows, operation of exhaust fans in apartments, opening and closing of trickle vents, the airtightness of the 
apartment, the presence or absence of weather-stripping on the apartment door, exterior wind and exterior and interior temperatures, and operation of corridor ventilation fans. The team attempted to hold these factors as constant as possible, but because the building was still under construction, over time many were altered and not accounted for.

Figure 36 shows more than 4 days' worth of measurements. Two of the four apartments that had enhanced sealing (Apartments 202 and 403) maintained a lower negative pressure. This indicated the exhaust fans were able to generate a greater suction on the tighter envelope. Though Apartment 303 also had enhanced air sealing, it lacked a sweep on the door to the corridor, so large amounts of air were allowed to enter through the door undercut. The blower door frame was placed in the entry door during compartmentalization testing, so this leakage is not reflected in the airtightness test results for this apartment (Figure 35). The sweep was installed later in the construction process, after the monitoring period. Not shown in Figure 36 is apartment 402, which had a malfunctioning data logger.

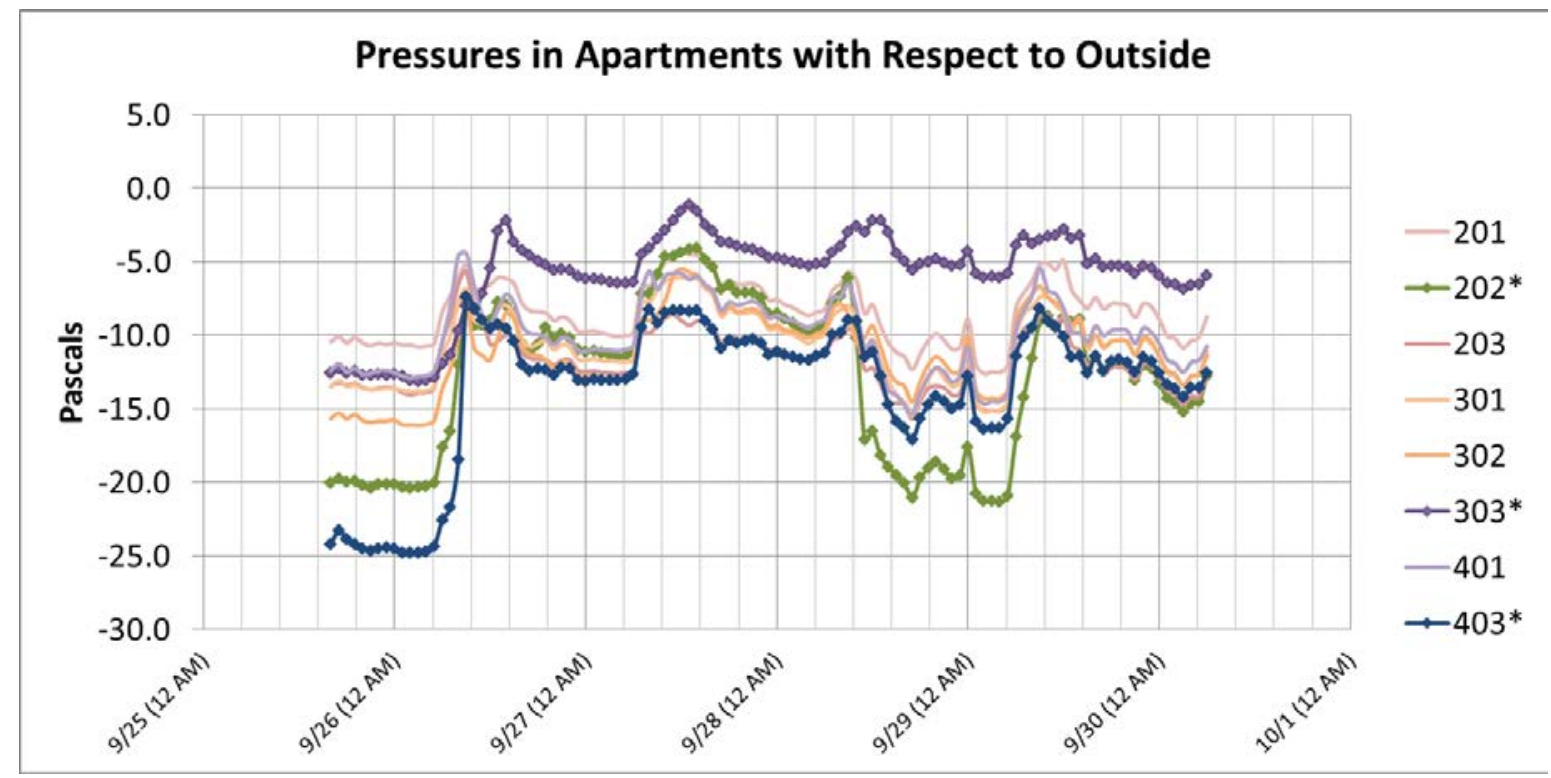

Figure 36. Pressures in apartments WRT outside over 4 days

Figure 37 shows a 24-hour time scale of the same apartments. The data loggers were launched at 4 p.m. on September 25, 2014, logging every minute. The values shown in the chart are hourly averages. Clearly the two highly sealed apartments that also had weather-stripping and door sweeps (Apartments 202 and 403) were able to maintain a significantly lower pressure, -20 to $25 \mathrm{~Pa}$. The highly sealed apartment that did not have a door sweep (Apartment 303) did not have a significantly lower pressure than apartments that were not highly sealed, which range from -10 to $-16 \mathrm{~Pa}$. The apartments all maintained a relatively steady pressure profile for the overnight period. Between 5 a.m. and 6 a.m., pressures began to shift. By 9 a.m., the pressure profiles were significantly different. 


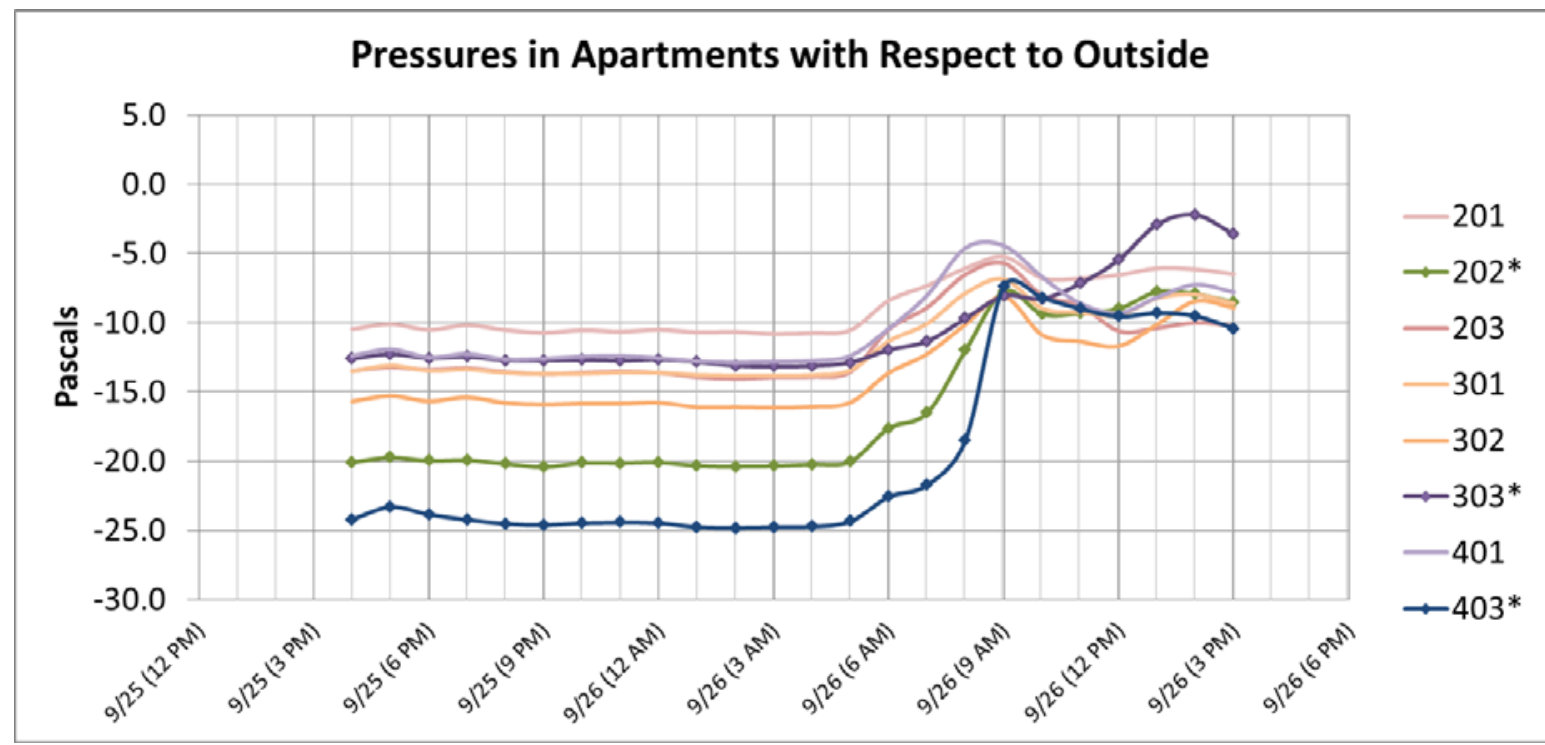

Figure 37. Pressures in apartments WRT outside over 24 hours

The change in pressure profile is likely attributed to the fact that the building was still under construction during the monitoring period, because workers entered the apartments periodically. The workday began around 6 a.m. and ended around 3 p.m. Pressures in the building overall began to shift when the workday began; infiltration in the building increased overall and affected pressures in the apartments. By 9 a.m., workers likely entered all the apartments at least once and perhaps left the doors and windows ajar. Pressure measurements after this point were less representative of the occupied design conditions, where performance of the passive vents was most important; entry doors and windows were closed. Although windows were not the intended sources of outdoor air, while open the performance of the passive vents was no longer critical to proper ventilation.

As mentioned previously, before the long-term pressure monitoring, short-term pressure monitoring was conducted in two apartments with different degrees of airtightness; \#402, which was sealed with aerosol $\left(0.08 \mathrm{CFM} 50 / \mathrm{ft}^{2}\right)$ and $\# 401$, which was conventionally air sealed $(0.27$ CFM50/ $\mathrm{ft}^{2}$ ). Both apartments had weather-stripping and sweeps on their entrance doors at the time of the short-term pressure monitoring. Pressures were measured using a DG-700 digital pressure gauge with an accuracy of $\pm 1 \%$.

The results of the short-term monitoring for the standard apartment (\#401) are shown in Figure 38. The top portion summarizes the six operating conditions evaluated; the bottom portion presents the corresponding change in pressure. Condition 1 represents the apartment at rest with no fans running and trickle vents closed. This was meant to determine if significant pressures were acting on the apartment from outside sources to begin with. At that time, few significant external pressures acted on this apartment, and an average of $-1 \mathrm{~Pa}$ WRT the outside was observed. Condition 2 represents the maximum pressure that could be expected on that apartment due to the operation of the exhaust fan; that is, with windows, doors, and trickle vents closed so the largest pathways for makeup air are cut off. Pressure increased to $-3 \mathrm{~Pa}$. Conditions 3 and 5 represent normal operations with windows and doors closed, trickle vents open, and the exhaust fan running. Pressure remained close to $-3 \mathrm{~Pa}$ WRT the outside. Condition 4 is the same, but the 
door to the apartment was slightly ajar. The door was closed to the point where it touched the frame but did not latch. This was meant to help interpret long-term pressure monitoring results when workers could leave the door cracked open. Condition 6 is a return to an all-off state.

\begin{tabular}{|l|c|c|c|c|c|c|}
\hline Condition & $\mathbf{1}$ & $\mathbf{2}$ & $\mathbf{3}$ & $\mathbf{4}$ & $\mathbf{5}$ & $\mathbf{6}$ \\
\hline & Exhaust off & $\begin{array}{c}\text { Maximum } \\
\text { pressure }\end{array}$ & $\begin{array}{c}\text { Normal } \\
\text { operation }\end{array}$ & Door ajar & $\begin{array}{c}\text { Normal } \\
\text { operation }\end{array}$ & Exhaust off \\
\hline Exhaust fan & off & on & on & on & on & off \\
\hline Trickle vents & closed & closed & open & open & open & closed \\
\hline Apartment Door & closed & closed & closed & open & closed & closed \\
\hline \multicolumn{7}{|l|}{} \\
$\begin{array}{l}\text { Approximate pressure } \\
\text { WRT outside }\end{array}$ & -1 & -3 & -3.5 & -1.5 & -3.1 & -1 \\
\hline $\begin{array}{l}\text { Approximate pressure } \\
\text { WRT corridor }\end{array}$ & 0 & -3 & -2.5 & -1.2 & -2.6 & 0 \\
\hline
\end{tabular}

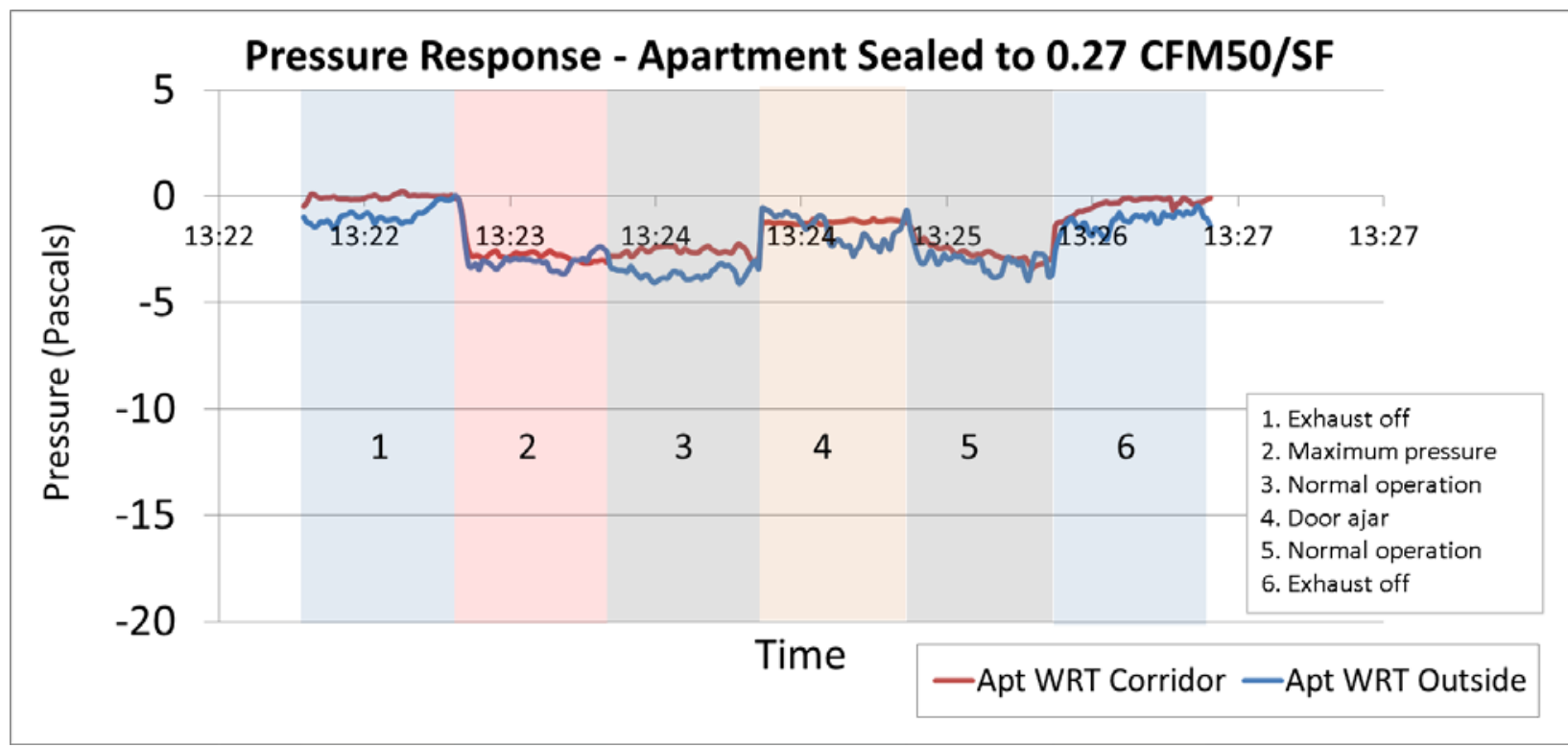

Figure 38. Pressure response in standard apartment, \#401 (0.27 CFM50/ft $\left.{ }^{2}\right)$

The graph in Figure 38 demonstrates this pressure response to these changing conditions in the standard apartment. The blue line represents the pressure in the apartment WRT the outside; the red line represents the pressure WRT the corridor outside the apartment. The colors used in the chart represent the various operating conditions and correlate to the time periods of the same color in the graph.

The same test was repeated on the highly sealed apartment. Figure 39 shows the pressure response for this apartment. 


\begin{tabular}{|l|c|c|c|c|c|c|}
\hline Condition & $\mathbf{1}$ & $\mathbf{2}$ & $\mathbf{3}$ & $\mathbf{4}$ & $\mathbf{5}$ & $\mathbf{6}$ \\
\hline & Exhaust off & $\begin{array}{c}\text { Maximum } \\
\text { pressure }\end{array}$ & $\begin{array}{c}\text { Normal } \\
\text { operation }\end{array}$ & Door ajar & $\begin{array}{c}\text { Normal } \\
\text { operation }\end{array}$ & Exhaust off \\
\hline Exhaust fan & off & on & on & on & on & off \\
\hline Trickle vents & closed & closed & open & open & open & closed \\
\hline Apartment Door & closed & closed & closed & open & closed & closed \\
\hline \multicolumn{7}{|l|}{} \\
$\begin{array}{l}\text { Approximate pressure } \\
\text { WRT outside }\end{array}$ & 0 & -15 & -12 & -3 & -12 & 0 \\
\hline $\begin{array}{l}\text { Approximate pressure } \\
\text { WRT corridor }\end{array}$ & 0 & -15 & -12 & -3 & -12 & 0 \\
\hline
\end{tabular}

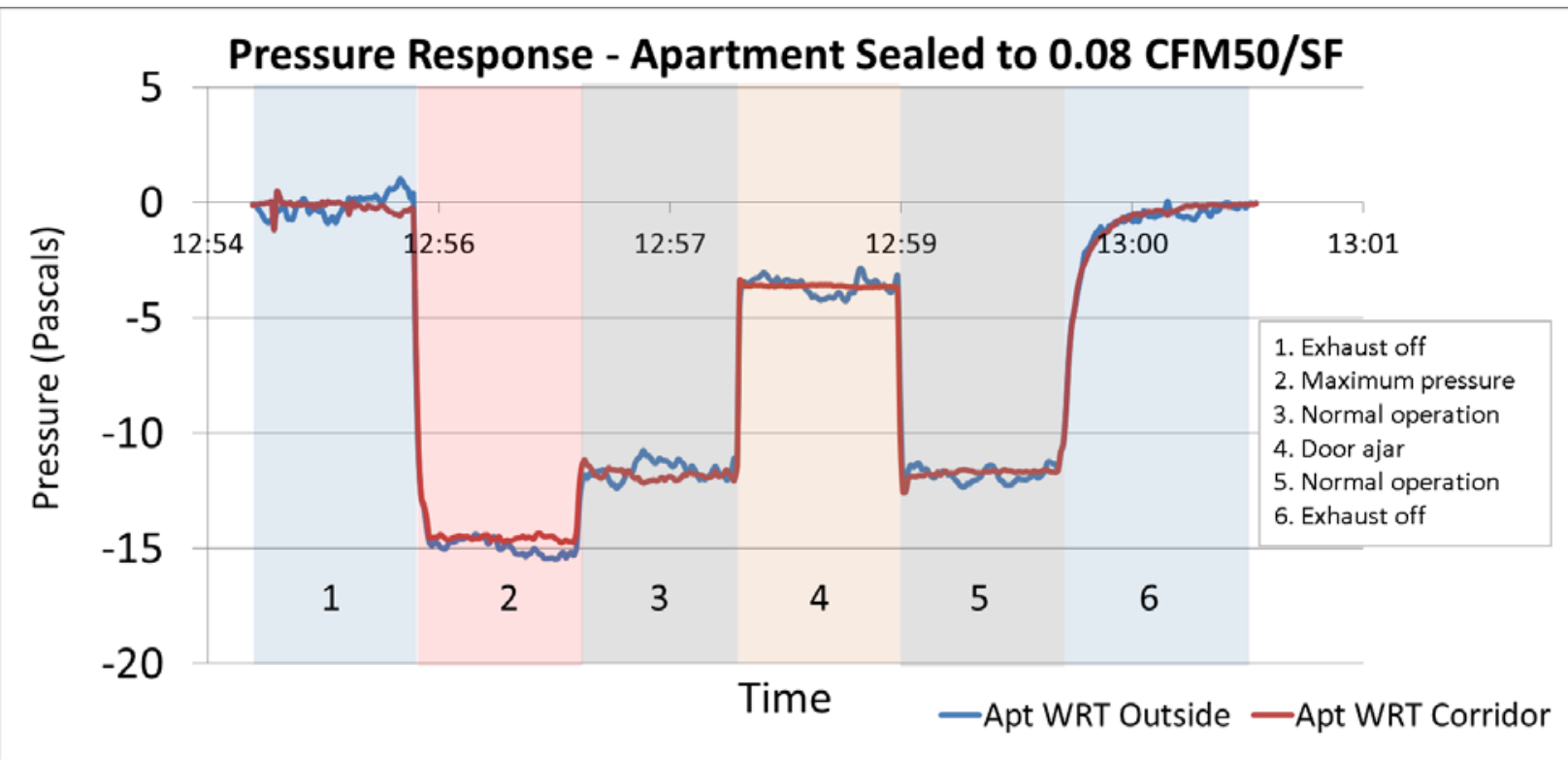

Figure 39. Pressure response in highly-sealed apartment, \#402 (0.08 CFM50/ft²

In the conventionally air-sealed apartment (\#401), the pressure WRT the outside and the pressure WRT the corridor tracked closely and typically ranged from zero to $-3.5 \mathrm{~Pa}$. Under Condition 1 , the apartment was essentially neutral. When the exhaust fan was turned on (Condition 2), the apartment became depressurized by approximately $3 \mathrm{~Pa}$. When the operating conditions were varied, a pressure change of $1 \mathrm{~Pa}-2 \mathrm{~Pa}$ could be observed. These results indicate that although the apartment air barrier could meet the airtightness threshold for a high-performance building program, it still leaked substantially. The building has so many other makeup air pathways that any depressurization of the apartment was easily relieved by air from its relatively leaky walls. A substantial pressure differential thus did not develop across the apartment/corridor boundary or the apartment/exterior boundary, so the passive vent is rendered relatively ineffective.

In the highly sealed apartment, the pressure WRT the outside and the pressure WRT the corridor track, as they did in the standard apartment; however, the effect of varying the operating conditions is much more apparent. The pressure WRT the outside shows more variation under each condition than the pressure WRT the corridor. This can most likely be attributed to wind. Under Condition 1, the apartment was essentially neutral, as expected. When the exhaust fan was turned on, the pressure immediately dropped to approximately $-15 \mathrm{~Pa}$. Because the apartment 
was so tightly sealed, the exhaust fan created a significantly greater pressure differential. When the trickle vents were opened, Condition 3, the pressure differential was reduced because air was permitted to enter through the vents. The pressure differential was further reduced when the door was cracked open, Condition 4. The effect was more pronounced, because the door permitted more air to enter than the trickle vents. The pressure response to each condition is clearly identifiable in Figure 39. This can be attributed to the high level of sealing and compartmentalization.

Condition 3 represents the typical operating conditions of the apartments. In the highly sealed apartment, the pressure across the trickle vent was approximately $12 \mathrm{~Pa}$. In the standard apartment, the pressure was $3.5 \mathrm{~Pa}$. The beginning of the long-term monitoring period also represents typical operating conditions. From Figure 37, the pressure in apartment 401 (the standard apartment from the short-term monitoring) was approximately $-12 \mathrm{~Pa}$. The logger in apartment 402, the highly sealed apartment, malfunctioned; however, the pressures in other highly sealed apartments ranged from $-12 \mathrm{~Pa}$ to $-25 \mathrm{~Pa}$. This increase in depressurization is likely due to the fact that the short-term monitoring was performed approximately 1 week before the long-term monitoring (Figure 36 and Figure 37) began. During this time, the level of airtightness of the apartments improved as construction neared completion.

Table 19 summarizes the air movement in the highly sealed and conventionally air-sealed apartments based on the long-term pressure monitoring. The flows from the corridor door and trickle vents were calculated using the typical operating pressures and the equations that were developed for an average door and trickle vent performance in the previous sections.

Table 19. Test Building \#3 Summary Flow Data

\begin{tabular}{c|c|c}
\hline & $\begin{array}{c}\text { Highly Sealed } \\
\text { Apartment }\end{array}$ & $\begin{array}{c}\text { Standard } \\
\text { Apartment }\end{array}$ \\
\hline Airtightness (CFM50/ft $\left.{ }^{\mathbf{2}}\right)$ & 0.08 & 0.25 \\
\# of Trickle Vents & 2 & 2 \\
Typical Operating Pressure WRT Outside $\mathbf{( P a )}$ & -22 & -12 \\
Air from Corridor Door & 43.4 & 31.0 \\
Air from All Trickle Vents & 17.0 & 12.9 \\
Typical Apartment Exhaust & 98 & 98 \\
\hline
\end{tabular}

\subsubsection{Exhaust Fan Power Consumption}

American Aldes VS4 in-line fans were used to exhaust air from apartments. Each apartment had one fan that served the kitchen and bathroom. This model has a rated power consumption of 3.7 CFM/W and exhausts 18-101 CFM, depending on the static pressure. 


\section{Discussion}

A comparison of the average airtightness and makeup airflows of typical one-bedroom apartments in the three test buildings is shown in Table 20. Airtightness results are from an average of the blower door measurements that were taken in apartments with the blower door in the door frame. Exhaust results are the average of measured values in one-bedroom apartments and represent the sum of bathroom and kitchen flows. Corridor door leakage is the average of the calculated flows from all one-bedroom units. The flows were calculated using the average door flow equation for each building and the pressure monitoring data from the period that represented intended operation (windows closed). The passive vent flows are averages of the calculated values for each one-bedroom unit using the passive vent flow equation that was developed for each building and the pressure monitoring data. These values represent the total flow from all passive vents in apartments. A typical one-bedroom apartment is assumed to have two passive vents. The pressure WRT the outside is an average of the measured pressures during periods when windows and doors were closed. The exhaust fan power is the design flow of the fan and the rated power at that flow.

Table 20. Comparison of Average Airtightness and Airflow in One-Bedroom Apartment Example

\begin{tabular}{c|c|c|c|c}
\hline & Bldg \#1 & Bldg \#2 & $\begin{array}{c}\text { Bldg \#3 } \\
\text { Standard }\end{array}$ & $\begin{array}{c}\text { Bldg \#3 } \\
\text { Highly Sealed }\end{array}$ \\
\hline Airtightness (CFM50/ft ${ }^{2}$ ) & 0.10 & 0.24 & 0.25 & 0.08 \\
Measured Exhaust (CFM) & 71 & 47 & 98 & 98 \\
ASHRAE 62.2 Local Exhaust & 71 & 50 & 60 & 60 \\
\hline Corridor Door Leakage (CFM) & 61 & 0 & 31 & 43 \\
Corridor Door Leakage (in. ${ }^{2}$ ) & 24 & 2.5 & 4.8 & 4.8 \\
Corridor Supply (CFM/apt) & 21 & 72 & 7 & 7 \\
Passive Vents (CFM) & 12 & 12 & 13 & 17 \\
ASHRAE 62.2 Whole-House & 22 & 20 & 21 & 21 \\
\# of Passive Vents & 2 & 2 & 2 & 2 \\
Pressure WRT Outside & -3.5 & -3.1 & -12 & -22 \\
\hline Exhaust Fan Power (CFM/W) & 3.3 & 2.3 & 3.7 & 3.7 \\
\hline
\end{tabular}

Building \#1 and Building \#3 were highly sealed and have similar levels of airtightness; however, due to the location of the blower door during the test, the significant air leakage around the door for both buildings is not reflected. The greater airflow from around these doors in Building \#1 was likely a combination of the lack of weather-stripping on the doors and the corridors in Building \#1 having a higher supply rate than Building \#3. Building \#1 also had a lower exhaust rate, so the net result was Building \#1 drew less air from the trickle vents. Building \#2 and Building \#3 were standard and had comparable airtightness levels; however, Building \#3 had a higher exhaust rate that resulted in greater flow from the corridor and trickle vents. The apparent lack of flow from the corridor in Building \#2 was not due to perfectly airtight doorways but due to averaging the positive and negative pressure data from the test apartments in that building. Several apartments had a slight net flow to the corridor; others had slight flow into the apartment. The result is no net average flow. This may be attributed to the corridor ventilation system being off during the monitoring period. 
The amount of outdoor air delivered to an apartment by passive vents was the result of a multitude of factors. Apartment airtightness, passive vent size, vent count, vent installation, apartment exhaust system performance, and door installation were important, although not exclusive, in determining the performance of passive vents.

Passive vents require a pressure differential across the vent to provide airflow. Apartment airtightness is critical in developing this pressure differential. The tighter the apartment is, the greater the pressure will be as a result of the exhaust. A higher pressure across the passive vent results in greater flow through the vent. A well-sealed apartment is also less susceptible to changes in conditions in other parts of the building.

Although all passive vents operate on the same principle, the type of vent and installation has direct impacts on the performance. Trickle vents and airlets, the two primary types of passive vents, were tested in this study. Deficiencies were found with the installation of each. Trickle vents were installed in windows by cutting holes through the window frames. The specifications for the vents detail the sizes and dimensions of the holes. The contractor is responsible to create the proper opening. In the sample of vents that were inspected, the free opening was on average half of the area specified.

Similarly, the CARB team found deficiencies with the installation of the airlets. Airlets consist of a cylindrical opening that connects the inside of the apartment to the outside. The cylinder has a removable filter that prevents debris from entering the apartment. The manufacturer installation specifications state that the airlet should be located 6 in. -12 in. from the ceiling to allow the cool outdoor air to mix with warmer room air to prevent drafts and discomfort. In Building \#2, the airlets were installed approximately 18 in. from the floor. Numerous airlets were installed without filters, which prompted residents to complain about drafts and cold floors. To resolve the issue, several residents covered the airlets to prevent cold air from entering the apartments. Although this situation is difficult to correct once it is constructed, it can be avoided quite easily with proper design and installation oversight.

The design and commissioning of the exhaust system are also critical factors in determining passive vent performance. The exhaust system, in conjunction with the apartment air barrier, is responsible for creating a pressure differential between the apartment and the outside. Building $\# 1$ and the highly sealed apartments in Building \#3 have similar airtightness levels and similar in-line exhaust systems; however, Building \#3 had higher measured ventilation rates and less leakage around the doors. This significantly increases the airflow from the passive vents. Interestingly, the design plans at Building \#3 specify 45 CFM of exhaust from the apartments; however, in reality the fans exhausted approximately twice that amount. Conversely, the design for Building \#1 specified 105 CFM-125 CFM of exhaust and measured considerably less.

In terms of the actual implementation, all three buildings had constant air regulator dampers installed at the exhaust registers. These dampers are designed to provide a constant airflow across a range of duct pressures. Each damper comes with a preinstalled insert that is calibrated for a specific airflow. The airflow may not have been specified when the dampers were ordered, or an incorrect insert may have been used. Regardless, this reinforces the importance of thorough commissioning of the building in the design and construction phases, including analysis and testing to ensure proper selection, operation, and installation. 
Another consideration in the exhaust system design is the type of fan-central versus in-unit. Both types have advantages and disadvantages, and a thorough comparison is beyond the scope of this report; however, based on the product literature, the in-line fans in Building \#1 and Building \#3 exhaust more air per watt of electricity than the central fans of Building \#2.

In addition to passive vents, one of the largest discrete sources of airflow is often the corridor door. Ironically, this source is generally not included in apartment airtightness metrics because a blower door is typically installed in the doorframe to test the apartment. The result is the apartment is actually leakier than blower door testing indicates. The amount of leakage through the door can vary considerably depending upon the installation and use of weather-stripping and sweeps. Door leakage effectively decreases the pressure differential of the apartment and thus reduces the airflow through the passive vents and allows significant makeup air to come from the corridor. As shown in Table 20, the average airflow from the corridor can be two to four times greater than from the passive vents, the intended source of makeup air.

Because numerous parameters affect the performance of passive vents, ensuring a consistent and specific flow of outdoor air is challenging. This challenge was highlighted during the long-term monitoring periods of this study. Considerable effort was made to evaluate the vents' performance during the design condition under which windows and doors are closed. Window and door sensors were installed and residents' cooperation was requested. These data showed that the vents were rendered useless much of the time due to open windows and doors, which is an acceptable result because windows are an acceptable source of outdoor air. In other cases, environmental and building conditions that will generally be beyond the control of even the best design overwhelmed the local apartment pressure differential. However, under the design conditions, poor design and installation of the passive vents, exhaust systems, air barriers, and door sweeps resulted in poor performance.

Given the difficulty in getting a passive vent system to perform consistently and reliably across a range of environmental conditions, clear, well-defined design criteria and thorough commissioning are needed. The next step for CARB will be to develop a measure guideline for the use of passive vents. 


\section{Preliminary Conclusions}

This project sought to answer the following research question:

- Do passive vents perform reliably among multiple building installations as an outdoor air strategy?

In the three buildings tested in this study, passive vents did not perform reliably. However, the evaluation enabled the CARB team to identify the criteria that significantly impacted performance and could improve the reliability of these vents as an outdoor air strategy.

Airtightness (specifically compartmentalization) is critical in creating an environment for passive vents to work properly. The apartments that were highly sealed had greater pressure differentials and more airflow from the passive vents. These apartments were also impacted less by conditions in adjacent units and other parts of the building.

The proper selection of exhaust rates and the execution of those systems are also of critical importance. "Exhaust-only" strategies have been cost-effective solutions in single-family homes for simultaneously providing continuous local exhaust and whole-house ventilation by relying on the exhaust makeup air to come from the outdoors through infiltration. Although the makeup air for exhaust in single-family detached homes may be safely assumed to come from the outdoors, this is not the case for attached housing. ASHRAE 62.2 does not prohibit "exhaust-only" strategies in multifamily buildings and does not mandate the provision of outdoor air. If attempting to provide the latter through passive vents at a level that meets ASHRAE 62.2-2010 whole-house ventilation rates, the evaluation demonstrated that specifying design exhaust rates that minimally meet ASHRAE 62.2 local exhaust would not be sufficient. The buildings in which the outdoor air rates through the passive vents were similar to the whole-house ventilation rates desired typically had measured exhaust rates that were more than $50 \%$ higher than required by ASHRAE for local exhaust. If trying to meet ASHRAE 62.2-2013 whole-house ventilation rates with fan flow, which are higher than they were in 2010, exhaust airflows would need to be even higher. If a building owner is attempting to provide all makeup air for the exhaust from the outdoors rather than by relying on any transfer air, the passive vent strategy does not seem capable of accomplishing that goal.

In addition to airtightness and the ventilation rates selected, the following steps should be taken to create a system for passive vents to deliver outdoor air reliably that meet the whole-house ventilation rates of ASHRAE 62.2-2010:

- Design the exhaust ventilation system to provide adequate pressure differential that is based on apartment airtightness, passive vent size, and corridor door leakage.

- Specify the size and number of passive vents based on the required airflow needed, apartment airtightness, and exhaust rate.

- Inspect passive vents to make sure they are manufactured and installed correctly.

- Seal the apartments to a high level of compartmentalization (less than $0.1 \mathrm{CFM} 50 / \mathrm{ft} 2$ ).

- Weather-strip corridor doors, and test them to ensure that they are as airtight as possible.

- These criteria will be developed and quantified in the measure guideline. 


\section{References}

Aldrich, R., and L. Arena. 2013. Evaluating Ventilation Systems for Existing Homes (Subcontractor Report, NREL/SR-5500-56988). Golden, CO: National Renewable Energy Laboratory. www.nrel.gov/docs/fy13osti/56988.pdf.

Aldrich, R., and G. Vijayakumar. 2006. "Ventilating Small Chicago Homes.” Home Energy Magazine January/February 2006.

ASHRAE. 2010a. ANSI/ASHRAE Standard 62.1-2010: Ventilation for Acceptable Indoor Air Quality. Atlanta, GA: ASHRAE.

ASHRAE. 2010b. ANSI/ASHRAE Standard 62.2-2010: Ventilation for Acceptable Indoor Air Quality in Low-Rise Residential Buildings. Atlanta, GA: ASHRAE.

CMHC. 2003. "Ventilation Systems for Multi-Unit Residential Buildings - Performance Requirements and Alternative Approaches." Research Highlights. Canada Mortgage and Housing Corporation October. www.publications.gc.ca/pub?id=254166\&sl=0.

EPA. 2010. ENERGY STAR Certified Homes, Version 3 (Rev. 07). National Program Requirements. Washington, D.C.: U.S. Environmental Protection Agency.

ICC. 2012. International Energy Conservation Code. Country Club Hills, IL: ICC

LEED. 2010. LEED ${ }^{\circledR}$ for Homes Rating System Multifamily Mid-Rise. Washington, D.C.: U.S. Green Building Council.

Maxwell, S., D. Berger, and N. Zuluaga. 2014. Evaluation of Ventilation Strategies in New Construction Multifamily Buildings (Subcontractor Report). Golden, CO: National Renewable Energy Laboratory, NREL/SR-5500-62313. http:/www.nrel.gov/docs/fy14osti/62313.pdf.

NCHH. 2009a. Improving Ventilation in Existing or New Buildings with Central Roof Exhaust. 2009. Columbia, MD: National Center for Healthy Housing.

NCHH. 2009b. NCHH Fact Sheet: Improving Ventilation in New and Existing Multi-Family Buildings with Individual Unit Ventilation Systems. Columbia, MD: National Center for Healthy Housing.

Ueno, K., J. Lstiburek, and D. Bergey. 2012. Multifamily Ventilation Retrofit Strategies (Subcontractor Report, NREL/SR-5500-56253). Golden, CO: National Renewable Energy Laboratory. www.nrel.gov/docs/fy13osti/56253.pdf. 
buildingamerica.gov

wasementer ENERGY

Energy Efficiency \& Renewable Energy 